\title{
Does the Marine Stewardship Council's Eco-labelling Scheme Require Sustainable Fisheries Management? a Study of the Marine Stewardship Council's Objections Procedure
}

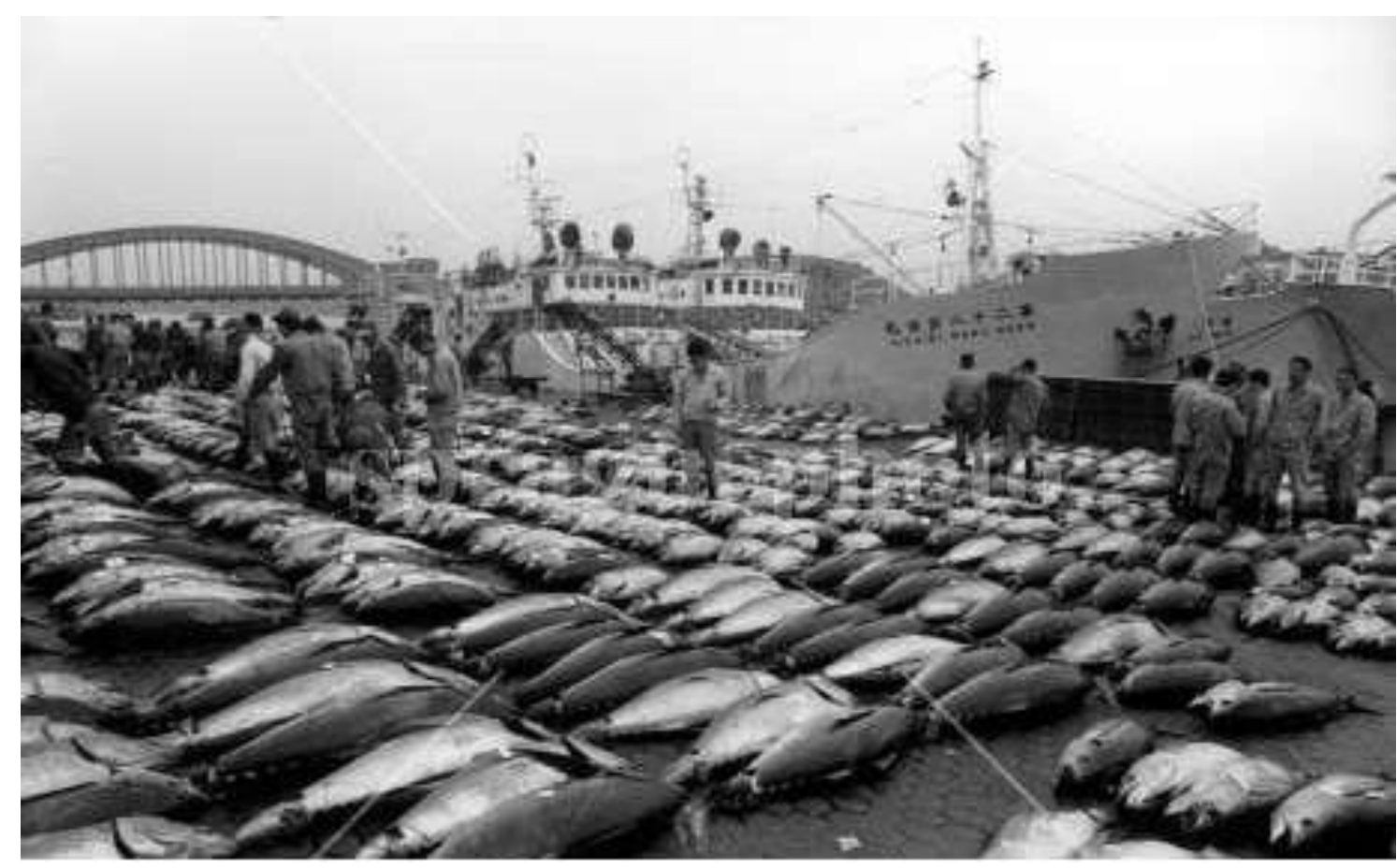

By: Joseph Edlin

A 90-point thesis

submitted to the Victoria University of Wellington in fulfilment of the requirements for the degree of Master of Environmental Studies. Victoria University of Wellington 2012 


\section{Acknowledgements}

This thesis would not have been possible without the unwavering help, guidance and support of the following:

- God: I would like to thank God for the inexhaustible strength, wisdom and guidance provided throughout this thesis writing process.

- Cath Wallace: As my only supervisor, Cath's personal and professional support during this thesis process has been invaluable. The comments, suggestions, support, feedback and understanding provided have kept me grounded, motivated, and inspired me to always achieve higher. I would like to extend my deepest thanks for this, surely this thesis has benefitted greatly under your guidance.

- My parents, brother and sister: I have the deepest gratitude for the support, understanding and love you so freely have given during the construction of this thesis. Through every season these qualities have remained the same, and I am greatly indebted to you for this. Without your support, this thesis would not have been possible.

- Church Family. I would like to acknowledge my Arise Church family; all of your prayers support and encouragement have been a source of great strength and positivity throughout. In particular I would like to mention Ps. Ben Carroll, Jono How, Joseph White, Beau Tewhaiti and Zechariah Taylor for their consistent and personal support throughout. Amidst every moment of joy, hardship and tragedy, you have reminded me of the qualities true friendship possesses.

- Chrisjan Jordaan: To my late friend and brother, thank you for your ever consistent prayers, commentary, humour and wisdom. Even though you were not able to see its completion, this thesis has undoubtedly been positively influenced through our friendship. Despite your unwavering humility, accept that I am indebted to you for this. I look forward to the day I can tell you face to face.

The list of individuals who have played a role in assisting and supporting me whilst writing this thesis is numerous. Unfortunately I cannot acknowledge you all, however know that I am immensely grateful to every person. 


\section{Contents}

$\begin{array}{ll}\text { 1.0 Study Outline } & 8\end{array}$

$\begin{array}{ll}1.1 \text { Introduction } & 8\end{array}$

$\begin{array}{ll}\text { 1.2 Contribution of this Research } & 15\end{array}$

$\begin{array}{ll}\text { 1.6 Aim of this Study } & 15\end{array}$

$\begin{array}{ll}1.5 \text { Research Questions and Objectives } & 16\end{array}$

$\begin{array}{ll}\text { 2.0 Methodology } & 18\end{array}$

2.1 Methodological Approach: General State of Inquiry 18

2.2.1 Research Paradigm 18

$\begin{array}{ll}\text { 2.2.2 Research Design } & 21\end{array}$

2.3 Research process 23

2.3.1 Objective 1: Literature Review 23

2.3.2 Objective 2: Data Collection and Documentation 24

2.3.3 Objective 3: Data Collection of Opinions 24

$\begin{array}{ll}\text { 2.3.4 Questionnaires } & 27\end{array}$

2.3.5 Objective 4: Data Analysis 28

2.4 Limitations 33

2.4.1 Limitations of Grounded theory in this Study 33

2.4.2 Limitations of this Study 36 
3.1 State of World Fisheries 39

3.2 Measure to Improve Fisheries Management $\quad 40$

3.2.1 Fisheries Management by Government $\quad 41$

3.2.2 Voluntary Measures 45

3.2.3 Market Failure 47

3.3 Eco-labelling: a new tool in Fisheries Management 49

3.4 Eco-label Examples $\quad 54$

3.4.1 Dolphin Safe Tuna $\quad 54$

3.4.2 Forest Stewardship Council 55

$\begin{array}{ll}3.4 .3 \mathrm{KRAV} & 56\end{array}$

$\begin{array}{ll}4.5 \text { Summary } & 58\end{array}$

4.0 The Marine Stewardship Council 60

$\begin{array}{ll}4.1 \text { Background } & 59\end{array}$

$\begin{array}{ll}\text { 4.2 The MSC Concept and Vision } & 60\end{array}$

4.3 Comprehensiveness of Standards $\quad 62$

$\begin{array}{ll}\text { 4.4 The Assessment process } & 63\end{array}$

$\begin{array}{ll}\text { 4.5 MSC Objections Procedure } & 67\end{array}$

5.0 Critique of the MSC Objections Procedure 71

$\begin{array}{ll}5.1 \text { Criticisms } & 71\end{array}$

$\begin{array}{ll}\text { 5.2 Principal-Agent Issues } & 77\end{array}$

$\begin{array}{lr}\text { 6.0 Scope of Research } & 80\end{array}$ 
7.1 Question Analysis: Objectors .... 81

7.1.1 Primary Concerns ... 81

7.1.2 Addressing of Issues by the Certification Body ... 84

7.1.3 Adequate Addressing of issues ....86

7.1.4 Level of Consideration Given by the IA to the Certification Body and Fishery Clients' Arguments and Evidence .... 88

7.1.5 Role Satisfaction of Independent Adjudicator

7.1.6 Payment of Objections Fee .... 91

7.1.7 Objections fee and barriers to Participation ... 92

7.1.8 Improvement to the Objections Procedure ... 93

7.2 Certification Body ... 94

7.2.1 Experience with the Objections Procedure ... 94

7.2.2 Role of the Independent Adjudicator ... 96

7.2.3 Consideration Given to Evidence and Arguments ... 97

7.2.4 Weighting Given to Evidence and Arguments by Fishery Client ... 98

7.2.5 Objections Payment ... 98

7.2.6 Objections Fee and Barriers to Participation ... 100

7.2.7 Improvements to the Objections Procedure ... 101

7.3 Fishery Client ... 103

7.3.1 Experience with the Objections Procedure ... 103

7.3.2 Role of the Independent Adjudicator ... 104

7.3.3 Consideration Given to Evidence and Arguments ... 105

7.3.4 Weighting Given to Evidence and Arguments ... 105

7.3.5 Weighting Given to Evidence and Arguments of the Objector

7.3.6 Objections Payment

7.3.7 Objections fee and barriers to Participation 106

$\begin{array}{ll}\text { 7.3.8 Improvement to Objections Procedure } & 107\end{array}$ 
8.2 How Does the Objections procedure facilitate Interaction Between Actors?

8.2.1 Objecting Body vs. Certification Body

8.2.2 Certification Body vs. Objecting Body

8.2.3 Fishery Client and Objecting Body

8.3 Role Satisfaction with the Independent Adjudicator

8.3.1 Independent Adjudicator and Objecting Body

8.3.2 Independent Adjudicator and Certification Body

8.3.3 Independent Adjudicator and Fishery Client

8.4 Objections Costs and Barriers to Participation

8.4.1 Objections Cost and the Objecting Body

8.4.2 Objections Cost and the Certification Body

8.4.3 Objections Cost and the Fishery Client

8.4.4 Barrier to Participation

8.5.2 Independent Adjudicator 


\subsection{Summary and Conclusions}

9.1 Inter-organizational Dynamics

148

9.2 Principal-Agent Issues

9.3 An Inefficient Process

9.4 Transparency; MSC's Strength or Weakness?

9.5. Determining and Objections Direction

9.6 Independent Adjudicator Gives Balance

9.7 Independent Adjudicators Purview Too Limited

9.8 Objections Payment Responsibility

9.10 Suggested Improvements

References 


\subsection{Study Outline}

\subsection{Introduction}

The Marine Stewardship Council eco-labelling scheme was formed in order to provide a means of promoting sustainable fisheries that moved away from conventional top-down management. In order to remain robust and transparent, MSC allows stakeholders to object to a certification through an objections process outlined by MSC. Over the past 15 years, this objections process has come under increasing scrutiny. The MSC OP has been accused of Ambiguous wording, principal agent issues and an unequal judicial process by some stakeholders and outside commentators. These accusations pose a real threat to the reputation of the MSC. If left un-addressed, MSC's credibility amongst consumers and academics has the potential to be lost. This thesis seeks to investigate the legitimacy and robustness of the MSC OP. There is a focus on the way in which the MSC OP facilitates interactions between objection actors, influences actors, and how each actor is empowered by the MSC OP methodology.

The past twenty years has seen a rapid acceleration in the degradation of world fisheries (Ward \& Phillips, 2008). Ineffective policy and management strategies have resulted in excessive and illegal catch, destructive fishing practices and perverse economic incentives. These impacts have primarily contributed to what is currently a concerning state in world fisheries (Mullon et al, 2005; Bensch et al, 2008). The FAO estimates that $80 \%$ of world fish stocks are either fully exploited, overexploited or have collapsed (Mora et al, 2009) and there is concern that many of fisheries that are listed as fully fished (52\%) are simply transitioning to an overfished status (Ward \& Phillips, 2008). One author even suggests that the global collapse of all taxa currently fished may occur by the year 2048 (Worm et al, 2006). 
Sighting the shortcomings of traditional, top-down, fisheries management strategies (such as command and control, tradable quota and voluntary systems) several authors have focussed their attention towards the consumer end of the market to provide a new means of sustainably managing fisheries (Espach, 2006; Gulbrandsen 2005; Tiesl 2008). The idea sought to capitalise on the primary goal of producers which is to obtain a greater market share for their product (Mason, 2008; Gulbrandsen, 2006). For this to occur, it is essential producers positively influence consumer preference. It was thought that if consumer preference required producers to fish sustainably, then fishers would be incentivised to do so in order to remain competitive (Durst et al, 2006). The concept of eco-labelling emerged from these discussions. An eco-label is a certification label placed on a product, communicating to the consumer that the product has met certain sustainability criteria during its production as defined by the eco-labelling organization (Gullastigue 2002; Mason 2008). By communicating such information, consumers are provided with the means to make sustainably responsible purchasing choices.

The most widely utilized eco-label in global seafood trade is that of the Marine Stewardship Council (MSC). Established in 1996 by the World Wildlife Fund for Nature (WWF) and Unilever (a major international exporter of seafood), MSC sought to create a global system of sustainable fisheries that will "provide powerful economic incentives for sustainable well-managed fishing" (WWF, 1996a) and thereby "halt a catastrophic decline in the world's fish stocks by harnessing consumer power" (ANP, 1996).

The MSC looked to build on the 1995 FAO Code of Conduct for Responsible Fisheries (FAO, 1995a), the UN Fish Stocks Agreement (FAO, 1995b), and resulted in further international fisheries agreements being developed through an inclusive consultation process between 1996 and 1999 (Anon, 2003). 
Three primary principles for sustainable fishing were agreed upon with which certified producers would need to comply. These are:

1. A fishery must be conducted in a manner that does not lead to over-fishing or depletion of the exploited populations and, for those populations that are depleted; the fishery must be conducted in a manner that demonstrably leads to their recovery.

2. Fishing operations should allow for the maintenance of the structure, productivity, function and diversity of the ecosystem (including habitat and associated and dependent and ecologically related species) on which the fishery depends.

3. The fishery is subject to an effective management system that respects local, national and international laws and standards and incorporates institutional and operational frameworks that require use of the resource to be responsible and sustainable.

Although MSC's effectiveness is debated (Gulbrandsen, 2008), the number of MSC certified fisheries has accelerated to 139 globally and is rapidly expanding as fishers perceive the benefits of certification (www.msc.org/track-a-fishery/certified. 06/03/2012).

It is recognised that an effective eco-label must maintain a high degree of transparency, trustworthiness and reliability amongst consumers (Gallastigue, 2002; Tiesl et al, 2008). MSC seeks to maintain these qualities through a transparent certification process, involving stakeholders, pursuing independent assessment and making available information regarding a fisheries assessment for certification online for the public to judge. 
The second method (and focus of this research) in which MSC seeks to maintain these qualities is through the use of an independent Objections Procedure (OP) (MSC, 2009). This allows a stakeholder to formally object to the certification of a fishery should they disagree with its certification. By employing the use of an OP, MSC increases its transparency and reliability; allowing stakeholders to scrutinize aspects of a MSC certification thought to require further justification. An objection can be based on three categories of discontent:

1. The objection identifies a serious procedural or other irregularity in the assessment process that made a material difference to the fairness of the assessment;

2. The score given for one or more performance indicators cannot be satisfactorily justified by the $\mathrm{CB}$ due to factual errors, omission of relevant information or arbitrariness;

3. Additional information has been identified that is relevant to the assessment by the date of Determination ${ }^{1}$ and was not available or known to the $\mathrm{CB}^{2}$.

(MSC, 2009)

The purpose of the OP is to "provide an orderly, structured, transparent and independent process by which objections to the Final Report and Determination of a Certifier can be resolved. It is not the purpose of the Objections Procedure to review the subject fishery against the MSC Principles and Criteria for Sustainable Fisheries, but to determine whether the CB made an error that materially affected the outcome of its Determination" (MSC, 2010d: 2).

\footnotetext{
${ }^{1}$ The Determination refers to the Final Determination report written by the CB (see below) post assessment. This report confirms or rejects MSC certification of the fishery in assessment.

${ }^{2}$ A certifier refers to the company tasked with assessing the sustainability of a fishery on behalf of MSC. The certifier is often referred to as the Certification Body.
} 
In order for the OP to support transparency and reliability in MSC, it is critical that the OP itself produces legitimate outcomes that address the concerns raised by the OB. However, during the eleven years MSC has been in operation, issues surrounding the legitimacy of contentious certifications and the robustness of the OP have been raised by several authors and environmental agencies (Highleyman, 2004; Forest \& Bird, 2007; Ponte, 2006; Pope, 2010).

Of the thirteen objections that have proceeded to adjudication ${ }^{3}$, only one has been upheld, three still being in assessment. These objections included the highly contentious Antarctic Toothfish, New Zealand Hoki, Bearing Sea and Aleutian Island Pollock, and Antarctic Krill fisheries. Resultant of historic objections, accusations regarding the legitimacy of the OP and its outcomes have begun to emerge. Several examples follow.

Highleyman (2004) accuses the MSC of giving the Certification Body (CB) too much responsibility in defining the scoring criteria of a fishery during assessment and contends that "MSC's claim of certifying sustainable fisheries in most cases is not justified under the definition established by its standards" (Highleyman, 2004; Pg. i). It is said that this enables the CB to justify their position in almost all circumstances.

After being involved in the 2007 New Zealand Hoki objection, Forest \& Bird New Zealand accuse MSC of being "fatally flawed" and sending "the wrong message to fishing companies world wide" (sic) (Forest \& Bird, 2007). There were instances during the Hoki objection where an independent panel of fisheries experts found "some validity to the Objectorss' position that this is not a fishery that should be certified as sustainable" (Forest \& Bird, 2007). However, due to the "procedures (the

\footnotetext{
${ }^{3}$ The formal objection phase of an MSC objection. See chapter 5.5
} 
OP) the Panel was operating under they were unable to stop the fishery being certified as "sustainable" (Forest \& Bird, 2007).

In the case of the 2009 Antarctic Krill objection filed by the Antarctic Southern Ocean Coalition (ASOC), the Independent Adjudicator ${ }^{4}$ (IA) identified a "serious procedural error" by the CB Moody Marine, however approved certification (ASOC, 2010). ASOC have accused the IA of ignoring its concerns during the objection regarding climate change impacts, biological uncertainties and the impact of fishing on the marine food web (ASOC, 2010).

The Yukon River Drainage Fisheries Association (YDRFA) objected in 2010 to the MSC certification of Alaskan Pollock, estimated to be worth nearly \$1 billion a year (MSC, 2010L). The YDRFA highlight that populations appear to have halved since 2004, with 2009 quotas being cut by nearly 20 per cent (Pope, 2010). The objection was however turned down. In this instance, it was accused that the financial gains of unsustainable fishing influenced the IA's decision. Jeremy Jackson, of Scripps Institution of Oceanography in San Diego, California, said: "Economic pressures to keep on fishing at such high levels have overwhelmed common sense" (Pope, 2010: 1).

Additionally, some authors have cited ambiguous wordings such as "reasonable", "adequately identified" and "appropriate consultative process" in MSC doctrine as empowering CBs to dispel condemnation (Peacey, 2000; Jaquet \& Pauly, 2008).

\footnotetext{
${ }^{4}$ Independent expert assigned by MSC to adjudicate an Objection See Objections Overview. See chapter 5.5
} 
Because there have only been thirteen objections that have proceeded to adjudication, there is good opportunity to study the experiences of objection participants. Additionally, because the MSC is fairly young as an organization (14years), research into the OP may provide insights into the emerging effectiveness of MSC as an eco-label.

This study employs a questionnaire based, qualitative research design in order to extract the views and perspectives of those involved in historical MSC objections. Additionally, official MSC objections documentation was used to help illustrate, provide insight and add perspective to the views of the questionnaire respondents. The views of individuals from all participating groups in an objection were sought and their responses analysed using Grounded Theory (GT).

\subsection{Contribution of this research}

A study focussing on the MSC OP has, to the knowledge of the author, never been conducted in the academic literature. It is hoped that this research will help shed light onto issues of process and credibility within the MSC OP in order to validate or dispel concerns, identify potential areas for improvement and encourage discussion regarding the structure and operation of the MSC Objections Procedure.

\subsection{Aim of the study}

The aim of this study was to examine the Objections Procedure of the Marine Stewardship Council's eco-labelling programme (MSC, 2009). Specifically the research focussed on how the structure and institutions of the MSC Objections Procedure has contributed to the outcome of historic objections, how the procedure has empowered different actors during the 
Objections Procedure and whether the Objections Procedure results in outcomes that support MSC's fundamental principles (MSC, 2010).

\subsection{Research question \& Objectives}

This thesis aimed to examine the following research questions and objectives in pursuit of achieving the overarching aim of the study:

1. How does the Marine Stewardship Council's Objections Procedure operate and how does it facilitate interactions between actors?

2. How does the Marine Stewardship Council's Objections Procedure contribute to an objections final decision and measures taken during after an objection?

3. To what extent does the Marine Stewardship Council's Objections Procedure lead to outcomes supporting the MSC's principles?

Research objectives used to answer the above questions were defined as follows:

Objective 1: Construct a conceptual framework for the research in which the role of the Marine Stewardship Council is placed in the context of global fisheries management methods. This is in order to identify the general forces within the MSC Objections Procedure and understand its overall function. In accordance with the thesis requirements, this will be in the form of a literature review.

Objective 2: Gather documentation providing an account of how each MSC objection has played out in order to gain an understanding of the recorded interactions between the actors. 
Objective 3: Acquire the opinions of different groups and individuals who have been involved in one or more MSC objections in order to gain their perspective and understanding of the MSC Objections Procedure.

Objective 4: Analyse questionnaire data using GT, placing the emergent themes in the context of institutional theory and MSC Objections Procedure protocol. This will inform the researcher of any common themes that have arisen through the different MSC objections, providing a real world context, and give insight into areas of contention amongst actors.

\section{Objective 5:}

A. Assess how the MSC Objections Procedure facilitates and empowers the actions between actors;

B. Using the conclusions of $5 \mathrm{~A}$, determine the extent to which the Objections Procedure leads to outcomes supporting MSC's fundamental principles. 


\subsection{Methodology}

\subsection{Methodological Approach: General State of Inquiry}

\subsubsection{Research Paradigm}

As an academic researcher, it is important to be clear of one's paradigm and the values held. It is therefore important to recognise the inevitable values associated with all research inquiry and attempting to minimize the incursions these values have on the research (Babcock, 1980).

There are two elements to this research's paradigm. The first accepts that the MSC OP is formed by and carried out within a framework defined by MSC (MSC, 2009). The MSC OP methodology provides a framework in which people and institutions may interact during an objection, shaping the behaviour of actors to a set of values and institutions within the objections methodology, as defined by MSC (MSC, 2010d).

The second element takes into account the postpositivistic and social constructivist nature of institutions and their interactions. This draws upon Kiser and Ostrom's (1982) "rational institutionalism" model which acknowledges that "an individual's perception of the world is influenced by a set of internally-generated motivations, and externally-generated world views, guides and rules instilled by the institutions in which people reside".

'Institutions' represent the conventions, norms and formally defined rules of society. These can include families, places of work, educational institutions, economic institutions, culture and groups (Scott, 1987; Vatn, 2005). 
In this research, the primary institutions are defined by the Marine Stewardship Council as the overarching organization within which the MSC OP operates. The principles and criteria of MSC operation, assessment methodologies and procedures each represent institutions within MSC.

The actors which operate within the MSC institutions during an objection are the Certification Bodies, environmental organizations and non-governmental organizations, fishery stakeholder groups and the Fishery FC (FC) (fishing company/industry seeking certification of fisheries) and Independent Adjudicator.

The behaviour and actions of the actors in this context is said to be the result of a complex web of dynamic forces that have negative and positive feedbacks and power to significantly alter the course of institutions (Butler, 2011). Therefore it is relevant to study the relationships and drivers between actors in order to gain an understanding of how the MSC Objections Procedure operates.

The array of interactions that occur during an objection renders a reductionist or positivist approach to this research inappropriate. This is because the forces driving the actions and reactions of actors during an objection cannot always be confined to a single source. The motivation for any action taken by one actor has potentially many origins. Because of potential underlying motivations (e.g. principal-agent incentives) of any actor, this research must allow for any unseen rationales and influences during an objection to emerge in order to gain a full description of the interactions between actors during an objection. Thus, the MSC OP cannot be reduced to any of its independent parts or to any of the (reducible) relations between 
the parts. This type of research therefore demands a study that is holistic and contextual (Silberstein \& McGeever, 1999; Brockman, 2006).

The difficulty in interpreting what might influence someone's view of a phenomenon (e.g. an event or process) makes it important that the researcher reduces the level to which they impose his/her ideas upon the data (Porter \& van der Linde, 1995). Research using this type of data requires that the data is allowed to 'speak' and reveal emergent features within the studied process without being manipulated by the researcher's conscious or subconscious biases. Therefore, this research decided that an inductive, postpositivist approach using qualitative research techniques (Flick, 2009) is most appropriate in the case of this study.

Because of the limited scope of this thesis, a case study design will be used, requiring 'key' informants to answer set questions. Whilst this approach limits the replicability and reliability of this study, it is hoped that the insights attained from the flexible and holistic approach of inductive inquiry will give great scope for further application.

\subsubsection{Research design}

There are two major approaches to qualitative research analysis evident in the literature: analytic induction and GT (Glaser \& Strauss, 1967). Analytic induction is unsuitable for this research as it requires an initial hypothesis.

It is acknowledged that theories such as market failure and principal-agency theory (see literature review) are utilized in this research; however these do not form the basis of a 
hypothesis. These theories merely assist in helping to contextualize data and themes produced where applicable.

GT varies from the customary model of research, where the researcher chooses a theoretical framework, and only then applies this model to the phenomenon to be studied (Allan, 2003). I have no previous, primary data to base an initial hypothesis on and to continually rehypothesize as data is analysed would be inefficient and impose time costs greater than a 90 point thesis will allow. In the light of this, GT will be employed to allow the data to demonstrate phenomena via a continual revision of categories and theories (Glaser 2002, Charmaz 2000). There are several ways in which GT can be used (McCreaddie \& Payne, 2010); however in this study, GT will be used to illustrate the interconnections and reflexivity between actors during an MSC objection. Emergent features in the data will be used to paint a picture of the forces acting on individuals and bodies during an objection to help ascertain how the MSC objections methodology influences the final objection outcome.

\section{Data sources}

As part of the MSC "vision \& mission" statements, MSC aims to be transparent with stakeholders and the public regarding all facets of its operation (www.msc.org/aboutus/vision-mission, 2011). This has resulted in MSC making public all official documentation and correspondence between actors during the certification and Objections Procedure available via their website www.msc.org. This archive provides a rich record of information regarding the interplay between actors during each MSC objection. Some records however have been removed from the MSC website but were made available following an email request to MSC. Although both the Hoki objections material and Antarctic Krill material provided was largely incomplete. 
The MSC documentation was supplemented with questionnaire data to help elaborate on the intricacies of the MSC objection interplay and to gain insight into the reasoning behind each actor's actions before, during and in response to an objection. 


\subsection{Research Process}

\subsubsection{Objective 1: Literature Review}

The literature review section provides a real world context for this research and a survey of relevant theory. It outlines the state of world fisheries, predominant management strategies used in modern fisheries, and the different forces at play in fisheries management common in the modern developed world. This is followed by a section outlining the development of the eco-labelling concept and its theoretical purpose. Three examples of established eco-labels are also described.

There is a strong theoretical basis in the review which provides insight into the different, institutional forces, incentives and mechanisms involved in eco-labelling and fisheries management. The theoretical areas explored centre around the economic management of a common pool resource, governmental, private and voluntary management strategies, the principal-agent relationships between fishing bodies, market failures (and attempts to correct them), and how eco-labelling has been proposed to address issues that have been historically difficult to solve. The material for this is derived primarily from academic articles, opinion papers, books and journals.

Subsequent of the review, a chapter describing MSC's development and implementation, the certification and assessment process and the MSC Objections Procedure is provided. This is further followed by a critique of the Objections Procedure, providing additional context for this research. 


\subsubsection{Objective 2: Data collection of documentation}

Documentation recording the events and correspondence between actors for each MSC objection was downloaded off the MSC website www.msc.org. Documentation from the 2001 New Zealand Hoki and 2010 Alaskan Pollock objections were not available online but were provided by MSC following an email request, however these were incomplete.

\subsubsection{Objective 3: Data collection of opinions}

Detailed questionnaires were chosen above other data gathering methods because of their ability to be mailed electronically to overseas participants. Interviewing and Skype was seen to be unacceptably time consuming and inconvenient for the researcher and participants. Questionnaires also provide a set group of questions, allowing for consistent comparison of answers regarding specific topic areas (Powell \& Renner, 2003). The questions were designed to extract information regarding personal and corporate experience with the MSC OP, whilst allowing the participant(s) to have the liberty to expand on points and opinions.

The aim was to extract the participant's opinions and experiences regarding elements of the MSC OP whilst granting a liberty to expand and provide insight into these. By doing so it was hoped the participants' answers would not be narrowly constrained in their scope. This approach to GT is more in line with Strauss \& Corbin's (1990) approach as opposed to Glaser's (1992) approach. As Tandon Bhal \& Leekha (2008) explain; Glaser (1992) believes in identification and specification of the research issues entirely upon the perception of the participant. In Strauss \& Corbin's (1990) approach, the researcher has the flexibility to 
choose the focus of the interviews around an area in advance, and data is gathered on that area.

A "key informant" approach (also known as "purposeful sampling" (Strauss \& Corbin, 1990b) was taken when identifying participants. To be labelled with "key" status the participant must have been closely involved in an MSC objection and be familiar with the happenings of the Objections Procedure in their case. Informants were identified via the MSC objections correspondence available on MSC's website and through personal correspondence with individuals and organizations that have participated in an MSC objection. Questionnaires were designed for four participant types: OB, FC, CB and IA. With the exception of the IAs, participants were generally found to be part of an NGO/environmental group, government, company or MSC. In some cases, identified individuals were able to suggest more suitable candidates for the study. Once participants were identified they were contacted by phone or email to explain the research topic and gain their participation in the study.

In accordance with Victoria University's Human Ethics Committee (HEC) requirements, participants were provided an information sheet (appendix 3) outlining the research, and asked to sign a consent form outlining the HEC conditions of participation and the researchers responsibilities (appendix 4). A summary of the questionnaire requests and responses can be found below: 


\begin{tabular}{|c|c|c|c|}
\hline $\begin{array}{l}\text { Participant } \\
\text { Type }\end{array}$ & $\begin{array}{l}\text { No. Questionnaires } \\
\text { Sent }\end{array}$ & $\begin{array}{l}\text { No. } \\
\text { Questionnaires } \\
\text { Replied }\end{array}$ & $\begin{array}{l}\text { Reasons Given for Refused } \\
\text { Participation }\end{array}$ \\
\hline $\begin{array}{l}\text { Independent } \\
\text { Adjudicator }\end{array}$ & 6 & 0 & $\begin{array}{l}\text { IA's felt compelled to not } \\
\text { participate due to the "quasi- } \\
\text { judicial" nature of their role. }\end{array}$ \\
\hline $\begin{array}{l}\text { Certification } \\
\text { Body (One copy } \\
\text { was sent to } \\
\text { each CB where } \\
\text { contact details } \\
\text { were available) }\end{array}$ & 8 & 3 & $\begin{array}{l}\text { Most certification bodies were } \\
\text { apprehensive to participate due to } \\
\text { their relationship with MSC. Some } \\
\text { refused contact information or to } \\
\text { forward the questionnaire. Others } \\
\text { failed to reply. }\end{array}$ \\
\hline Objecting Body & 10 & 6 & Too busy. Some did not reply. \\
\hline Fishery FC & 2 & 1 & Too busy to participate. \\
\hline Total & 26 & 10 & \\
\hline
\end{tabular}

Table 1. Summary of questionnaire participation for each participant type 


\subsubsection{Questionnaires}

Questionnaires were designed to present a structured set of questions that would produce answers around defined themes. (See Appendix 2a-d for questionnaire templates). These themes included:

\section{CB, FC \& OB}

- Which MSC objection the participant had been involved with and briefly why they were objecting (if the $\mathrm{OB}$ ).

- Overall objections experience.

- Level of satisfaction that concerns raised were appropriately addressed by the opposing party

- Level of input and consideration of evidence by the IA

- Satisfaction with weighting given to evidence and arguments by the IA.

- Level of satisfaction regarding the weighting given to evidence and arguments from other parties by the IA

- Level of satisfaction regarding the role of the IA

- The financial burden of an objection

- Possible improvements

- Fulfilment of MSC principles

IA

- Satisfaction with role parameters

- Satisfaction with objections process

- Ability to weight evidence in a fair and transparent manner

- Strengths/limitations of the MSC OP

- Possible improvements 
The questions were adapted for each participant type but aimed to get the participant to elaborate on the defined theme to provide any convergence or contrast in opinion.

Questions regarding satisfaction during the MSC Objections Procedure were primarily in a Likert Scale (See Wuensch, 2005) formation, but with an additional option to expand on ones answer in subsequent questions.

\subsubsection{Objective 4: Data analysis}

\section{Qualitative Research}

Qualitative research is focussed primarily on collecting and analysing non-numeric data with the goal of achieving information depth rather than breadth (Baxter et al, 2001; Coleman \& O'Connor, 2007). While quantitative research is more occupied with questions such as, how much? how many? how often, qualitative research is linked with questions such as; why? how? and in what way? Additionally, where quantitative research often operates in a deductive way, qualitative research frequently operates in an inductive way (Coleman \& O'Connor, 2007). A deductive process is initiated by existing theory and uses this to formulate some hypotheses, and through testing these hypotheses tests the theory itself. In contrast, inductive research attempts to gather explanation and meaning through the collection and analysis of empirical data. Saunders et al (1996) defines this notion by stating; 'Where you commence your research project from a deductive position, you will seek to use existing theory to shape the approach which you adopt to the qualitative research process and to aspects of data analysis. On the other hand, where you commence your research 
project from an inductive position, you will seek to build up a theory which is adequately grounded in a number of relevant cases'. Likewise, inductive research can also contribute an important role in the hypotheses generation (Fitzgerald, 1998).

Whilst this thesis uses the above type of GT analysis, it is must be acknowledged that is concurrently uses existing theory to explore institutions, incentives and principal-agent relationships. Without GT, the application of existing theories to the MSC OP would be based merely on speculation. GT data is required to confirm or deny existing theory and has the potential to create new theory.

\section{Grounded Theory}

GT seeks to take an area of study, and allow the interlinkages and constructs of them to emerge from that study area (Corbin \& Strauss, 1990; Tandon Bhal \& Leekha, 2008). It is an inductive approach wherein theory is generated from the data itself. According to Strauss \& Corbin (1998), the theory derived from GT data is more likely to resemble what is actually going on than if it were assembled from putting together a series of concepts based on experience or through speculation.

As previously mentioned, there have been two approaches to GT. Glaser's (1992) approach believes in identifying and specifying the research issues based upon the perception of the

participant. In Corbin \& Strauss's (1990) approach, the researcher has more flexibility to choose the focus of the interviews (and other forms of qualitative data gathering) around an area in advance. This research has uses a purposeful sampling method; hence Corbin \& Strauss's approach has been followed. 
Extracting theories and patterns from qualitative data is a multi-step process. As Corbin \& Strauss (1990: pg. 7) state, “Theories can't be built with actual incidents or activities as observed or reported; i.e., from “raw data." The incidents, events, happenings are taken as, or analyzed as, potential indicators of phenomena, which are thereby given conceptual labels." Identifying theory from data using GT involves coding the data at different levels of analysis. "Coding represents the operation by which data are broken down, conceptualized and put back together in new ways"' (Corbin \& Strauss, 1990: pg. 57).

In agreement with GT (Strauss \& Corbin, 1990), questionnaire responses were coded at increasing levels of analysis.

Coding is defined by three distinct 'steps' or 'phases'. These are "open coding, "axial coding" and "selective coding". These are described below.

\section{Open Coding}

Open coding involves "breaking down, examining, comparing, conceptualizing, and categorizing (qualitative) data" (Corbin \& Strauss, 1990: 61) into categories or "codes". "Codes" or "labels" refer to a "phenomenon" (that is, a problem, an issue, an event, or a happening) that is identified as significant by the respondents" (Corbin \& Strauss, 1998: 124). These phenomena are identified in the respondent's questionnaire transcript and assigned a corresponding code for identification. 
The following are examples of open codes:

- Insufficient justification of score (IJS)

- $\quad$ Principal agent issues (PAI)

- Unsatisfied with IA role (UIAR)

Each was assigned a numerical identification and written beside corresponding lines on the questionnaire transcripts. This facilitated the iterative process required by GT.

\section{Axial Coding}

The second phase to GT, Axial coding, is the "process of relating categories to their subcategories, termed "axial" because coding occurs around the axis of a category, linking categories at the level of properties and dimensions" (Corbin \& Strauss 1998: 123).

During axial coding, subcategories are associated with their corresponding properties and dimensions (Corbin \& Strauss, 1990). Axial coding focuses on how categories intersect and link. Rather than representing the phenomenon itself, a subcategory answers questions about the phenomenon (such as: when? Where? Why? What? Who? And how?), in turn generating greater explanatory power (Strauss \& Corbin, 1998) 
Examples from this thesis of open codes and their corresponding axial code include:

\begin{tabular}{|l|l|}
\hline Open Code & Axial Code \\
\hline Unsatisfied with IA role (UIAR) & $\begin{array}{l}\text { Due to Questionable independence of IA } \\
\text { (UIAR - IAQ) }\end{array}$ \\
\hline Insufficient justification of score (IJS) & Inadequate management (IJS - IM) \\
\hline Principal agent issues (PAI) & $\begin{array}{l}\text { CB financed by the FC } \\
\text { (PAI - CBFFC) }\end{array}$ \\
\hline
\end{tabular}

\section{Selective Coding}

Selective coding is defined by Strauss \& Corbin (1998: 143) as "the process of integrating and refining the theory", the term "theory" referring to the current, interpreted state of the data. Selective coding involves integrating and refining categories identified in open and axial coding. During selective coding, 'core categories' are identified through a process of refinement and a 'story' or comparison is constructed around this. Essentially the codes identified in open and axial coding are refined until there can be no further refinement. These core themes are used to identify relationships, trends, causal links and emergent features in the data which allows the researcher to form a basis for theory, or reverse engineered hypothesis (Allan, 2003).

\section{The use of GT in this Research}

The use of GT when analysing the questionnaire responses in this study was largely successful. Common themes amongst and between actors were identified and there was good contrast and convergence in themes and opinion expressed. Because the questionnaire questions were related to 
similar topics for each actor, the underlying causal links and emergent features of the data provided for interesting analysis. Additionally, the application of existing theories (e.g. principal-agent theory) to the GT data allowed for the confirmation or rejection of these theories in the MSC OP, and suggested additional theory development.

\subsection{Limitations}

\subsubsection{Limitations of Grounded Theory in this Study}

It is impossible for a researcher to undertake a project with a "clean" mental state; devoid of preconceived notions and ideology regarding what may emerge from the type of data GT provides (Malterud, 2001). GT attempts to let the 'data do the talking' by systematically analyzing themes in the data and allowing theories to emerge from them (Strauss \& Corbin, 1990). However, the obligation to develop a theoretically informed and a well-constructed research question for a thesis demands a certain amount of preconception by the researcher. Having some initial preconception is however not entirely disregarded. Bailey (2007: Pg. 127) points out that themes and theories do not emerge from the data "like daffodils" but rather are drawn out by the researcher. Funder (2005) argues that the manner in which these themes are extracted will depend in part on the researcher's institutional experience. Therefore it is almost impossible to avoid some sort of preconceived interpretation of GT data as one never approaches the research with a 'clean slate'.

GT itself, and in the context of this research, harbours potential issues that may limit the results of this study. When sampling in GT, one questions successive participants until essentially no new data is emerging from the questions (Cutcliffe, 2000). This research 
project is limited to the number of MSC objection participants who made themselves available for questioning. Each study group contains several individuals who could potentially partake in the study; thus limiting the number of potential participants to the number of MSC objections filed. Additionally, participant numbers are constrained further by the availability and usefulness of the participant. Therefore, any themes or theories derived from the data will reflect those who have been recorded to date. Because of the limited pool of participants available and those who chose not to participate, there is room for bias in the information received. Because participants who take part in the study are only those who agree to participate, the willingness or lack thereof will bias results, particularly where participants feel a sense of injustice or have strong opinions.

Additionally, GT begins with the researcher having no evolving theory to act as a guide in theoretical sampling of data. Baker et al (1992) maintain that the researcher using GT initiates the sampling process by interviewing "significant" individuals, those who have good experience in the topical area. Where there is a limited amount of respondents, the information provided will be limited in its scope to the experience of participating individuals and potentially not cover every possible theme to saturation.

The final significant limitation to this research surrounds the use of a literature review. Strauss \& Corbin (1994) recommend that researchers do not conduct a literature review prior to data analysis. By avoiding a literature review initially, it is more likely that the emergent hypotheses or theory will be grounded in the data (Strauss \& Corbin, 1994). However Smith \& Bailey (1997: 20) acknowledge that general reading of the literature may be carried out prior to data collection in order to obtain a feel for the issues at work. The demands of a thesis however require that a literature review be carried out to place the proposed research in the context of the wider literature. 


\subsubsection{Limitations of this Study}

The small sample size of twenty six participants is primarily due to the subjective nature of this study; however it also allows for qualitative richness. As previously noted, the pool of potential participants is limited at the upper bound to the number of MSC objections filed (13 as of 31/02/2012). Because GT requires knowledgeable participants to supply data, this was unavoidable.

Participant numbers were further constrained by refusals to participate. In total, 16 of 26 individuals approached refused to participate or simply could not allocate the time to complete the questionnaire (Table 1). Of the four participant types, only the OBs $(n=6)$, the CB's $(n=3)$ and FC (n=1) completed the questionnaires. Five of the six IAs felt that participation would undermine their role with the MSC, despite anonymity, and most FCs did not have the time to complete the questionnaire and were particularly difficult to find contacts for. This limits the perspectives provided in the study to nine participants, and three participant types (OBs, $\mathrm{CB}$ and $\mathrm{FC})$.

The participant types represent opposing sides to an objection and provide some indication of the opinions held by either side. Because OBs were more forthcoming in their participation, there is a danger of framing bias where the often critical tone of OBs can be allowed to direct the data analysis path. The limited FC and CB participation restricts the scope and detail of opposing points of view.

The relationship between the FC, Certification Bodies and MSC appeared to cause them to be more unwilling to participate in the study, despite assured anonymity. This was unfortunate, 
and limited the FC and CBs points of view to a few individuals, leaving a narrow sample of the overall opinion pool of such groups.

Additionally, without the IAs input there is a limited ability to discuss the role the Adjudicator plays during an objection or place the opinions of other respondents in the context of the Adjudicators abilities. The definition and limitations of the IAs role are made available by MSC, along with records of action taken by the Adjudicator during each objection; however a lack of participation in the questionnaires confines the data to recorded behaviour, not personal perspective.

Because the nature of the research involves individuals and organizations who have challenged one another's points of view in regards to MSC certification, there is potential for participants to express their distaste for other parties by taking a more aggressive approach when given the opportunity to comment on them. This may exaggerate some responses, distorting their recorded perspective from actual truths.

The themes and perspectives identified in this study may have been influenced by the author's area of study. Several of the questionnaire respondents belong to and represent various NGO's and environmental groups. Additionally, as the author of this study is grounded in the area of environmental science, there is potential scope for the unconscious influencing of data analysis.

The conclusions of this study will address a topic area that has received little academic focus, despite being controversial in the eyes of some individuals and groups. It is hoped that this study will identify any shortcomings in the MSC Objections Procedure and recommend 
changes that will move the MSC in a positive direction. Even if ignored by MSC and other readers, the issue of a how privately designed and run objections systems remain objective is becoming increasingly relevant. Hopefully this research can direct attention to this area in the academic realm. 


\subsection{Literature Review}

\subsection{State of World Fisheries}

World fish production is an integral part of the global provision of food, supplying at least $15 \%$ of the animal protein consumed by humans and indirectly supporting food production by aquaculture and livestock industries (Mora et al, 2009). The Food and Agriculture Organization (FAO) of the United Nations has documented the rapid expansion of international seafood trade over the past 20 years (Ward \& Phillips, 2008). Vladimarsson (2007) estimates that 38\% of the world's seafood now enters international trade (compared to $10 \%$ of meat (Delgado et al, 2003), just over half of this is contributed by developing countries (FAO, 2007)

Associated with an increase in the international trade of seafood has been a greater acceleration in the degradation of world fisheries (Ward \& Phillips, 2008). The FAO, which monitors the state of world fisheries has estimated that $80 \%$ of the world's fish stocks are either fully exploited, overexploited or have collapsed (Mora et al, 2009). There is concern that many of those that are listed as fully fished (52\%) are simply in a state of transition to an overfished status (Ward \& Phillips, 2008).

There is further concern regarding the impact of the various fishing methods used globally (Worm et al, 2006, 2009; Mullon et al, 2005). Fishing methods such as beam or bottom trawling and shellfish dredging alter the benthic habitat of marine ecosystems, the consequences of which are not yet fully understood (Schwinghamer et al, 1996; Jones 1992). However, the information available is alarming. Worm et al (2006) sought to assess the current and future consequences of destructive fishing practices and concluded that "Human-dominated marine ecosystems are experiencing accelerating loss of populations and species, with largely unknown consequences.....marine biodiversity loss is increasingly impairing the ocean's capacity to provide food, maintain water quality, and recover from perturbations" (Worm et al, 2006: 787). 
As major fish stocks are depleted, there has been a tendency to 'fish down the food chain', an effect which involves the systematic depletion of lower trophic level species as higher trophic stocks become depleted. This phenomenon is illustrated by a study in the North Atlantic showing that the biomass of predatory fishes (with a trophic level $=/<3.75$ ) declined by two-thirds through the second half of the twentieth century, even though this area was already severely depleted before the start of this period (Christensen et al, 2002; Pauly et al, 2002).

Combined, these issues have resulted in a disquieting state in world fisheries, suggesting that future declines are to continue if current fishing practice remains unchanged (Bensch et al, 2008). One study has suggested that the global collapse of all taxa currently fished may occur by the year 2048 (Worm et al, 2006).

\subsection{Measures to Improve Fisheries Management}

Globally, there have been numerous attempts to manage fisheries in a sustainable manner (Pauly et al, 2002). Examples of successful management have been documented (Wilen, 2006); however their success has tended to be location specific and difficult to apply to different species and management structures (Stone 1997; Gilman et al, 2008). In the modern era, fisheries management in developed countries has predominantly been conducted by governments and top-down type management, however market based mechanisms and voluntary measures have also been used (Symes \& Phillipson, 1997; Nash, 2002) 


\subsubsection{Fisheries Management by Government}

Top down or 'command and control' (C\&C) fisheries management is common amongst developed nations. C\&C fisheries management generally involves a governing body (e.g. government, fisheries department) regulating the level of fishing effort and catch or fish mortality allowed by fishers, often in the form of Total Allowable Catch (TAC), gear restrictions and area closures (Wilen, 2006). The decisions surrounding these policies are often settled upon in highly charged political arenas (Tientenberg \& Wheeler, 2001).

$\mathrm{C} \& \mathrm{C}$ management requires the governing or standard setting body to consistently obtain robust and reliable information about stocks, flows, and processes within the resource system, as well as information regarding the human-environment interactions affecting those systems (Dietz et al, 2003). This is challenging as fisheries data frequently contains high levels of uncertainty (Bensch et al, 2008).

Decision makers regularly require information that characterizes the types and magnitudes of this uncertainty, as well as the nature and extent of scientific ignorance and disagreement (Moss \& Schneider, 2000). Moreover, because every environmental decision involves tradeoffs, data is needed concerning individual and social values and the effects of decisions on various valued outcomes (Dietz et al, 2003). Because fisheries data is often expensive and difficult to obtain, it is seen as preferable that governments are in charge of commissioning fisheries research as they frequently are able to invest more resources into research (Organisation for Economic Co-operation and Development, 2000: 129). Subsequently better management decisions are in theory able to be made based on this data. However, due to the misapplication of data and the influence from vested interests, often this has not proved to be the case (Cummins, 2004). 
Fisheries management decision making is frequently conducted within a political process that reacts to a lack of scientific consensus and information uncertainty by adapting slowly (Wilen, 2006). In the minds of many, this impaired political process has brought us to a situation where the entire global marine ecosystem is in jeopardy (Stone, 1997; Wilen, 2006; Reiser, 1997; Berkes, 2003).

Fisheries scientists are reported often to view the predominant cause of fisheries decline as bad behaviour on the part of the user or extractor (Mullon et al, 2005). To quote one of the most widely cited critiques of conventional fisheries management (Ludwig et al, 1993: 36), "shortsightedness and greed of humans underlie difficulties in management of resources" and "wealth or the prospect of wealth generates political and social power that is used to promote unlimited exploitation of resources". The question of why user groups behave badly is not often raised by fisheries scientists. Resource users are assumed to be 'greedy' and 'short-sighted' as a natural condition. Using this view, if the objective of management is sustainable fisheries, the aim of policy must be to control and restrain the immutable bad behaviour of users (Wilen, 2006). Consequently, action by fisheries managers frequently involves controlling fishing mortality with top-down measures (Fela, 2010).

The points of failure in such systems are potentially many. Critics note that controlling fish mortality is more difficult than it appears. Fishing practices tend to differ in how they disrupt critical ecological components (Reiser, 1997). Thus, it is not enough to control the amount of effort expended on fishing. Overfishing is often the result of a failure to control where, when and how fishing occurs. Grafton et al (2007) noted that in many cases the $\mathrm{C} \& \mathrm{C}$ approach has been unsuccessful because fishers have been able to substitute from regulated to unregulated inputs in what has been called 'capital stuffing'. In this game, managers are forced to apply ever more stringent controls over a wider range of inputs, sometimes termed an 'input control spiral' (Grafton et al, 2006). In turn, this makes enforcement more difficult whilst making it more costly to fish.

$\mathrm{C} \& \mathrm{C}$ management requires robust information inputs being fed to policy makers in order that policy makers take the best course of action by the data supplied (Thorson et al, 2010). When governments 
lack the will or resources to safeguard 'protected areas', major environmental damage comes from hard-to-detect 'nonpoint sources', and when the need is to encourage innovation in behaviours or technologies rather than to prohibit familiar ones, $\mathrm{C} \& \mathrm{C}$ approaches may be less effective (Hannesson, 1993; Surronen \& Sarda, 2007. They are also economically inefficient in many circumstances (Berkes \& Folke, 1998; Heal, 1998; Colby, 1995).

Many economists believe that at the heart of the problem, bad behaviour is not inherent in fishers as individuals but is induced by the governance systems they are forced to operate within (Heal, 1998, Fela, 2010). In particular, fishers' fundamental decision-making incentives are distorted by insecure harvest privileges so that they are led to compete wastefully with each other, and with managers, for increased quantities of fish (Thorson et al, 2010). Insecure harvest privileges, in turn, are a historical artefact of the peculiar institutions within which fishers and other user groups operate in most modern fisheries (Wilen, 2006). Ludwig et al (1993) also points out that failure is often attributed to a political process that does not listen to scientists or that is captured by those out to promote unlimited exploitation of resources.

A second commonly used management tool by governments is that of 'rights based management' or 'property rights'. During the 1980's-1990's many fisheries management critics argued the root cause of poor fisheries management decisions was motivated by economic self-interest (Cloutier, 1996). They propose that overfishing occurs due to resource appropriators competing in an open access system and being un-willing to incur certain short-term losses to achieve long-term gains (Reiser, 1997).

The preferred solution was to assign individual 'property rights' in the form of Individual Fishing Quotas (IFQ's) to overcome the issue of common pool losses (Christy, 1973; Batstone \& Sharp, 2003; Homans \& Wilen, 2002). The idea was to define the resource (in the case of fisheries this would be stock levels), determine which level of extraction would allow for sustainability of the resource (e.g. maximum sustainable yield (MSY)) and divide this amongst a defined set of appropriators (fishers). 
In doing so, it was believed sustainability could be obtained as the total amount of extraction could only ever reach a previously defined sustainable limit. Concurrently, because the fishers have ownership of their resource portion, it was thought there would be an incentive to ensure the future sustainability of a fishery as overall stock levels determine the present level of catch now and in future (FAO, 1999).

IFQ systems have been implemented in 148 countries including New Zealand, Iceland, the Netherlands and Canada, all with varying success. In 2008, a global scale study of quota based management systems such as ITQ's concluded that overall quota systems helped prevent the collapse of declining fish populations. It was found that catch share fisheries were only half as likely to collapse (Costello et al, 2008). However, not all cases have proven positive with some resulting in static or declining biomass (Chu, 2009).

\subsubsection{Voluntary Measures}

Voluntary agreements in fisheries management occur when the fishing industry agrees to implement measures to improve fishing sustainability on their own accord. Measures often include gear restrictions, designation of no fishing zones, lowering TAC's and restricting fishing season duration (Symes \& Phillipson 1997). Industry bodies often introduce voluntary measures in response to diminishing fish resources or public pressure (Dietz et al, 2003). Voluntary measures are an important tool used by industry to communicate their 'commitment' to sustainability and corporate social responsibility (See Ward \& Phillips, 2008) (Wilen 2006).

Whilst there have been several positive examples of the use of voluntary measures in fisheries (Gilman et al, 2008; Surronen \& Sarda, 2007), voluntary measures have failed in many cases to curb un-sustainability in fisheries (Terra Nature, 2004; Dietz et al, 2003; Symes \& Phillipson, 1997). 
By nature, voluntary measures are generally enacted where a positive incentive is perceived by the industry (Nash, 2002). Success appears to depend on the existence of incentives that will benefit leaders over laggards, creating a potential market advantage and positive public image for the leader's product (Dietz et al, 2003).

The Commission of the European Communities (CoEC, 1996: 6) identifies at least three potential benefits to voluntary agreements:

1. The encouragement of a pro-active cooperative approach from industry, which can reduce conflicts between regulators and industry.

2. Greater flexibility and freedom to find cost-effective solutions that are tailored to specific conditions.

3. The ability to meet environmental targets more quickly due to decreased negotiation and implementation lags.

However, the extent to which voluntary measures actually benefit the sustainability of fish stocks is questionable. In some cases, closed areas have either already been heavily exploited, contain little fish of economic value (e.g. Benthic Protected Areas in New Zealand), or are rarely fished in the first instance (Symes \&Phillipson, 1997). TAC reductions are frequently agreed upon in response to declining catch levels, reflecting reduced fish stocks as opposed to precautionary limits (Cloutier, 1996; Teitenberg \& Wheeler, 2001). Additionally, the governing and regulation of voluntary measures is highly problematic. Voluntary measures are implemented and agreed upon by industry and sometimes governing bodies. Because measures are an industry initiative it is easier for actors to dilute policy and/or not implement changes at all with little possibility of enforced consequences (Terra Nature, 2004). The ease with which industry can flout their own rules creates an incentive to 
apply voluntary measures where conditions are favourable, only to relinquish them when conditions become challenging (Surronen \& Sarda, 2007; Teitenberg \& Wheeler, 2001; Nash 2002).

\subsubsection{Market Failure}

Proponents of using the market as a fisheries management tool suggest that governments should use market based mechanisms as frequently as possible by creating markets or market conditions (Dubbinik \& Vliet, 1996). Advocates suggest that governments often use the wrong instruments to tackle public issues, assuming public issues arise from "market failure" (Baumol \& Oates, 1988; Pearce \& Turner, 1990). Market failure occurs when "the price mechanism or the social market system, the so called invisible hand, fails to bring about a social optimum" (Tisdell 1993: p. 7). If the status quo requires individuals to behave in a way that produce a social optimum; the incentive structure is that public and private interests diverge and the policy objective is to re-set these so that private interests align to public interests (Dubbinik \& Vliet, 1996). Market failure occurs when social optimum is not attained and the allocation of goods and services becomes inefficient.

$\mathrm{C} \& \mathrm{C}$ regulations attempt to correct for market failures through legal and administrative measures, however these may fail to correct market imperfections (Neher, 1990) or generate cost misallocations. As a result, governments have had to invest enormous amounts of resource and effort to correct unwilling subjects. As a means to remediate this dilemma, many governing bodies have employed the use of Individual Transferrable Quotas to answer market imperfections. The use of ITQ's is a major step towards individual property rights intended to help restore the ideal workings of the market mechanism and assailing the problems of governability (Hannesson, 1993; Pearse, 1994; Dubbinik \& Vliet, 1996).

Advocates of ITQ and property rights systems suggest that ITQ's could solve biological, economic and administrative issues of fisheries considerably (Fela, 2010). The biological issues - the (threat of) 
depletion of the fish stocks - are said to be quelled because ITQ's enable individuals to act as private owners of a resource, having an interest in the conservation of their resource by protecting their ITQ asset. The economic issue, which is evident in the waste of labour and capital in superfluous catching capacity, excessive costs and (generally) reduced incomes (Pearse, 1994) is said to be softened as long as ITQ's enable individuals to escape the prisoners dilemma (Le \& Boyd, 2007), and make independent decisions about how to apply and organize the available production factors (Dubbinik \& Vliet, 1996). Additionally, as quotas are transferrable, the market mechanism should stimulate a price on them, thereby bringing about a trend where quotas are transferred from least efficient to the most efficient fishers (FAO, 1999).

Experience has shown the pitfalls of the market based mechanisms in fisheries management (Dubbink \& Vliet, 1996; Gibbs, 2010; Leadbitter, 2008). ITQ's have shown to produce excessive fishing capacity in fishers, resulting in a fight between financial gain and governmental regulation. The governance of the Dutch North Sea flatfish sector by ITQ's is an example of this. When ITQ's were introduced to the fishery in 1977 , the catch was set approximately $50 \%$ less than the previous season (Salz, 1991), leaving the fishing fleet greatly overcapacity.

Because the larger fishing vessels were financed on the basis of easily accessible loans, fishers felt that on one shoulder there was pressure from the bank to keep on fishing, whereas on the other shoulder the government was applying pressure to reduce fishing. The fishers predominantly decided to do the former, enabled by weak monitoring and enforcement policy; low fines for violations; and logistical and administrative help from auctions (Dubbinik \& Vliet, 1996).

Between 1977 and 1987 the beam trawler fleet increased from 495 vessels to 616 vessels (LEI/DLO Fishery Department, 1991), increasing capacity and catch effort required. This trend forced the government into greater regulation; however this still did not correspond with sustainable fishing practice. One such regulation was implemented by the Ministry of Agriculture, stating that if there was proof that the season's quota had been met early, the season would be closed at this point, even if 
individuals had not caught their individual allocation. Because fishers knew the season could be over at any point, the uncertainty motivated fishermen to race even harder for fish than before (Dubbinik \& Vliet, 1996).

This particular case demonstrates some of the major pitfalls of market failure in fisheries management. Market based regulations surrounding fishing only make fishers more determined to extract their ITQ as rapidly as possible.

\subsection{Eco-labelling: a new Tool in Fisheries Management}

During the past twenty years, there has been an increasing recognition that more traditional fisheries management methods, targeted at the supply end of the market are insufficient to guarantee the goals of resource conservation through sustainable fisheries production and may generate economic inefficiency (Caswell \& Anders, 2009). This has brought a more concerted focus towards the opposite (consumer) end of the market spectrum (table 1). The thought is that if the producers cannot be effectively regulated by a top-down governed fisheries management framework, then influencing producers via a bottom up approach may deliver a more effective structure to fisheries management, promoting a different set of incentives and mechanisms (Barham, 2002). The role of the consumer in the market system is the role of a purchaser of goods provided by the market producers (Bostrom, 2006). Therefore, any bottom-up fisheries management would need to influence consumer purchasing preference. The power of this approach is that producers require consumers to buy their products to make profit and to remain competitive in the market. It is the goals of most producers to have consumers prefer their products over another producer's product in order to increase their market share (Mason, 2008).

To effectively promote sustainable fisheries, the consumer would need to obtain information regarding the state of the fishery, production methods, processing methods and environmental impacts 
of the fishery. Due to the search and information costs of obtaining such knowledge, this is impossible to accomplish singly for even the most astute consumer (Gullastigue, 2002). This barrier to information results in what economist's label 'imperfect information'. If everyone has perfect information (on price and quality attributes) then every buyer will select exactly the composition of price and quality that he or she wants from the market, or will not buy at all if no offering is desirable (Caswell \& Anders, 2009).

Imperfect information can lead to market failures. Market failures occur in this context when "there is demand for products of a particular quality but the market does not provide them because of a lack of information or of market mechanisms to serve that demand" (OECD, 2009: 6). For example, consumers may be willing to pay for a fishery product with high quality attributes but only if they can be assured of this quality level. The market fails if sellers cannot credibly assure quality and consumers cannot discern quality.

A second example of market failure occurs when demand is societal rather than consumer driven. For example, epidemiological data may link a food-borne illness to a particular type of fishery product. Consumers may not make the connection between incidents of illness and specific foods. The market may fail to give incentives to companies to produce safer products because of the consumer's lack of awareness and an inability of watchdogs to identify and punish offending companies (Hannesson, 1993).

Obtaining sufficient information regarding quality takes considerable time and effort, resulting in high search costs (Nelson 1970, 1974). The benefit of gaining more information will be larger the greater the product cost. Concurrently, gaining more information has an opportunity cost that varies, for example, with a consumer's socio-demographic profile (e.g. income). Consequently, a buyer's marginal willingness to pay for information and the marginal costs of obtaining the information will vary. 
In an attempt to overcome this asymmetry of information and to harness the power of consumer purchasing preference to promote sustainable fisheries, the use of eco-labelling and certification schemes has been promoted (Jaquet \& Pauly, 2007; Potts \& Haward, 2006).

An eco-label (EL) is a mark or label placed on a product certifying that the product complies with set standards (e.g. fishing sustainability) as defined by the labelling organisation. Eco-labelling schemes bridge the knowledge gap between producers and consumers by communicating product information that is normally unseen by the consumer (Gullastigue 2002; Mason 2008).

In most cases, the labelling organisation will have designed a set of criteria that participating producers must comply with in order to obtain the rights to use the EL on their product. The criteria for certification reflect the aims of the labelling organisation and the types of practice they wish to promote (Barham, 2002).

The idea is that consumers will recognise an EL as a way of communicating that the product is produced in a more desirable (in the case of fisheries, sustainable) manner and therefore should be purchased over products that do not have such a label. Eco-labelling represents information that the consumer could never know about a product, reducing information a-symmetry and empowering the consumer to make more informed purchasing choices (Barham, 2002; Youssef \& Ayed, 2008). In the case of fisheries, if the consumer feels a sense of social responsibility to promote sustainable fisheries, then it is thought that this consumer will purchase eco-labelled seafood over non-labelled seafood, even if this incurs a greater financial cost. By reducing the search costs of sustainability information, the consumer is freed up to make a more informed product selection (Mason, 2008; Ward \& Phillips, 2008). Because the use of EL's has been primarily confined to the past two decades, confirmation of this effect is limited. Several studies however do provide evidence of this (Teisl et al, 2007; Veisten, 2009; Thøgersen et al, 2010) 
By creating consumer preference in the market, the EL gives an incentive to companies to seek and comply with eco-labelling schemes to remain competitive or increase their market share (Table 1). By encouraging participation in eco-labelling schemes, eco-labelling organisations incentivise a proportion of the industry to act in a manner reflecting the goals of the organisation. In the case of fisheries, eco-labelling may require fishers to catch, process and transport seafood in a sustainable manner in order for such suppliers to obtain certification of compliance with the label. This type of incentive reduces the need for top-down fisheries management, motivating fishers to comply or risk losing profits and market share (Sammer \& Wustenhagen, 2006).

Factors that Influence the Effectiveness of Private Environmental Regulatory Regimes

\begin{tabular}{|c|c|c|c|}
\hline & & & Institutional requirement \\
\hline \multirow[t]{7}{*}{$\begin{array}{l}\text { Demand-side } \\
\text { factors }\end{array}$} & \multirow[t]{3}{*}{ Market } & Consumer preference & $\begin{array}{l}\text { Competitive markets with environmentally conscious consumers } \\
\text { (domestic or foreign) }\end{array}$ \\
\hline & & $\begin{array}{l}\text { Client preference or pressure } \\
\text { (supply chain pressure) }\end{array}$ & $\begin{array}{l}\text { Asset specificity and/or coordination among clients (easiest under } \\
\text { conditions of high industry concentration) }\end{array}$ \\
\hline & & Enhanced company image & Company or brand differentiation \\
\hline & \multirow[t]{4}{*}{ Nonmarket } & Threat of further state regulation & Competent state regulation \\
\hline & & Threat of negative public campaigns & Presence of activist groups and media for public dissemination \\
\hline & & Threat of litigation & $\begin{array}{l}\text { Judiciary open to public claims against firms alleging environmental } \\
\text { malpractice }\end{array}$ \\
\hline & & & Institutional requirement \\
\hline \multirow[t]{4}{*}{$\begin{array}{l}\text { Supply-side } \\
\text { factors }\end{array}$} & Market & $\begin{array}{l}\text { Availability of verification instru- } \\
\text { ments across the entire commodity } \\
\text { chain }\end{array}$ & $\begin{array}{l}\text { Organization and oversight of program across commodity chain } \\
\text { through network or central administration }\end{array}$ \\
\hline & \multirow[t]{3}{*}{ Nonmarket } & Organization and administration & $\begin{array}{l}\text { Industry concentration, leadership by major firms, and capable ad- } \\
\text { ministrative agency }\end{array}$ \\
\hline & & Availability of external support & $\begin{array}{l}\text { Capable NGOs or other independent organizations willing to col- } \\
\text { laborate }\end{array}$ \\
\hline & & $\begin{array}{l}\text { Government position relative to } \\
\text { program }\end{array}$ & $\begin{array}{l}\text { State legitimacy as a voice for public interest, credibility of govern- } \\
\text { ment initiatives }\end{array}$ \\
\hline
\end{tabular}

Table 1. Factors that Influence the Effectiveness of Private Environmental Regulatory Regimes (Espach, 2006:

61) 


\subsection{Eco-Label Examples}

There are numerous examples of EL's used globally. The EL database 'Ecolabel Index' tracks 431 EL's (http://www.ecolabelindex.com. 07/03/2012). It is impossible to give examples for every EL. For the sake of brevity, three established EL examples are provided below. Each example demonstrates the development and implementation of an EL.

\subsubsection{Dolphin Safe Tuna}

Canned tuna is the second most consumed seafood by quantity in America (NOOA, 2002). The majority of tuna is sourced from the Eastern Tropical Pacific (ETP), accounting for almost one quarter of the world's tuna catch (National Research Council, 1992). It is well known that dolphins are often associated with yellowfin tuna in the ETP (Teisl et al, 2002). As a result, dolphins have been targeted by fishers in the ETP as a way of finding tuna. During this process dolphins may be killed, and up until a few decades ago no mitigation action was taken. From 1960 to 1972 the US National Research Council (1992) estimated that on average more than 100,000 dolphins were killed each year by the U.S. tuna fleet and, in the early 1970's, biologist began warning that commercial tuna fisheries in the ETP threatened dolphin populations (Congressional Research Service, 1997).

During the late 1980's, consumers became aware that the harvest of yellowfin tuna in the ETP caused the incidental mortality of dolphins (Teisl et al, 2002). Media attention ensued and the issue generated significant controversy, eventually resulting in calls for consumer boycotts of canned tuna. As a result, the three largest tuna canners in the U.S. market announced a dolphin safe labelling policy in April 1990 (Shabecoff, 1990). Additional canners quickly followed suit. The U.S. government responded by passing the Dolphin Protection Consumer Information Act of 1990 which mandates that tuna products cannot be labelled as "dolphin safe" unless dolphins were not used to capture tuna during the entire trip, as verified by an on-board observer. The combination of U.S. laws and eco- 
labelling effectively closed the U.S. market off to tuna caught where dolphins were at risk (Joseph, 1994).

\subsubsection{Forest Stewardship Council}

The Forest Stewardship Council (FSC) is an international conglomerate of environmental and social NGOs, producers and retailers of forest products, and certification agencies that promote standards for environmentally, socially and economically sustainable forest management (Espach, 2006). Founded in 1993, the initial aim of the FSC was to unite an array of sustainable forestry labels under a single, global eco-label so that buyers could confidently purchase wood certified as coming from sustainably managed forests. FSC is the only forest certification scheme to have standards based on continued participant performance in their requirements of compliance (Jenkins, 2000). By offering both forest certifications and chain of custody certifications the FSC is able to certify products across the supply chain. The FSC has been considered a pioneer of this market based "eco-consumerist" approach (Hochstetler, 2003). FSC international also sets worldwide compliance, auditing, and enforcement procedures. Independent, external verifications by an accredited auditor are mandatory. Audits are required every six months for chain custody certification during the first four years. Enforcement is left up to public monitoring and an open investigative process. Any individual or group can call for the investigation of a local FSC certification, a process that consists of outside reviews, requiring full reports from all major local stakeholders (Espach, 2006).

The impact of the FSC was recognised within a few years. Both supply and demand for certified timber grew dramatically in the 10 years after the founding of the FSC (Taylor, 2005). By mid 2002, over 109 million hectares of forest was FSC certified under all schemes, representing some $18 \%$ of the 600 million hectares expected to produce wood in the following three decades (Atyi \& Simula 2002: 10; Van Dam 2003: 3). In 2010, over 120 million hectares of forests were FSC certified in over 80 countries - the equivalent of roughly $5 \%$ of the world's production forests (FSC, 2010). The rapid 
growth rate in FSC certified products is a response to market demand for FSC certified products. The value of FSC labelled sales is estimated at over \$US20 billion, demonstrating a growing political and economic force endorsing and promoting the FSC system (FSC, 2010). The growth in FSC certified wood products is expected to increase in future as market players continue to recognise the advantage of becoming certified (Taylor, 2005).

\subsubsection{KRAV}

The KRAV EL is native to Sweden and is an example of a more recently developed multiple attribute EL, incorporating criteria related to many types of environmental aspects and for several stages of the product's life cycle (Thrane, 2009). Whilst FSC is multi attributed by focussing on multiple areas of production (e.g. chain of custody, environmental harm), KRAV's labelling criteria include less common areas of focus such as animal welfare and energy consumption (KRAV, 2011). KRAV is organised and associated with, at present, 27 members representing farmers, processors, trade, environmental and animal welfare interests (KRAV, 2011). Around 3, 000 farmers and approximately 450 companies in processing and trade are associated with KRAV. At present there are more than 5, 500 KRAV-certified products. Five Certification Bodies carry out inspections according to KRAV standards (KRAV, 2010)

When looking at the fisheries component of KRAV, there is a focus on aspects of sustainable fishing that other eco-labels have omitted such as energy policy, climate change and animal welfare (Thrane, 2009).

These criteria demonstrate the comprehensive nature of the KRAV eco-label, addressing many types of environmental aspects in several life cycle stages (Thrane, 2009). In 2010, KRAV carried out a major survey of public opinion with the help of the consumer research company SIFO. The results showed that: 
- $99 \%$ of the Swedish population knew of the KRAV label

- $\quad 59 \%$ regarded the KRAV label as very positive

- In a comparison of common food labels, KRAV was rated highest in regards to quality

The KRAV model is an example of the successful application of an eco-label model on a national scale. At this scale, public awareness and quality perception is very good. Because KRAV focuses on many non-traditional aspects of environmental management, it has the potential to address many different environmental issues at once. Given its local popularity, it is in an even greater position to achieve this as producers are increasingly required by consumers to be KRAV certified. 


\subsection{Summary}

This literature review has covered much of the background theory and reasoning behind the design and use of EL's. The review describes many of the recent sustainability trends in global fisheries and provides a real world context in which global fisheries management is based. A thorough assessment of widespread fisheries management tools is given, focussing on: traditional top-down management, market based instruments, voluntary measures and property rights.

This review makes it clear that the described fisheries management tools have failed to holistically curb unsustainability in global fisheries. Eco-labelling presents a new tool in fisheries management and has the potential to be an effective agent of change in fishing sustainability. By removing asymmetries in information and empowering the consumer to make sustainable choices in their purchase, EL's can incentivise producers to become certified in order to remain competitive, promoting the EL's values.

Three EL examples have been given: Dolphin Safe Tuna, Forest Stewardship Council and KRAV. Each provide an illustration of an established EL scheme and give insights into the different areas of influence an EL can target.

The implementation of eco-labelling in seafood has been a relatively new concept, only being promoted consistently in the past twenty years. Due to seafood EL's being in their infancy, their full success is still largely unknown. Initial indications suggest that there is merit in the EL argument, but this will require further research and investment as the effects of current EL's become fully known. 


\subsection{The Marine Stewardship Council}

\subsection{Background}

Observing the decline in global fisheries and the ineffective fisheries management systems governing them, many authors in the late 1980 's began to support the concept of eco-labelling as an important tool in fisheries management (Cummins, 2004). Whether out of direct support or sheer frustration at the lack of alternatives, environmental agencies and institutions began to explore the feasibility of a global scale eco-labelling programme in fisheries (Salzman, 1991; Teisl \& Roe, 1999; Wessells et al, 1999).

In February 1996, Unilever and the World Wildlife Fund for Nature (WWF) responded by announcing a joint eco-labelling venture called the Marine Stewardship Council (MSC). The MSC is designed to create a global system of sustainable fisheries that will "provide powerful economic incentives for sustainable well-managed fishing" (WWF, 1996a) and thereby "halt a catastrophic decline in the world's fish stocks by harnessing consumer power" (ANP, 1996).

The MSC is an outgrowth of WWF's 1994 Endangered Seas Campaign (WWF, 1996b) and is based on the Forest Stewardship Council programme established in 1993 (WWF 1996a). A critical component of the MSC establishment was the partnership between WWF and Unilever. In 1997, Unilever had a twenty-five percent share of the European and US frozen fish market and also had major fishmeal and fish oil enterprises (Smelly, 1997 in Constance \& Bonnano, 2000). In 1997 Unilever received nearly US $\$ 50$ billion in sales, marketing over 100 brands through its 300 subsidiary companies with operations in 88 countries (Unilever, 1998). With such a large market share, Unilever was an ideal partner for WWF as a market foot-hold could already be established from MSC's conception. 


\subsection{The MSC Concept and Vision}

Whilst WWF and Unilever may have had different motives for creating the MSC, they stated a shared objective aimed at ensuring the long-term viability of global fish populations (WWF, 1996a). According to Michael Sutton of WWF, "The history of fisheries management is one of spectacular failures. By working together with progressive seafood companies, we can harness consumer power in support of conservation and make it easier for governments to act" (Constance \& Bonanno, 2010: 194). Caroline Whitfield of Unilever concurs with Sutton, adding that, "Two of our core principles are that sustainable business is good business, and that we work in partnership to meet our goals. This initiative, on behalf of millions of consumers, is entirely consistent with these principles" (Constance \& Bonanno, 2010: 194).

In April 1998, the MSC released its first public draft of their "Principles and Criteria for Sustainable Fishing." These principles are intended to guide the efforts of the Marine Stewardship Council towards the development of sustainable fisheries on a global basis (MSC, 2010a):

1. A fishery must be conducted in a manner that does not lead to over-fishing or depletion of the exploited populations and, for those populations that are depleted; the fishery must be conducted in a manner that demonstrably leads to their recovery.

Intent: "To ensure that the productive capacities of resources are maintained at high levels and are not sacrificed in favour of short term interests. Thus, exploited populations would be maintained at high levels of abundance designed to retain their productivity, provide margins of safety for error and uncertainty, and restore and retain their capacities for yields over the long term" (MSC, 2010a: Pg. 5). 
2. Fishing operations should allow for the maintenance of the structure, productivity, function and diversity of the ecosystem (including habitat and associated and dependent and ecologically related species) on which the fishery depends.

Intent: "To encourage the management of fisheries from an ecosystem perspective under a system designed to assess and restrain the impacts of the fishery on the ecosystem” (MSC, 2010a: Pg. 5).

3. The fishery is subject to an effective management system that respects local, national and international laws and standards and incorporates institutional and operational frameworks that require use of the resource to be responsible and sustainable.

Intent: "To ensure that there is an institutional and operational framework for implementing Principles 1 and 2, appropriate to the size and scale of the fishery" (MSC, 2010a: Pg. 6).

\subsection{Comprehensiveness of Standards:}

The Principles and Criteria for MSC certification sought to build on the UN Food and Agriculture Organization (FAO) Code of Conduct for Responsible Fisheries (FAO, 1995a), the UN Fish Stocks Agreement (FAO, 1995b) through an inclusive consultation process between 1996 and 1999 (MSC, 2003). This process involved more than 300 organisations and individuals, included two expert drafting sessions and a series of international workshops in various regions around the world. 
As work on the MSC Principles and performance requirements progressed, it became evident that the MSC would need to draw stringent boundaries around what should and should not be included (O'Riordan, 1997). Essentially, MSC had to decide if the principles and criteria only should address fishing operations and environmental issues, or if they should also address social and development issues (Auld, 2007). The MSC decided to keep standards narrow, focussing primarily on fishing operations and avoiding the deep complexity of development issues. Standards were based around the three principles for sustainable fishing (as above) and are supplemented by a number of more specific operational/management criteria. Independent $\mathrm{CBs}$ are required to adapt the Principles and Criteria to meet local fishery conditions (Ponte, 2006).

\subsection{The Assessment Process}

* For full assessment methodology details, see appendix 5

When a fishery wishes to apply for certification, they notify MSC of their intentions and select an independent CB to conduct the assessment (MSC 2010a). The MSC provide an approved list of CBs in which the FC may choose from.

Aside from being the author of the standards, this is the largest participatory role MSC has in the certification process (Cummins, 2004). The MSC's role in the assessment process is primarily confined to accrediting the certification bodies whom are tasked with assessing each applicant fishery using the MSC Fisheries Certification Methodology. CBs are independent of MSC in the sense that they are not directly paid by MSC, a measure designed to achieve un-biased assessment (Cummins, 2004). Instead, they are paid by the FC to conduct the assessment, which itself will be seen to generate problems (Highleyman, 2004).

The CB undertakes a pre-assessment to determine if the fishery has a high chance of gaining certification in current condition, will gain certification if some elements are altered, or will not gain 
certification. If the fishery is considered by the CB to have a good chance of success, the fishery proceeds into full assessment.

Where full assessment is pursued, the CB assembles an expert panel to assess the fishery. The full assessment process is governed by a further set of principles which state that the assessment must:

- Ensure relevant and adequate information is available to the $\mathrm{CB}$ to aid the fishery assessment.

- Ensure that all opportunities to participate in the assessment process are provided to interested parties.

- Ensure that the process is clear and transparent to interested parties.

(MSC: 2010c: 11-12)

Step 2 of the Full Assessment is the stage at which formal assessment occurs and determinations are made about fishery certification. Scoring guideposts and performance indicators are used for different aspects of the fishery, in correspondence with the MSC principles (Fig 1). Scores are out of 100 (i.e. the presence of an effective management plan can gain a score of 0-100, zero being non-existent and 100 being in full compliance). The fishery is then assessed against these performance indicators. All elements of the fishery must receive a score of at least 60 , having an overall scoring average of at least 80 to obtain MSC certification. 


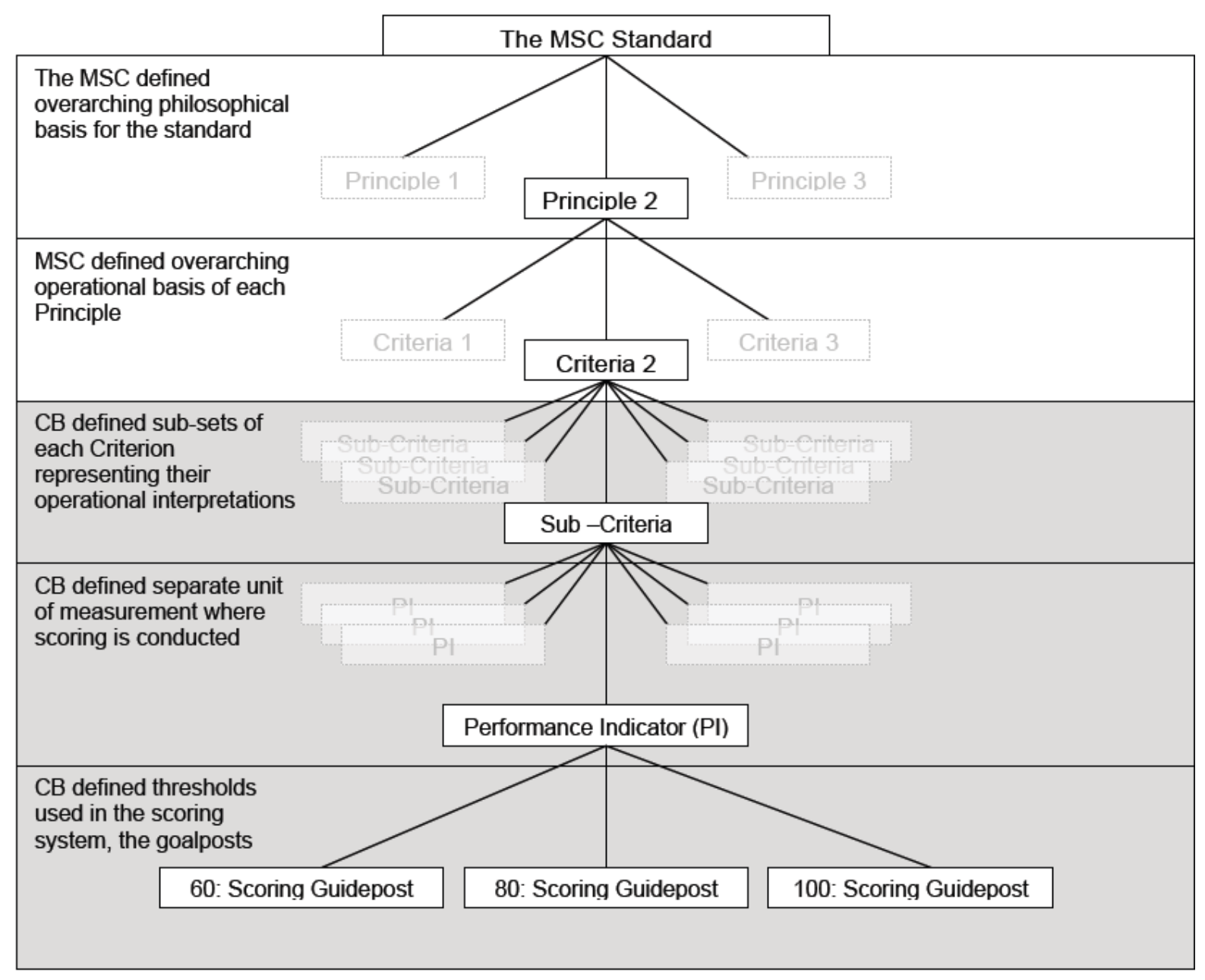

Figure 1. MSC assessment tree hierarchy. Role of MSC and CB (CB) in defining assessment criteria (MSC, 2010k)

If the fishery passes the initial assessment, a draft report is compiled for review by the CB. The draft report is reviewed by a group of experts consisting of at minimum the peers of the experts on the assessment team. The Draft incorporates FC response and conditions (if applicable), scores, weightings and certification outcomes. The CB must notify MSC and stakeholders of the proposed peer reviewers and allow 10 days for stakeholders and the MSC to submit written comments and/or objections as to the selection of a proposed member of the peer review panel (MSC, 2010c).

Once the draft report has been critiqued, the CB publishes the final determination and report, making any corrections it deems necessary in response to comments by reviewers or stakeholders. Should a 
stakeholder still disagree with the final report, they have the 21day window to initiate the MSC Objections Procedure (described later).

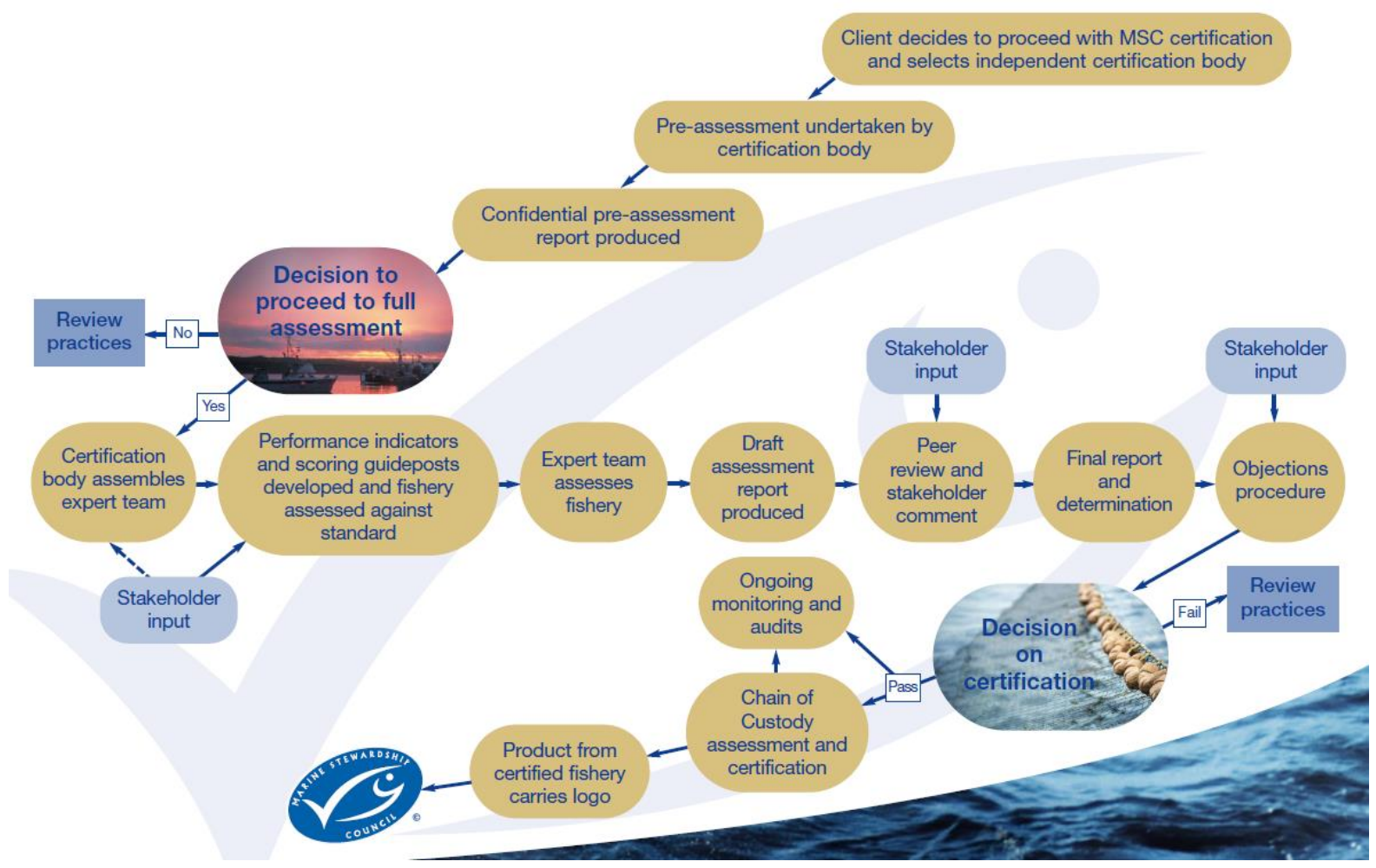

Figure 2. Flow diagram of the MSC certification process. (Available at: http://www.msc.org/documents/getcertified/fisheries/Assessment_FloChart.pdf/view. Accessed 27/01/2012)

Should the final report be accepted, a chain of custody assessment is carried out. This involves analysing the "procedures implemented by a fishery and subsequent handlers to ensure that products from a certified fishery are not mixed with products from any other fishery during processing or distribution for retail sale" (MSC, 2010c: Pg. 39). This type of assessment is carried out on an annual basis for all certified fisheries.

Should the chain of custody pass MSC standards, then the fishery is fully certified and licensed to bear the MSC logo on their product. 


\subsection{MSC Objections Procedure}

* For full illustration of the MSC Objections Procedure, see appendix 6

* For full description of MSC Objections Procedure Methodology, see appendix 7

The MSC Objections Procedure is activated when a stakeholder disagrees with the final draft report written by the Certifying Body. The reasons for submitting an objection can be related to three categories:

4. The OB identifies a serious procedural or other irregularity in the assessment process that made a material difference to the fairness of the assessment;

5. The score given for one or more performance indicators cannot be satisfactorily justified by the $\mathrm{CB}$ due to factual errors, omission of relevant information or arbitrariness;

6. Additional information has been identified that is relevant to the assessment by the date of Determination and was not available or known to the $\mathrm{CB}$.

(MSC, 2009: C146)

The purpose of the Objections Procedure is to "provide an orderly, structured, transparent and independent process by which objections to the Final Report and Determination of a $C B$ can be resolved. It is not the purpose of the Objections Procedure to review the subject fishery against the MSC Principles and Criteria for Sustainable Fisheries, but to determine whether the CB made an error that materially affected the outcome of its Determination” (MSC, 2010d: Pg. 2). 
By defining the OP this way, the $\mathrm{OB}$ is unable to object based on issues that relate to the MSC Principles and Criteria for Sustainable Fisheries with which the CB is operating within, rather the OB must object to an error or oversight by the CB in its assessment of a fishery. Therefore, it is not the MSC's core principles that are scrutinised, rather, the assessment methodology of the CB. Outside of appointing the IA, MSC is largely independent from the objection.

When the Notice of Objection is received by MSC, an IA (IA) is assigned to the objection case. The IA assesses the objection to determine whether it has "a reasonable prospect of success" (MSC, 2009: Pg. 4). If the IA determines the objection to be worthy of the Objections Procedure, the objection proceeds to the formal Objections Procedure.

The formal Objections Procedure is a format in which the CB and OB can state their argument and justify their position. Initially, the IA approaches the CB with the OB's points of objection in the hopes that any issues can be resolved without proceeding to formal adjudication. If the issues remain unresolved, the objection moves to an oral hearing and formal adjudication (MSC, 2009: Pg. 5, sec 4.7). The OB may submit any additional material related to the Notice of Objection at this time. Before the hearing can commence, the objecting party must sign a contract agreeing to cover the costs of objection. The limit for cost recovery was previously $£ 15,000$ (MSC, 2009), however was lowered to $£ 5,000$ in 2010 (MSC, 2010M). Should the OB face exceptional financial circumstances, they may apply to the IA for a fee waiver (MSC, 2009b: 9).

During the oral hearing, there is an opportunity for the $\mathrm{OB}(\mathrm{s})$, the $\mathrm{CB}$ and the Fishery to present their respective cases in person or via video or teleconference. Should the IA determine that additional sessions are required, the hearing may continue at a later date via electronic communications or other means (MSC, 2009) 
Following the oral hearing, the IA issues a written decision either confirming the original Determination by the $\mathrm{CB}$ or remanding the Determination to the $\mathrm{CB}$. If the Determination is remanded the $\mathrm{CB}$ has 10 working days to submit a written response to the MSC, FC and the OB.

Written submissions regarding the response may be submitted to the IA no later than 5 working days following the response by the CB (MSC, 2010c).

The IA will, within 10 working days of the response by the CB, either accept the response as an adequate resolution to the matters raised in the remand and approve the original (or amended Determination) or uphold all or part of the objection.

The CB will then consider amending the Final Report and Determination in the light of the findings of the IA. The CB is not bound to make any changes if they can satisfactorily justify their reasons to the IA. Finally, this will form the basis for the Public Certification Report.

As of February 2012, thirteen fisheries have gone to adjudication under the MSC Objections Procedure (www.msc.org/track-a-fishery, April 23, 2011). These fisheries include:

1. Danish Plaice Otter Trawl

2. Gulf of California, Mexico Sardine Fishery

3. Aker, Biomarine Antarctic Krill Fishery

4. North East Atlantic Mackrel

5. New Zealand Albacore Tuna troll

6. New Zealand Hoki

7. Antarctic Toothfish

8. Bering Sea Aleutian Islands Pollock Fishery

9. Atlantic Swordfish 
10. Denmark Blueshell Mussel

11. Fraser River Sockeye Salmon

12. Pacific Hake

13. Western and Central Pacific Skipjack Tuna

Of these objections, three fisheries (1,2 and 5) are currently in progress (01/02/2012), the North East Atlantic Mackerel objection was upheld, and the remaining nine have had their objections declined by the IA and the fishery subsequently certified.

In the Antarctic Toothfish objection, the IA found the CB had in fact committed a "serious procedural error" (MSC, 2010i: 1), however after the CB's response, the IA was "satisfied (this) had not made a material difference to the fairness of the assessment" . Other elements of the objection were dismissed "subject to certain amendments being made to the Final Report and Determination" (MSC, 2010i: 1). Therefore, one part of the objection was upheld, the other declined. 


\subsection{Critique of the MSC Objections}

\section{Procedure}

\subsection{Criticisms}

Some of the earliest criticisms of the MSC have centred on questions of feasibility and legitimacy. This is unsurprising in the early stages of such a programme where the effectiveness of theoretical strategies begin to take shape in practice. However, many of these issues remain relevant.

The most comprehensive, independent assessment of MSC was conducted by Highleyman (2004) on behalf of the Homeland Foundation, Oak Foundation and Pew Charitable Trusts. The assessment surveys the concerns of various authors and investigates controversial fisheries which gained certification. Some of the key findings of this report include (See appendix 1 for full list):

1. MSC's claim of certifying sustainable fisheries in most cases is not justified under the definition established by its standards, the Principles and Criteria;

2. Principle 2 requires fishing operations to maintain the structure, productivity, function, and diversity of the eco-system on which the fishery depends, but routinely is not met. MSC has a leadership opportunity to drive best practices towards eco-system based management;

3. MSC has narrowly interpreted the meaning of controversial fisheries in ways that reduces its flexibility and ability to guide its own future (original authors wording); 
4. CBs have too much flexibility in determining how principles and criteria are applied, including the thresholds for compliance, allowing for inconsistencies and low thresholds. Recognising this, MSC is taking steps to propose greater interpretation and guidance to CBs;

5. MSC is not yet considered as a credible consortium organization because key environmental stakeholders do not feel that the MSC mission includes them in a substantive way;

6. MSC has made important decisions in the in the last two years to increase stakeholder representation on the board but must continue this trend to restore the organization's credibility;

(Highleyman, 2004: 1)

Highleyman (2004) continued by focusing on the interactions of the MSC principles with the then management systems. MSC promotes its eco-label scheme as a new and effective way to improve fisheries management. But how does this interact with other efforts to reform fisheries management policy?

In Australia, Highleyman (2004) concluded that MSC principles and criteria appear to have had a positive effect, promoting stronger policy standards by providing the model for Australia's Guidelines for the Ecologically Sustainable Management of Fisheries (MSC, 2003). However, other case studies Found MSC found to be in conflict with some fisheries conservation efforts:

- For the South Patagonian Toothfish, conservationists contend that the certification of this stock will interfere with their efforts to stigmatize illegally caught Toothfish from other stocks (Stokstad, 2010) 
- In the New Zealand Hoki Fishery, major conservation groups protested certification and recertification of this deep water trawl fishery because of fur seal and bird bycatch that the MSC now proclaims part of a sustainable fishery (MSC, 2002).

- For Alaskan Pollock, numerous conservation organizations identified that populations had nearly halved since 2004 (Pope, 2010). They further contend that the MSC certification of more than a third of all fish caught in the U.S. as sustainable would give the powerful Factory Trawlers Association political cover for sweeping under the carpet significant ecosystem, by catch and habitat concerns in this fishery (MSC, 2005).

When such contentious issues arise, the question of which avenue becomes more likely to achieve conservation outcomes comes to the foreground. It is true that conservationists do not always achieve their goals; yet conversely it is equally true that MSC does not have the experience or ability yet to make the case that certification will achieve them either (Highleyman, 2004).

Because the MSC label is proposed as a means of conveying information regarding a fishery in order to the correct market failure of asymmetric information, it is important that the information communicated by the label is accurate and reliable (Jaquet \& Pauly, 2007).

Many of the above criticisms pose a significant threat to the credibility and transparency of the MSC scheme. One of the key components of maintaining transparency and accountability in the MSC certification process is the existence of an Objections Procedure. Therefore, it is vital that this mechanism is functioning in an independent, credible and un-biased way, ensuring certifications that the consumer can consistently trust.

During the eleven years MSC has been in operation, issues surrounding the legitimacy of particular certifications and the robustness of the Objections Procedure have been raised by several authors and environmental agencies (Highleyman, 2004; Forest \& Bird, 2007; Gulbrandsen, 2005; Ponte, 2006). 
Highleyman's (2004) assessment of MSC raised several negative points regarding MSC assessment and the outcomes of some MSC Objections:

The first example of a controversial certification and consequential objection is that of the New Zealand Hoki fishery. The NZ Hoki fishery was first certified in 2002 following a lengthy assessment process by the CB SGS. The of New Zealand (in conjunction with the Environment Conservation Organizations of NZ (ECO)) lodged an objection to the initial certification arguing the fishery was unsustainable and in danger of collapse. WWF and the Royal Forest \& Bird Protection Society New Zealand lodged an additional objection during re-assessment in 2007. Their main arguments included:

"Hoki stocks have dramatically collapsed. Since 2001, when the fishery was first certified, the Hoki catch has fallen from 250,000 tonnes a year to 100,000 tonnes - a 60\% reduction" (Forest \& Bird, 2007: Pg. 2)

"The fishery lacks a fish stock recovery plan, which is required under the MSC's own rules. It also causes serious damage to the seabed by bottom trawling and routinely kills hundreds of seabirds and marine mammals as by-catch every year" (Forest \& Bird, 2007: Pg. 2)

The response by SGS was to stick by its initial position, using the freedom MSC standards gives the $\mathrm{CB}$ to determine scoring guideposts, performance indicators and their subsequent scores (MSC, 2010b). In this case, MSC methodologies allowed the CB to define key scoring variables and the fishery's corresponding ratings. The $\mathrm{CB}$ appears able to justify their actions in almost all circumstances, provided they can justifiably align their scoring system with MSC Fisheries Certification Methodology (MSC, 2010c).

A comprehensive third-party assessment and independent objections panel composed of the $\mathrm{CB}$ and three MSC appointed, independent experts released this statement post the 2002 Hoki objection: 
“... there are several instances ... where the Panel found itself in disagreement with the CB in relation to the scores awarded. In each case, the Panel members would have taken a more conservative approach and would have awarded a lower score. In the circumstances of this particular certification process which received an overall passing score "by the skin of its teeth", a lower score on almost any indicator would have resulted in a failure to recommend certification. Taking a holistic view to the overall state of the hoki fishery, the panel sees some validity to the OBs' position that this is not a fishery that should be certified as sustainable." (Sustainable Seas, 2009)

Whilst MSC has defended the Hoki certification (MSC, 2008), there is much contention surrounding the ease in which Hoki was certified and subsequently defended in the appeals process, despite showing signs of un-sustainability (Forest \& Bird, 2007; Sustainable Seas, 2009; Greenpeace, 2009).

In 2010 the Yukon River Drainage Fisheries Association (YDRFA) objected to the MSC certification of Alaskan Pollock, estimated to be worth nearly \$1 billion a year (MSC, 2010L). The YDRFA highlight that populations appear to have halved since 2004, with 2009 quotas being cut by nearly 20 per cent (Pope, 2010). It was also argued that the Pollock fishery took food away from the endangered Steller Seal population (Conroy, 2007). The objection was subsequently turned down. In this instance, it was accused that the financial gains of unsustainable fishing influenced the IA's decision. Jeremy Jackson, of Scripps Institution of Oceanography in San Diego, California, said: "Economic pressures to keep on fishing at such high levels have overwhelmed common sense" (Pope, 2010: 1). Additionally, following criticism towards MSC regarding its market share, it has been argued that MSC was particularly keen to certify such an enormous global fishery (Conroy, 2007: 216).

In the case of the 2009 Antarctic Krill objection, the Antarctic Southern Ocean Coalition (ASOC) accused the $\mathrm{CB}$ of ignoring valid scientific opinion and disregarding new information. For example, Stephen Nicol (an acknowledged world expert on krill in the Antarctic) made a number of critical comments regarding the fishery which the $\mathrm{CB}$ mostly dismissed. He stated that "There is little doubt 
that the data being collected are insufficient to detect impacts of fishing - and there is no mechanism to alter the krill management approach even if impacts were detected" (FisheyFellow, 2010: 1). The $\mathrm{CB}$ responded saying "The reviewer is correct, but his concerns do not render the harvest strategy ineffective, in our opinion" (FisheyFellow, 2010: 1). Despite these accusations, and the IA identifying a "serious procedural error" by the CB, the certification was upheld (ASOC, 2010). ASOC have accused the IA of unjustifiably ignoring its concerns during the objection and allowing the CB to easily justify error (ASOC, 2010).

Additionally, several authors have cited ambiguous wordings such as "reasonable", "adequately identified" and "appropriate consultative process" in MSC doctrine as empowering CBs to dispel condemnation (Peacey, 2000; Jaquet \& Pauly, 2008).

\subsection{Principal - Agent Issues}

The economic theory of Principal -Agent issues (or agency theory) has been identified in fisheries as a point of strife in achieving effective management (Jensen, 2007).

Specifically, agency theory is directed at the ubiquitous agency relationship, in which one party (the principal) delegates work to another (the agent), who performs that work (Kirkley et al, 2003).

Agency theory is concerned with resolving two problems that can occur in agency relationships. The first is the agency problem that arises when (a) the desires or goals of the principal and agent diverge and (b) it is difficult or expensive for the principal to verify what the agent is actually doing. The problem here is that the principal cannot verify that the agent has behaved appropriately. The second is the problem of risk sharing that arises when the principal and agent have different attitudes toward 
risk. The problem here is that the principal and the agent may prefer different actions because of the different risk preferences (Eisenhardt, 1989)

In the case of MSC, principal-agent issues and the corresponding incentives of each participant become rather complex. If we begin with the MSC, that is the principal of the $\mathrm{CB}$ who as agent assesses the FC. MSC provides the standards and criteria against which fisheries are to be assessed. However the $\mathrm{CB}$ is also the agent of the FC which pays for the assessment of its fishery and certification. Thus, immediately there is tension of incentives for the CB.

MSC is also the agent of the consumer (principal), conveying information to them in an attempt to alter their purchasing behaviour. This provides a system of simultaneously conflicting incentives. MSC (as the agent) is seeking a CB that can competently assess a fishery according to its principles (MSC, 2010b). However, because MSC is non-profit, it receives a large proportion of its finance via certification fees and levies collected from the industry (MSC, 2003).

In this respect, MSC has incentive to certify enough fisheries in order to remain financially viable. Additionally, to become an effective EL, MSC must certify a large share of the fish producing market, further incentivising certification.

Because MSC is reliant on FCs gaining certification, both from a financial and reputation point of view, the $\mathrm{CB}$, as the agent to MSC, is incentivised to certify FCs in-order to remain an approved assessing body for MSC. The CB relies on the industry to provide the finance for assessments, meaning the $\mathrm{FC}$ is the principal of the $\mathrm{CB}$. Because the $\mathrm{CB}$ will lose financial gain if it makes no assessment, it is in the interests of the $\mathrm{CB}$ to consistently certify fisheries so as not to risk being rejected for a more lenient CB.

In the case of MSC, agency theory would suggest that the incentive structure for certification promotes the lenient certification of fisheries. The flow of money from fishery to CB and the need to 
be recognised by MSC as a credible assessor means the $\mathrm{CB}$ may potentially be under pressure to push through certifications where there is controversy surrounding the fishery. This set of incentives may provide some insight into some of Highleyman's (2004) criticisms of MSC regarding the inability of MSC to maintain their own principles and criteria. Additionally, the inability of OBs to be successful may be at least in part attributable to the principal - agent structure of the MSC. 


\subsection{Scope of Research}

As previously stated, it is vital that MSC addresses the asymmetry of information between fishery companies and the consumer by conveying accurate and reliable information. Because of controversy surrounding the MSC OP, there is room for research to focus on the legitimacy and robustness of MSC objections protocol.

Several criticisms suggest that the $\mathrm{CB}$ has too much influence in defining scoring systems for a fishery, allowing for ease of self-justification and empowerment (Highleyman, 2004; Stokstad, 2010; Pope, 2010, FisheyFellow, 2010). By having this authority, the CB may proceed to justify the certification of a controversial fishery. The following research will seek to explore whether there is substance to these claims and if so, how MSC OP methodology may facilitate this.

At the time of writing, there have been ten objections that have come to conclusion, with three in progress. Because of this small number, there is an excellent opportunity to closely look at the interactions between parties during an objection, and to assess how the MSC OP methodology and the behaviour of each party influence the final decision. An assessment of how the MSC Objections Procedure facilitates interactions between parties and empowers those involved in an objection will shed light on the credibility of the MSC OP and consequently the legitimacy of the label in communicating sustainability in certified fisheries.

Additionally, an understanding of the objection dynamics can help determine to what extent MSC promotes sustainable fishing, and how (if at all) it may be improved to enhance MSC credibility. 


\subsection{Results}

\subsection{Question Analysis: Objectors}

As previously identified, the research questionnaires were first categorized into broad and sub categories (open \& axial coding) and further refined during the selective coding process.

The dominant themes and inter-linkages resulting from this process are presented and discussed for each participant type and question category asked.

\subsubsection{Primary concerns}

OBs were asked to explain the primary concerns they raised in regards to the fishery or fisheries that were objected to. Their responses have been refined into four categories:

\section{Consideration of Scientific Evidence}

Several OBs were concerned with what they perceived to be a disregard for "best scientific evidence" by the $\mathrm{CB}$. Complaints centred on ignorance by the $\mathrm{CB}$ of crucial fishery information that was said to greatly influence the sustainability of a fishery. These factors included:

- Rapid decline in fish population.

- No signs of stock recruitment.

- Ignoring ecological and habitat impacts when setting catch levels.

- Catch of endangered or threatened marine mammals and seabirds. 


\section{Insufficient Evidence \& Unknown Fishery Effects}

OBs were quick to point out areas in the assessment conducted by the $\mathrm{CB}$ where they believed there was insufficient evidence to justify the scores given and unknown effects of fishing which would materially contribute to the unsustainability of a fishery.

These included:

- Insufficient evidence that harvest strategies were effective.

- Ecosystem effects and the impact on larvae distribution from fishing are unknown.

- Uncertainty and "virtually no knowledge of the frequency and location of spawning" in some species.

- Unknown effects of environmental changes in some fisheries.

- Unknown stock distinctions (many stocks considered genetically distinct but not assessed as so).

\section{Inadequate Management of Fishery}

Current and proposed management strategies of fisheries came under great scrutiny in several objections and formed the basis for the primary argument in several cases. Concerns included:

- Management structures used in some fisheries "inherently risks overfishing populations" by failing to consider "ecosystem-wide impacts".

- The management decision making process was heavily criticised in some cases (e.g. "decision making process is not adequate to ensure sustainable management of the....fishery"). 
- Management by adjacent countries "undermines the sustainability" of some fisheries, particularly those stocks which are not geographically distinct.

- Lack of formalized and transparent management tools.

\section{Uncertainty and Risk}

A prominent theme to emerge from the data was the consistent criticism of CB's for not (in the OBs' opinion) accounting for uncertainty and risk associated with data and management strategies in fisheries. Primary areas of concern include:

- The uncertain impact of "bycatch" species.

- Uncertainty around the "geographic context" of stocks and their "spawning grounds".

- Uncertainty surrounding the robustness of stock models.

- Uncertainty surrounding the impact on "predators" of the target species.

- Uncertainty surrounding untested management techniques and rules. 


\subsubsection{Addressing of Issues by the Certification Body}

Objecting respondents were asked to state their position on a likert scale regarding how satisfied they were that issues raised were adequately addressed by the $\mathrm{CB}$, followed by an explanation of their position (See appendix 2C). The response categories have been divided into the likert rankings provided (e.g. Satisfied, neutral, dissatisfied etc), and the dominant themes for each response category stated and explained (No OB reported themselves as being satisfied/very satisfied).

Very Unsatisfied

Ignoring of Public Comments and New Scientific Information. Responding OBs accused the $\mathrm{CB}$ of ignoring "new scientific information that was made available before making its final determination" which they felt would have "made a material difference to the assessment". Additionally, there were concerns expressed over an apparent lack of "interest in public comments submitted during the assessment period".

Relationship Between Certifier and Client Creates a Conflict of Interest. OB's identified that the current MSC structure may influence the agenda of the $\mathrm{CB}$. One OB stated "The current relationship between the certification bodies and the FCs creates a conflict of interest in the certification bodies. The certification bodies are paid directly by FCs, not the MSC, and compete with each other for the business of the FCs. The FCs, then, are able to choose certification bodies based on which is most likely to award certification in the fastest time possible for the smallest fee and impose the fewest conditions" (sic),

CB Dismissive of Contrary Conclusions. In several instances, OBs felt as though the CB was dismissive of their evidence and claims presented, despite both being robust in the OBs' view. This is exemplified by the statement "(the $\mathrm{CB})$ was consistently dismissive of 
conclusions contrary to their own and often did not make an effort to provide more than cursory justifications for their scores and conclusions". OBs felt that CBs were often "dismissive of peer reviewers who questioned their judgments, even when those peer reviewers were experts in the fishery" and felt that the $\mathrm{CB}$ was more interested in securing certification rather than assessing the fishery in the correct manner.

\section{Dissatisfied}

Inadequate Justification of Position by the Certification Body. Some OBs found the CB was quick to argue that the objection information presented "was incorrect and their scores were justified, without adequately justifying their position", often agreeing to additional conditions applied to the fishery but rarely "changing their score". One OBs felt this was because the $\mathrm{CB}$ " did not consider...(the OBs') information as valid and convincing enough to demonstrate a problem with the fishery".

CB Inflexible if Certification Ensured. Scores for the performance indicators of a fishery were often highly contentious during objections. Some OBs felt the CB would often manipulate scores in a way that reduced criticism but ensured the fishery would remain certified. One OB demonstrated this specifically by stating "Interesting to see that the score for one PI (performance indicator) was lowered and another PI was raised to maintain the average P2 score of 80 . Another $\mathrm{OB}$ felt that the $\mathrm{CB}$ had very little "flexibility" when responding to issues, with the primary objective being "to defend the assessment".

\section{Neutral}

The CB Responded Adequately. One OB felt that the response given from the CB was "adequate" in addressing the issues raised and tried to "accommodate" concerns. However this made no material difference to the outcome of the objection. 


\subsubsection{Adequate Addressing of Issues}

OBs were given an opportunity to discuss the conditions in which they would have felt considered their concerns had been adequately addressed by the CB. The requirements have been categorized into four themes:

Performance Indicators Lowered. This answer seems almost obvious in that the OBs are more often than not pursuing the non-certification of a fishery. However, it was a theme that was highly prevalent. Four Objectors were often not satisfied with minor changes to PI scores or additional conditions placed on the fishery. One OB stated "we would have needed to see the CB lower the fisheries' scores for the performance indicators about which we had concern or, presented conclusive evidence justifying their scores".

Impartial Certification Body. As stated previously, there is a perceived conflict of interest between the $\mathrm{CB}$ and the FC. This has led one $\mathrm{OB}$ to conclude that the $\mathrm{CB}$ 's are "clearly biased as they work for the "Client",", arguing for an additional "buffer" between the CB and the FC. One OB was displeased with the term "Client" as it implied a bias to a vested interest. To remediate this issue, it was considered by one respondent that the $\mathrm{CB}$ should be "impartial" and independent from the applicant to reduce incentives to certify.

Burden of Proof on the Certification Body. Currently, the burden of proof is on the OB to provide reasons why a fishery should not be certified. As stated by one OB "(the) burden of proof....is on stakeholders rather than the FC". This is said to become an issue when coupled with the (accused) bias of the CB. Due to conflict of interest, the $\mathrm{CB}$ in some cases has been accused of appearing to "give the benefit of the doubt to the applicant where data is not available", hindering the robustness of the assessment. OBs felt the burden of proof should be on the $\mathrm{CB}$ and FC to demonstrate why their assessment is accurate in light of the objection accusations. 
Precautionary Approach to Assessment. This theme has some similarity with the first in that the lowering of Performance Indicators would have required the $\mathrm{CB}$ to espouse a precautionary approach to assessment in several cases. OBs felt that an "absence of data should have led to lower scores on....performance indicators, but (often) did not". Uncertainty was seen as a factor that should have required "changes in scores and conditions". Ultimately, it was recognised that to account for uncertainty in fisheries data "meant adopting a more precautionary approach to their analysis of the fisheries".

\subsubsection{Level of Consideration Given by the IA to the Certification}

\section{Body and Fishery Clients' Arguments and Evidence}

Each OB was asked to give their opinion on the level of consideration they felt the IA gave to evidence provided by the $\mathrm{CB}$ and FC. The level of consideration was first defined by Likert Scale for the CB and FC (see appendix 2A) and the respondent was given an opportunity to explain their answer for each. The Likert answers chosen for the $\mathrm{CB}$ and FC are presented below, followed by the refined themes of the corresponding answers.

\section{Fishery Client:}

\section{Excessive}

Undue Deference to Applicant. In one instance it was considered by the OB that the IA had given "undue deference to the arguments of the applicant $(F C)$ " which led to "an acceptance of standards" considered unjustified in the case of this fishery. 


\section{About Right, Too Little}

Both options were selected on two occasions, however no reason was provided for either.

\section{Certification Body}

\section{Excessive, Too much}

Burden of Proof. Again this theme was prominent within these answers. One OB stated "Clearly the burden of proof was on the OB to prove that the fishery should not be certified", supported by another stating "The MSC Objections Procedure puts the burden of proof on the $O B$ and not the $C B$ ". Because MSC objection rules require the OB to prove "that the $C B$ was doing something that "no reasonable" $C B$ would do" it is difficult for an $\mathrm{OB}$ "to prove their case unless, for example, the CB makes completely egregious decisions".

Rule Interpretation and Adherence. IA's were accused of sticking "to very strict interpretations of the objections rules", often giving the "benefit of the doubt to the CB" despite indicating "sympathy with our (the OB's) arguments". This strict adherence to protocol is seen as a major stumbling block of the MSC Objections Procedure. One OB went as far as saying "it seemed unless we could prove that the CB said that the sky was green, we'd be unable to succeed in our arguments".

\subsubsection{Role Satisfaction of Independent Adjudicator}

OBs were asked to provide their level of satisfaction regarding the role the IA plays in the MSC Objections Procedure on a Likert Scale (see appendix 2A), Other) and explain their answer. This is assessed as previously for each Likert category identified. 


\section{Unsatisfied}

IA Scope too Narrow. OBs found the MSC defined limits surrounding the role of the IA to be a hindrance to the Objections Procedure. As pointed out by one OB "They can only confirm the certification or remand the assessment for new scoring or request additional considerations". Consequentially "The IA cannot make a finding that the fishery should not be certified". In this respect it was felt the "The IA's purview is too limited" and that and objection is more a "matter of process" than an assessment of the fisheries sustainability. Another OB supported this notion stating "The only instance in which .... a decision being overturned completely (i.e., certification not upheld, several objections have been partially upheld but this did not hinder certification) was one that was particularly egregious (Faroese mackerel).

Justification Under Uncertainty. A consistent theme amongst OBs when discussing the ways in which CB's use data in their assessments was that addressing of data uncertainty. OBs expressed dissatisfaction surrounding this topic, arguing "it is too easy for CBs to make a plausible argument" in the "face of uncertainty". OBs indicated that they felt that even if the "Adjudicator thinks the argument is wrong, or not really supported by the evidence, the bar is so high that he is constrained from upholding the objection unless a score is completely unreasonable". This is considered "the opposite of the precautionary approach that is typically associated with a "sustainable" approach to resource use".

\section{Satisfied}

Clear and Professional. In one case the OB found the IA to operate "professionally", being “clear about his jurisdiction" and providing "clear guidance”. 
Provided Balance. Another OB felt the IA "played a clear role in balancing the table to give our (the OB's) concerns more power and importance than was given before by the CB and $F C "$.

\subsubsection{Payment of Objections Fee}

Objecting participants were asked to state who they thought should finance the Objections Procedure and the reasons for their stance. Responses are divided into two categories (MSC should pay, OB should pay) corresponding with answers given, and the reasoning for each are synthesised into main themes.

\section{MSC Should Pay}

Objection Costs too High. Some OBs felt the fee to lodge an objection is too high and served "as a severe impediment to lodging an objection". Additionally, an objection "requires a substantial amount of staff time on the part of the $O B$, as well as travel costs". It was argued by one OB that because of the costs there is a "direct impact on access-and thus legitimacy-of the MSC process".

Payment Dependent on Merit. A common theme identified amongst OBs was that of payment by merit of objection. Several OBs argue that the IA must first assess the merit of an objection before it may proceed to a formal process. One OB argued that "It should be the MSC's responsibility to ensure that its label is being appropriately applied". If the IA considers the OBs' case to have merit then it is "in MSC's best interests" to go through with 
the objection and ensure its credibility. Therefore, MSC should ultimately pay for the objection should it be found to have merit by the IA.

\section{OB Should Pay}

Maintain Fee Waiver Option. One OB was supportive of OBs paying for an objection; however they felt that the option to waive the fee for those organisations who cannot afford the resources necessary, should be maintained.

\subsubsection{Objections Fee and Barriers to Participation}

Participants were asked to comment on whether they felt the price of the objections fee limited the ability of a stakeholder to object. Their answers have been separated into affirmative (yes) and negative (no), with themes developed for each. It should be noted that those that could pay for an Objection were for the most part included in this study

\section{Affirmative}

Cost of Objection Limits Organizations' Ability to Object. It was agreed by most OBs that "Stakeholder involvement is stifled by costs of participation". Because OBs historically "rarely win", the cost of an objection often requires NGO's "to weigh their odds of a successful objection (unlikely in the MSC process) against the fee". Whilst the fee has been reduced from $£ 15,000$ to $£ 5,000$ in 2010 , it is still considered "too high". In several instances, "had (a waiver) not been granted" several NGO's "would not have been able to pursue the objection". Despite the difficulties for NGO's in finding the funding to object, many "still feel obligated to object rather than let certifications proceed unchallenged" 


\section{Negative}

Process Rather than Cost. One NGO felt that it was "not so much the cost of the process", but the "complexity, length and frustration of the process" which limits a stakeholder's ability to object.

\subsubsection{Improvement to the Objections Procedure}

Participants were asked to comment on ways in which they believed the MSC Objections Procedure could be improved (if at all). The answers have been divided into three themed categories which represent the scope of concerns raised.

\section{Objection Fee}

Fee Elimination. Some OBs felt the objection fee should be "eliminated", or included in "the costs to industry of the MSC certification".

IA

Neutrality. Some OBs felt that the IA's should be from a "neutral" background, being "truly independent and not selected and employed by the MSC", a relationship which implies a conflict of interest.

Insufficient Expertise. There was concern expressed as to the expertise of IA's. Most were perceived to be "legal experts" rather than experts in fisheries and sustainability, consequently not being "qualified to adjudicate substantive matters of sustainability". 


\section{Burden of Proof}

Responsibility of the CB. One OB argued strongly for the development of "standards for the level of data/burden of proof required both of the $C B$ and $O B s$ " in response to a "strong feeling that a great deal of deference is given to the $C B$ ". Others felt the burden of proof should solely be on the CB. "The burden of proof needs to shift more to certification bodies and away from $\mathrm{OBs} "$.

\subsection{Certification Body}

\subsubsection{Experience with Objections Procedure}

$\mathrm{CB}$ respondents were asked to indicate how they perceived their overall experience with the Objections Procedure on a Likert Scale (very good, good, neutral, mixed, bad, very bad) (See appendix 2A) to explain for their indicated position. Results are displayed in accordance with their Likert answer, with associated themes presented.

\section{Mixed}

Legal Process Inappropriate. The respondent felt the "(objections) process worked well", however was of the opinion that the Objections Procedure is "essentially a legal process" that deals with "technical issues" and this is "not necessarily appropriate". The respondent expressed a frustration with the Objections Procedure, feeling that "Much of the process was taken up with explaining basic issues in stock assessment to non-stock assessment scientists". Despite this, there was acknowledgement that the Objections Procedure "appeared to produce improvements in explanation and more robust results". 
Inefficient Process. The respondent also felt that the Objections Procedure "seems very long, expensive and inefficient", and indicate that they did "not think it dealt with the concerns of the stakeholders raising the objection"

\section{Bad}

Objections Procedure Open to Abuse. The respondent "agree ['s] with the Objections Procedure in principle, but", feels that the, "system can be easily abused by people wishing to raise [the] profile of own argument, or rally against the MSC as a whole”. They point out that the critical question for the Objections Procedure to answer is "has the assessment team made a mistake or come to the wrong judgement"? Because assessments generally must "take into account a wide range of views and opinions", the subsequent outcome is "never likely to please everyone". Recognising this, the respondent was quick to highlight again that the question is not, is everyone pleased, "but was the judgement correct, given the evidence?" In the opinion of this respondent: "Too often objections seem to allow well funded NGOs to continue to put forward their argument - even though those issues are typically already taken into account, as part of a balanced assessment", indicating a dissatisfaction with the freedom and scope with which organizations may object. 


\subsubsection{Role of the Independent Adjudicator}

CB's were again asked to rate their satisfaction regarding the role of the IA in the Objection Process and to explain their ratings.

\section{Neutral}

Applied Methodology Well. One CB seemed reasonably pleased with the role of the IA stating "They appeared independent and applied the process methodology reasonably well with some exceptions". However they were critical of the manner in which the IA considered some information, pointing out that "there was a tendency to err on the side of caution and spend time dealing with issues which had not (sic) material effect on the outcome of the case”.

Issues of Competency. There was doubt cast over the IA's competency in assessing issues in fisheries science as indicated by the statement "I am not convinced the adjudicator was competent to understand fully the issues". This was not perceived to lead to "poor outcomes", but rather to result in a more "inefficient process".

\section{Satisfied}

Focus on Methodology. There was recognition that the IA's task is to focus more on the "application of methodology". This is seen as a "good thing" in that the issues raised often boil down to "technical issues - and perspectives / opinions".

Tendency to Negotiate. With a focus on the application of methodology, the IA has been criticised for "perhaps a tendency to negotiate" between parties which can result in changes being made "simply to get a satisfactory outcome for all parties, rather than necessarily because it is required / right". 


\subsubsection{Consideration Given to Evidence/Arguments}

CB's were asked to give a satisfaction rating regarding how they perceived the level of consideration the IA gave to the arguments and to the evidence they put forth.

\section{Satisfied}

IA Accepted Arguments. One CB was satisfied with the IA's considerations because their arguments put forth were generally accepted by the IA. This was not perceived however to be due to any favour toward the $\mathrm{CB}$ but rather a lack of counter evidence by the OB. This is exemplified in the statement "the adjudicator usually had to accept the MSC assessment teams arguments based on our judgement because the OBs were unable to provide evidence to conflict with it". The CB appears to indicate this is common during objections by pointing out that "Most objections were dismissed"

\section{Neutral}

OBs Overly Considered. Another CB was satisfied with the level of consideration given to themselves by the IA, but often felt that "the IA will often bend over backwards to listen to their (OBs') view point". This is said to occur even where evidence "is submitted late or in the wrong format". 


\subsubsection{Weighting Given to Evidence and Arguments of the Fishery}

\section{Client}

CB's were asked to give a satisfaction rating regarding how they perceived the level of consideration the IA gave to the arguments and evidence that the FC put forth. Only one $\mathrm{CB}$ responded to this question.

IA Prefers $3^{\text {rd }}$ Party Evidence. The CB felt that the IA was "most comfortable with information from $3^{\text {rd }}$ parties" (e.g. CCAMLR, ASOC) and often information from the FC "was not really critical"

\subsubsection{Objections Payment}

$\mathrm{CB}$ respondents were asked to state who they felt should pay for an Objection and why. Their responses have been categorised into two themes.

\section{Unsure}

One CB had "no idea" as to who should pay for the costs of an Objection. Respondents were not asked to suggest improvements to the Objections Procedure in this question; however they were quick propose some. One stated "I do think the procedure should be a lot less costly, clearer and straightforward. It should also more clearly define scope to exclude objections which have nothing to do with MSC".

\section{Outcome Dependent}

Another CB felt the covering of objection costs "depends on the outcome". They argue that if "an $O B$ puts in an objection which ultimately results in little or no change - they should 
pay and pay costs to the FC. However, if the objection has merit and results in significant change, or a change in outcome, then the FC should cover their own costs and the cost of the $C B^{\prime \prime}$.

\section{Objector Should Pay}

Incentive to Object. $\mathrm{CB}$ respondents highlight a perceived connection between cost and incentive to object. "By allowing OBs to object without financial risk or penalty, there is no disincentive to object, and objections become more frequent and opportunistic. If an NGO doesn't have to pay to object, and they have a salaried member of staff who can do so, then why not object? Even if they only want a small change".

Publicity. The Objections Procedure is seen as good publicity for the OB, and the objections fee a means of achieving this. "An objection is very good publicity for an NGO, almost regardless of the outcome. Given the tendency to negotiate a settlement, the OB will typically get something changed - even if not methodologically warranted, so they can issue a press release to highlight the change that they forced. In short, it's good publicity for the $O B$ whether they win or lose, so they may as well object - unless there is a financial penalty". 


\subsubsection{Objections Fee and Barriers to Participation}

Certification Bodies were asked to comment on whether they thought the objections fee hindered the ability of stakeholders to object to a certification. Both CB's answered "No" to this question; however their answers have been divided into two categories.

\section{Cost is not a barrier to Object}

It was perceived by CB's that the costs of objection appear not to provide a barrier to objection at all. Both indicated this through statements like "NGO stakeholders seem very keen to use expensive legal-type processes" and "most objections come in from organisations with plenty of money and salaried individuals able to spend time on it".

\section{Cost is a Barrier to Certification}

Both CBs indicated that they felt the objections fee actually provided a disincentive for small scale fisheries to apply for MSC certification and "ironically limits the certification to big industrial fisheries". Their view is based around the question "do the potential costs of objection deter fisheries from going into assessment in the first place?". The answer to this question from the CB's point of view is presented in this statement: "The current situation means that the cost of an objection could exceed the cost of an assessment-even where the objection does not result in a material change (i.e the CB reached the correct conclusion in the first place). This is clearly crazy and is a further disincentive for small scale fisheries to enter the MSC scheme”. 


\subsubsection{Improvement to the Objections Procedure}

CB participants were also asked how they thought the Objections Procedure could be improved (if at all). All answers are related to methodological improvements, but separated into five themes:

\section{Reduce Complexity}

Despite the MSC methodology being "greatly simplified" after the Revised Fisheries Certification Methodology Objections Procedure (MSC, 2010b), making it "much easier and transparent to explain a certification", there are concerns it is again becoming "very complex". This is a concern to the CB because "Complexity results in errors, and increasing likelihood that fisheries will fail or objections will be upheld due to technical mistakes in the methodology, rather than because the fishery does not meet the MSC principles fisheries".

\section{Application of Test}

Although a short answer, one CB stated the Objections Procedure should "apply the spurious and vexatious test a bit more robustly and dismiss opportunistic objections". This indicates a concern with the application of the Objections Procedure and an apparent dislike for the process itself.

\section{Discourage Shotgun Approach}

One CB felt the Objections Procedure encourages a "shot-gun approach to finding fault with the MSC assessment" resulting in the OB "objecting to every performance indicator" in an attempt to gain traction on any issue. The $\mathrm{CB}$ was of the opinion that "most issues can 
dismissed out-of-hand, but take time and resources to deal with" and that "this [shotgun approach] should be discouraged"

\section{Improved Reporting}

It was identified that "many issues can be dealt with by improving clarity in reporting, well defined forms of evidence and improved scoping (what falls within MSC requirements)". These issues are thought of as "not require(ing) an Objections Procedure". It is encouraged that a "better way to report the objections should be found". "The RSTF report (MSC summary report, post objection (for example see MSC, 2005)) which has the submissions bound up in the final report making it almost impossible for anyone without enormous amounts of free time to follow what went on". Because of this, it is difficult for those who are analysing the certification of a fishery to accurately synthesise what occurred and the criteria used by the CB.

\section{Avoid Legal Approach}

The legal approach of the Objections Procedure has been criticised by CB's. One CB stated that "Any method which avoids a legal-type approach would be an improvement in my opinion" and further suggested that "the current approach will never be efficient (and alarmingly has required personal attendance of people at hearings in some cases)". It is proposed that a "more in-depth peer review process would be a better approach (e.g. a panel of 3 independent assessors with relevant technical knowledge)", However it is acknowledged that "identifying acceptable reviewers may be difficult". 


\subsection{Fishery client}

There was only one respondent from the FC questionnaire category (see appendix 2D). Whilst limited, there is useful information in the response received. These are analysed in the same way as previous questionnaires and presented here.

\subsubsection{Experience with Objections Procedure}

\section{Bad}

Objections Procedure Open to Abuse. The FC indicated that they feel the Objections Procedure is not just a tool used for genuine concerns about a fishery, but also interorganizational dynamics. "The objection process gives lead to abuses from certain stakeholders who do not use the procedure because of genuine concerns with the assessment, but because of internal politics in their organisation".

Major Costs Involved. The FC was also concerned with the "huge costs" involved in an objection, some potentially equalling "the original assessment costs" through " extra time spent, extra costs (of the) assessment team, travelling costs..". Consequently FC's are "faced with a considerable delay in the certification (months)".

OB Rights. The FC expressed that it felt the Objections Procedure empowered the OB by attributing them with "all the rights", ultimately meaning "he (the OB) dictates the procedure completely". The FC outlines the liberties they feel the OB is free to undertake. These include:

"1/ can throw with mud and allegations in his notice of objection

2/ decides on the way forward in the negotiation for reconciliation phase 3/ decides on the oral hearing" 


\subsubsection{Role of the Independent Adjudicator}

Satisfied. The FC was "satisfied" with the role of the IA primarily because the objection "turned out very positive for us (the FC)", resulting in a favourable ruling.

Dissatisfied. The FC was however dissatisfied with the role of the IA prior to the oral hearing. The FC noted that the IA's role "leaves too limited scope for the IA to move and make decisions prior to the expensive oral hearing”.

\subsubsection{Consideration Given to Evidence and Arguments}

Mixed

Pleased at Oral Hearing. The FC felt that the level of consideration by the FC was good during the "oral hearing" phase.

Limited Consideration Prior to Hearing. The FC felt treatment was different prior to the oral hearing and were often given the "impression that the IA did not consider anything and just wanted to move to oral hearing.

\subsubsection{Weighting Given to Arguments and Evidence}

Very Satisfied

The FC was very satisfied with the weighting given to their evidence during the objection. The FC felt that "the IA's decision that the fishery was to be certified was due to the weight given to our arguments and evidence". 


\subsubsection{Weighting Given to Arguments/Evidence of the Objector}

\section{Very Unsatisfied}

Negative Publicity. The primary concern expressed here regarded the impact of an objection on individual and organizational reputations and the integrity of those being objected against. There was perceived " $a$ lot of negative publicity for the FC and the assessment team that was alleged....besides the request for rescoring". Despite FC's being "completely cleared", allegations" remain on the "MSC website for months" allowing room for "speculations and harming peoples' and organisation's integrity and reputation”. Regardless of a win or loss, "a formal apology or rectification by the OB is NOT in the objection procedure".

\subsubsection{Objections Payment}

OB Should Pay. Not only does the FC feel the cost of the objection should be "paid by the $O B$ ", but also they should pay for "all the costs the objection brings for the FC". The FC illustrates this by stating "the..... fishery would NOT have been able to pay all the costs the objection brought along. The fishery would have been forced to stop the assessment, giving in to the $O B$ 's requirements, and not have had the chance to win the objection and be certified. In this instance the "industry funded the objection". They argue that the costs to the $\mathrm{OB}$ are "peanuts compared to costs involved for the FC".

\subsubsection{Objections Fee and Barriers to Participation}

The FC was of the opinion that the objections fee did not hinder the ability of stakeholders to object, simply stating: "NO, this amount is peanuts compared to what costs are involved for the fishery/FC concerned". 


\subsubsection{Improvement to the Objections Procedure}

Increase the Role of IA. The FC argues that to improve the Objections Procedure, the IA's "role and power" needs to be increased; being "motivated to drop or sustain points in the objection at that moment" (moment of objection).

Oral Hearing up to FC. The FC feels that the decision to proceed to an "oral hearing,", "should be up to the FC/fishery to decide". They are clear that this "initiative should NOT be left to the $O B$ " (emphasis in the original). The FC goes further into this issue by asking the question: "the $O B$ posts an objection explaining concerns, making a case. If the FC/CB decide that from the report and the responses given to the objection, the IA has all the elements to base her decision upon, why should there be an oral hearing on request of the $O B ? "$ 


\subsection{Discussion}

\subsection{Introduction}

The results of this study have given good indications as to how the MSC Objections Procedure is perceived to function by the questionnaire respondents. There are also insights into the distribution of empowerment during an Objection. OBs were rarely satisfied with the components of the Objections Procedure examined, whereas the CBs indicated a much more positive purview. The single responding FC gave mixed reactions, tending to take issue with the role and actions of the Objecting Body.

\subsection{How Does the Objections Procedure Facilitate}

\section{Interaction Between Actors?}

\subsubsection{Objecting Body vs. Certification Body}

For every objecting participant, there were unique and common interpretations as to how the $\mathrm{CB}$ acted and responded during an objection towards the $\mathrm{OB}$. These interpretations give useful insight as to how the OP may facilitate interactions and empower actors during an objection.

OBs were consistent in their distaste for the way in which the information and issues they presented were considered and used during an objection. This was particularly evident when asked how they felt the $\mathrm{CB}$ addressed issues raised. No $\mathrm{OB}$ rated themselves as being satisfied or very satisfied in this area. Since only one objection has been upheld, this may 
seem rather unsurprising. However the reasons provided were diverse yet also had a degree of consistency across Objectors.

There was an underlying impression that the CB often treated the OB's case with contempt with the primary focus being to defend the assessment, rather than achieving what was best for the sustainability of the fishery.

"(the $\mathrm{CB})$ was consistently dismissive of conclusions contrary to their own and often did not make an effort to provide more than cursory justifications for their scores and conclusions".

This position was pushed further by an apparent lack of willingness to consider "new scientific information that was made available before making its final determination" and indicating little "interest in public comments submitted during the assessment period".

Objectors did not provide any grounds for this type of behaviour; however the questionnaire questions did not implicitly require them too. The CBs are endorsed by MSC to be an independent scientific body that applies MSC's Principles and Criteria for Sustainable Fishing to a robust assessment scheme (MSC, 2010a). Therefore, in accordance with FAO eco-labelling guidelines (FAO, 2004), CBs should be independent and objective in their scope, devoid of any preferential tendencies.

Clearly OB do not consider CBs to uphold these values. There are few direct reasons given for this, however OBs have provided indicators suggesting why CBs may be motivated to take this stance. When placed in context with the MSC OP Methodology we can begin to form a picture of potential motivating factors acting on CBs, motivating them to take a defensive stance. 
During the assessment of a fishery, it is the responsibility of the $\mathrm{CB}$ to: "actively seek the views of the Fishery Client and stakeholders (including managers, scientists, industry and environmental NGOs) about the fishery and its performance in relation to any relevant conditions of certification and issues relevant to the MSC's Principles and Criteria for Sustainable Fishing” (MSC, 2011b).

Should a stakeholder believe this failed to occur or that "the Certification Body failed to consider material information put forward in the assessment process by the fishery or a stakeholder" (MSC, 2009: Section 4.8.2) they may file an objection on these grounds.

The opinions expressed by OBs may have some merit in light of the responsibilities assigned to CBs by the MSC OP Methodology (see MSC, 2009). The OP is designed "to determine whether the CB made an error that materially affected the outcome of its Determination". It is not the purpose of the OP "to review the subject fishery against the MSC Principles and Criteria for Sustainable Fisheries” (MSC, 2009: Section 4.2.1).

By defining the Objections Procedure in this way, the CB is placed in a defensive position by requiring a validation of their assessment. It then could be argued that $\mathrm{CBs}$ are motivated to look less objectively upon a OBs evidence in order to justify their position, rather than ensure the quality of the assessment. Because an objection cannot challenge MSC's Principles and Criteria, the objection is purely focussing on the OB's assessment. Additionally, an OB cannot claim issue with the MSC guidelines used to shape their assessment when confronted with objection claims. 
Accusations of bias and non-objective information amongst fishing industry scientists are not recent (Mowat, 2004; Standing, 2008). Industry scientists have frequently been accused of hiding information or manipulating data in ways that represent a certain party's interests (Sumaila \& Jaquet, 2008). These types of accusations give rise to scepticism and distrust regarding the objectivity of fisheries data (Mowat, 2004).

It has been suggested by several OBs that MSC Certifiers are in fact not independent but are motivated to act unobjectively due to conflicted interests. This concern is expressed by one OB who stated:

"The current relationship between the certification bodies and the FCs creates a conflict of interest in the certification bodies. The certification bodies are paid directly by FCs, not the MSC, and compete with each other for the business of the FCs. The FCs, then, are able to choose certification bodies based on which is most likely to award certification in the fastest time possible for the smallest fee and impose the fewest conditions".

The accusations presented originate from the fact that the FC pays the $\mathrm{CB}$ to assess its associated fishery and the MSC credits the CB as a suitable assessor (MSC, 2011b). This is clearly significant in that it suggests principal-agent issues within the MSC assessment structure.

FCs are encouraged by MSC to "take the time to research CBs and choose the one that offers you the best service and price for your needs" (MSC, 2011b: 14). The MSC itself does not profit from any certification and all contractual matters between the $\mathrm{CB}$ and the FC are dealt with between these two players. The MSC certification guide clearly states that "you, as the 
$F C$, are ultimately responsible for ensuring that your CB is giving value for money and is capable of delivering the service" (MSC, 2011b: 15).

Principal-agent theory (agency theory) would suggest that principals (in this case the FC) will seek to hire an agent (the $\mathrm{CB}$ ) that will produce the most favourable results (i.e. certification) at the least cost (Eisenhardt, 1989). Because of this, CBs are incentivised to produce the most favourable results for the FC at minimum cost while providing a sufficiently credible assessment; potentially creating an environment where assessments are passed more easily than if the CB was wholly independent of the FC and MSC. Any such effect would defeat the intended purpose of the MSC label which seeks to make available the sustainability information of a fishery to customers via the label.

Such a bias is implied by OBs who consistently expressed concern at the degree to which they felt the CBs ignored their comments and inflexibly defended their assessments. OBs noted a willingness to change performance indicator (PI) scores where certification was assured or score losses could be compensated by the raising of others.

Such perceived behaviour does little to quell the growing distrust of industrial fishing and their conservation efforts. Sidney Holt, a distinguished marine biologist from the Independent World Commission on the Oceans has been quoted as saying:

"I read many of the publications for the fishing industries. For every sentence there may be published about . . conservation, there will be a page or more about the building of more, bigger and more powerful boats, the construction of bigger nets . . Making profits now or soon is the name of the real game" (Schoon, 1998: 1) 
It is important that MSC is not seen appear to be enabling industrial fishing to operate unsustainably, behind the sustainable veil of the MSC label. There is a valid case for a review to be conducted into the principal agent relationships formed by the MSC structure. In addition to creating an atmosphere of distrust by OBs, these relationships leave MSC open to criticism, threatening the labels legitimacy and reliability as a transparent communicator of sustainability information in fisheries. Because public opinion determines much of an ecolabel's success (GEN, 2004), it is important that MSC clarify this area of uncertainty in order to maintain its integrity in the public eye.

\subsubsection{Certification Body vs. Objecting Body}

The views expressed by $\mathrm{CBs}$ in regard to the role and function of the $\mathrm{CB}$ indicate vastly different issues and experiences. On the evidence gathered, CBs appear to be generally satisfied with the OP. Such satisfaction is coupled with an underlying frustration regarding the role and parameters allocated to OBs, and the efficiency with which the OP is conducted.

Issues of inefficiency centred on the Objections Procedure requiring large quantities of time and resources. Efficiency was said to be compromised due to the OP focussing on "technical issues", something that was considered "not necessarily appropriate" for the types of issues faced in an objection.

One $\mathrm{CB}$ was vexed at having to explain "basic issues in stock assessment to non-stock assessment scientists" during an Objection. This viewpoint is interesting not only because it relates to the OP efficiency, but also alludes to contempt regarding OB's expert qualifications despite many OBs having substantial experience in fisheries, often being experts themselves. 
Additionally it may give insight as to why OBs feel that CBs can disregard their scientific opinion.

It is common for $\mathrm{CBs}$ to explicate elements of their assessment and data interpretation during an objection. Because the CB's assessment is self-defined, methodologies must be reiterated to the $\mathrm{OB}$ where there is lack of clarity. To help in interpreting this information, OBs frequently have or, employ, experts in fisheries management to assist in their objection.

Because stock assessments can be conducted using varying methodologies, each with distinctive characteristics and inconstant levels of uncertainty (Patterson et al, 2001); no single fisheries scientist interprets or conducts stock assessments in a uniform way. Modern fish stock assessments can rely on dozens, sometimes hundreds, of individual judgements about data usage, weighting, years to include and what conditions to assume in models (FAO, 2006). Hilborn (2002) (himself a consultant to FCs) argues that fisheries management is often not transparent because so many arbitrary decisions are made in the stock assessment process. In the light of this, $\mathrm{CBs}$ are inevitably going to be required to spend time explaining areas of their assessment and their logic during an objection.

Consequently, the efficiency of the Objections Procedure is diminished. Even though assessment methodologies are made available by the $\mathrm{CB}$ in the Final Determination, it is identified by one CB that to trawl through the myriad of information presented is highly time consumptive.

The assessment process itself may benefit from greater transparency between CBs and stakeholders, particularly through the data gathering and analysis stages. By keeping 
stakeholders well informed of the different decisions and judgements made regarding a fishery during assessment, issues may be resolved prior to the Final Determination, nullifying the need for an OP. Such a system however may inherently be inefficient itself due to extra time taken in explanation during assessment.

Another CB noted that the OP did appear "to produce improvements in explanation and more robust results". Judging by this comment, it is indicated that the OP itself does provide assessment clarification and produce a more robust outcome. These elements could be clarified through the assessment process without requiring an objection.

CBs also felt that the design of the OP leaves it vulnerable to "abuse" from stakeholders wishing to raise their profile or push an agenda. Because the OP is intended to be conducted in an open and transparent manner, those wishing to view formal Objections correspondence between parties may do so via the MSC website (except for in the contentious objection cases of Alaskan Pollock and New Zealand Hoki, for which documents are only available via email request). $\mathrm{CBs}$ suggest that the transparent nature of the $\mathrm{OP}$ provides a platform for people wishing to raise the profile of an argument, or "rally against MSC as a whole".

It is alleged that by objecting, an $\mathrm{OB}$ can raise the awareness of issues they feel require attention and publicly look to be proactive on issues of sustainability regardless of the outcome. One CB describes this type of behaviour stating:

"An objection is very good publicity for an NGO, almost regardless of the outcome.

Given the tendency to negotiate a settlement, the $O B$ will typically get something changed-even if not methodologically warranted, so they can issue a press release 
to highlight the change that they forced. In short, it's good publicity for the $O B$ whether they win or lose, so they may as well object - unless there is a financial penalty".

From this perspective, it seems the incentive to object is high when an organization is motivated by publicity, and the resource costs are small or easily satisfied. OB comments regarding costs however would suggest this is rarely the case. The use of financial restriction in controlling objections will be discussed later on.

\subsubsection{Fishery Client and the Objecting Body}

Whilst there was only one FC respondent, it is worth noting their point of view as it provides a greater diversity of opinion albeit a limited perspective from the industry. Also, several major points correspond with that of other respondents.

Like the $\mathrm{CBs}$, the $\mathrm{FC}$ identified the vulnerability to abuse from OBs as a major stumbling block of the OP.

"The objection process gives lead to abuses from certain stakeholders who do not use the procedure because of genuine concerns with the assessment, but because of internal politics in their organisation"

It is implied here that OBs are in some cases not wholly motivated by issues with a CBs assessment, but also internally motivated factors. The exact nature of these motivations are not specified, however subsequent comments may allude to the context of this statement. 
The FC was directly critical of the way they perceived that the OP empowered the Objecting Body during and objection. The Objections Procedure was said to give "all the rights" to the $\mathrm{OB}$, freeing them to "dictate procedures completely". In doing so, the FC felt that the OB was enabled to act in a way that empowered them to:

"1/...throw with mud and allegations in his notice of objection 2/ decide(s) on the way forward in the negotiation for reconciliation phase 3/ decide(s) on the oral hearing",

These three points provide a curious insight into the Objections Procedure. The first focuses on the OB's purported ability to "throw with mud and allegations" when filing their Notice of Objection (NoO). The reference to "mud" here can only be assumed to mean the throwing of allegations intended to negatively impact the image of the recipient.

This is interesting in that the Objections Procedure clearly states that "an objection has a reasonable prospect of success if, in the view of the IA......It is not spurious or vexatious" (MSC, 2009: Section 4.5). By this definition, the IA will only consider the NoO valid if allegations are backed by relevant, authentically sourced evidence, intended not to vex or harass. Therefore, any objection presented by the OB should in theory only be allowed to proceed if not vexatious. The $\mathrm{OB}$ is free however to publish further information and/or accusations in other media fora, allowing OBs to not only attack other organizations, but tarnish their public image in the process.

It is beyond the scope of this research to determine whether NoO contain spurious or vexatious information; however there are clear discrepancies between what this FC considers unsuitable allegations for objection and the opinion of the IA. There is room for further 
research into the legal rights of $\mathrm{OBs}$ to publicly declare objection information and surrounding commentary, and the rights of involved parties to preserve their reputation.

The second point is in reference to the reconsideration and consultation phase of the OP (MSC, 2009: Section 4.6). Here, the involved parties attempt to negotiate an agreement after the NoO has been accepted by the IA. The $\mathrm{CB}$ and FC are given an opportunity to respond to the NoO through the IA. Once this has commenced, the IA consults with the FC and OB as to "whether the response of the Certification Body, including any proposed amendments to the Final Report and Determination, adequately addresses the issues raised in the NoO" (MSC, 2009: Pg. 5).

Should the IA, in consultation with the OB, find that the CB's response does not adequately address issues raised and no common ground can be found, then the "IA shall notify all parties that the adjudication phase will commence immediately in accordance with Section 4.7” (MSC, 2009: Section 4.6.5).

The point made by the FC implies here that the OB determines the course of the above process. This appears to have merit in the sense that the $\mathrm{OB}$ must agree to the response to the NoO in order to avoid adjudication. Should the OB not agree, the IA is required to proceed to adjudication as he/she has already acknowledged that the issues raised are of merit by accepting the NoO.

An illustration of this can be seen in the case of the Suriname Atlantic Seabob Shrimp objection filed in December of 2009. The OB (WWF) filed a NoO which was subsequently 
accepted by the IA. Following a response from the CB and a series of telephone conferences, the IA decided to proceed to adjudication stating:

"WWF have informed me that they no longer think resolution this way is possible and that I should proceed to adjudication......I wish to inform all parties that I have therefore decided, pursuant to paragraph 4.6.5 of the Objections Procedure, to proceed to formal adjudication of this objection” (MSC, 2011c: Pg. 1)

It is clear here that the IA acted upon the OB's stance that no resolution could be found. From this perspective, the view held by the FC that the OB decides the way forward leading up to the adjudication stage has merit.

This FC is critical of this type of process stating "(if) the IA has all the elements to base her decision upon, why should there be an oral hearing on request of the Objector?". Essentially, the $\mathrm{FC}$ is arguing that prior to formal adjudication, all the necessary information regarding the fishery and objection is made available to the IA. Should the IA have the power to rule at this point, the adjudication process could be avoided more frequently as IA's could make an informed ruling more early on if possible.

By virtue the Section 4.6-4.7 of MSC OP Methodology (MSC, 2009), the power to proceed to adjudication is granted to the $\mathrm{OB}$ only. The FC cannot directly insist on adjudication; however the intent to proceed to adjudication can be provoked in the OB by simply refusing to address issues in the NoO. Therefore, the adequacy of the response to the NoO is not determined completely by the IA, but by the acceptance of the Objecting Body. OBs unwilling to negotiate or accept changes outside their demands are free to instigate formal adjudication. As implied previously by CBs, should the Objecting Body have alternative 
motives for objecting, there is little preventing the objection proceeding to adjudication once the NoO has been accepted.

This is significant in that $\mathrm{OBs}$ can use the OP to influence certification. By instigating adjudication, $\mathrm{OBs}$ require the $\mathrm{FC}$ and $\mathrm{CB}$ to invest resources into an Objection. Should the FC not be able to fund an objection, they may be forced to withdraw from certification all together, regardless of the objection's legitimacy.

The third point is difficult to substantiate as there is little documentation regarding the happenings in an oral hearing during adjudication. The oral hearing is "intended to provide an opportunity for the Certification Body, the Objecting Body(s) and the Fishery Client(s) (if not the objecting party) to present their respective cases in person" (MSC, 2009: 5). After seeking further clarification, the FC made it clear that they felt because the OB was in the offensive position during an objection, they should not have the possibility to demand an oral hearing. The costs of proceeding to and beyond an oral hearing are considered great, particularly financially. Because objections often address multiple areas of the assessment, it is often required that several members of the $\mathrm{CB}$ and $\mathrm{FC}$ attend the hearing at great financial cost. As previously mentioned, if the FC cannot finance an objection, they may enter a position where they are forced to relinquish certification.

Finally, the FC raised the issue of negative publicity. As stated previously, the Objections Procedure has the potential to be a publicity arena for those wishing to express their opinion regarding MSC or related topics. Again, the FC felt aggrieved by the accusations of the Objecting Body towards itself and the $\mathrm{CB}$, some of which were thought to have been unrelated to the assessment. 
"(There was) a lot of negative publicity for the FC and the assessment team that was alleged....besides the request for rescoring"

The FC seemed perturbed by the allegations raised by the OB remaining on the MSC website "for months" despite the FC being "completely cleared". It was felt that this allowed for “speculations and harming peoples' and organisation's integrity and reputation".

These statements illuminate the area of reputational risk during an Objections Procedure. Throughout an objection, stakeholders are able to make accusations against other parties, even if it is assessment related. For example, if an OB felt that there was a conflict of interest with one or more of the assessment personnel then they would be entitled to raise these concerns directly. However, should the allegations be found to be false, there is no mechanism to rectifying any reputational damage caused by harmful accusations during an objection.

It is known by defamation law that the impact of accusations on reputation can linger past any vindication (Schaffer, 1990). Therefore the FC has a legitimate case when requesting a mechanism that publicly clears the innocent party of wrong doing after an objection. The Objections Procedure should not be a forum in which organizations can look to damage the reputation of another, particularly when accusations are proved false. 


\subsection{Role Satisfaction with the Independent Adjudicator}

The IA's role involves determining the course which an objection takes, deciding the final ruling after adjudication. The IA does not have the power to decline certification of a fishery; they are required to assess the given arguments by each stakeholder and make a decision whether to accept the original assessment or remand the determination to the CB. Should the determination be remanded, the $\mathrm{CB}$ has ten days to make any changes necessary and respond to the IA, FC and OB. The IA determines whether the CB's response is an adequate resolution to the matters raised and approves the original/amended determination or upholds the objection. All changes are written into the Final Report and Determination (MSC, 2010b).

There are notable discrepancies between the interpretations of the IA's role amongst the different respondents. OBs tended to highlight issues of process and the limitations applied to the IA, although some were pleased with the scope in which the IA operates. Certification Bodies were more positive in their view of the IA, but noted some issues around the adjudication process. The FC had mixed views and felt the IA was more effective in the preadjudication stages of the Objections Procedure. 


\subsubsection{Independent Adjudicator and Objecting Body}

One OB was positive in their assessment of the IA's role during an Objection. They felt the IA was "clear and professional about his jurisdiction" and gave "clear guidance" as to the course of the objection. This type of action is unsurprising in that the IA is required to state the scope in which they are able to act and the course an objection can take in all objection correspondence.

OBs also commented on the 'balance' they felt the IA brought to the Objections Procedure Stating:

"(the IA) played a clear role in balancing the table to give our concerns more power and importance than was given before by the CB and FC"

The above statement gives an interesting position on 'balance'. It is implied here the IA was necessary to increase the significance of the OB's position to that given by the CB and FC. In this respect the $\mathrm{OB}$ indicates a position of disempowerment at the hands of the $\mathrm{CB}$ and $\mathrm{FC}$ without the IA's input. From this OBs' point of view, the IA empowers them to raise issues that must be satisfied, even if dismissed by the $\mathrm{CB}$ or FC. This of course is a primary reason for having an IA and validates the need for the OP to be facilitated by an independent expert who is capable of mediating such a process. Without an IA, there would be a real risk of legitimate issues having their significance reduced.

Those OBs concerned with the IA's role were particularly focussed on the scope in which the IA operates. Because the IA cannot rule a fishery unsuitable for certification, it was thought the IA's "purview is too limited" and the OP is more a "matter of process" on the way to 
certification rather than an arena where valid concerns prevent certification. This is highlighted by the fact only one objection has ever been overturned completely (Faroese Mackerel), a fishery perceived to be "particularly egregious" by OBs. One OB illustrated this type of experience stating:

"it seemed unless we could prove that the CB said that the sky was green, we'd be unable to succeed in our arguments"

Much of the frustration expressed here was preceded with distaste in how the IA and CB dealt with the uncertainty surrounding a fishery in many objection cases. All objections considered in this study have disputed the handling of data uncertainty to some extent. Whilst fisheries science is never exact and inherently contains uncertainty (FAO, 2006), OBs felt that "it is too easy for Certifiers to make a plausible argument" in the "face of uncertainty”.

It is beyond the scope of this research to judge the handling of data uncertainty issues by an IA, however there have been cases where the CB has changed PI scores after the initial determination was remanded due to uncertainty. None of these has resulted in certification being blocked.

An example of this can be found during the Ross Sea Toothfish objection (2009-2010) where the OB claimed that a precautionary approach to quantitative uncertainty was not adhered to, a claim that the IA in part agreed with stating: 
"To my mind, the score is not justified by the evidence on the Record and I would remand this PISG (Performance Indicator Scoring Guidepost) to the CB for further consideration” (MSC, 2010d)

The $\mathrm{CB}$ responded by defending their position to the IA, finally concluding with the statement:

"We therefore maintain that the results of monitoring are quantitatively evaluated against precautionary target and limit reference points on a regular and timely basis. We therefore propose 'no change' to the score for this PI.

The IA responded by upholding their position in part stating: "I consider that the further explanation provided by MML (CB) at (b) is adequate to respond to the remand", however subsequent elements of the fishery were not agreed to: "In these circumstances, it is illogical to award a theoretically 'perfect' score of 100. No reasonable CB could award such a score on the evidence available to it and, for this reason, the score of 100 cannot be justified" (MSC, 2010h). Despite the position of the IA and OBs, the Toothfish was certified on November 162010.

As previously mentioned, OBs consider the manner in which the $\mathrm{CB}$ can justify their position in the face of uncertainty to be too easy. The above example may illustrate this. Because fisheries data can be highly dubious, MSC may benefit from a more robust way of handling this data. In July 2009 MSC released its Risk Based Framework which defines how data limited fisheries are to be assessed. The impact of this framework is yet to be assessed; however it is only enacted where a fishery is data deficient. Should there be adequate data; 
the default assessment process is used which requires uncertainty be 'accounted' for (MSC, 2010b). Because all fisheries data contains varying degrees of uncertainty, MSC may benefit from more solid and well defined guidelines surrounding its use.

\subsubsection{Independent Adjudicator and Certification Body}

Comments by CBs regarding the IA tended to focus on the "application of methodology" and its subsequent impact on the OP itself. The IA's role was seen as one that was required to mediate and apply the Objections Methodology during an objection. The application of methodology was regarded as a "good thing" as many of the objections was seen to have often boiled down to "technical issues - and perspectives / opinions". Additionally, One CB noted a tendency to "err on the side of caution and spend time dealing with issues which had not material effect on the outcome of the case" (sic).

This appreciation for the way in which the IA applies the Objections Methodology in one sense is unsurprising. The CB is required to assess a fishery in accordance with the MSC Fishing Assessment Methodology (FAM) which is a highly technical and prescriptive method of assessment. The purpose of an objection is to bring to attention any mistakes that would make a material difference to the assessment within the MSC FAM framework. Therefore, if a CB assesses a fishery and applies MSC's FAM justifiably, it is difficult to dispute certification, regardless of whether the $\mathrm{OB}$ feels the $\mathrm{CB}$ made a mistake in the assessment. Highleyman (2004) identifies and is critical of this in his report stating:

"CBs have too much flexibility determining how principles and criteria are applied, including the thresholds for compliance, allowing for inconsistencies and low thresholds" 
This theme can be observed in the Aker Biomarine Krill objection where the Antarctic and Southern Ocean Coalition (ASOC) objected to the Antarctic Krill fishery being certified primarily on the grounds that the certification of one boat could not represent the sustainability of an entire fishery. The IA concluded:

"However logical this may appear at first blush, it does not comport with the terms of the MSC principles” (MSC, 2010j: Pg. 5)

This is an example where an OB has objected on grounds that could be given considerable merit outside the MSC principles. However because the IA must stick to the MSC FAM and its technical prescriptions, the objection was overturned as the primary issue raised regarded MSC's principles rather than the assessment itself.

There were also themes raised concerning issues of competency with the IA and their understanding of technical information. IAs are required by MSC to "have demonstrated expertise in one or more of the following areas":

- Jurisprudence.

- Fisheries Law.

- Dispute resolution and/or mediation preferably related to natural resource management.

(MSC, 2011d) 
One CB was "not convinced the adjudicator was competent to understand fully the issues". The reasons for this are not given, however it could be argued that the expertise required of an IA is sometimes not concurrent with all of the issues tackled.

Whilst each IA undoubtedly has expertise in one or more of the described areas, the issues addressed in an objection often are highly technical and require detailed knowledge of fisheries science and stock behaviour ecology, something not required of an MSC IA specifically.

This is significant in that an IA should be competent in the areas being adjudicated. It is somewhat surprising that an IA is not required to have any fisheries science expertise. It is a clear indication that MSC sees the OP as more of a legal process than scientific disagreement, a direction that is risky. It is acknowledged adjudicators cannot have expertise in all areas, however when adjudicating issues concerning fisheries sustainability it would seem logical to require competence in fisheries science.

Science works well with defined questions, objectives and testing (Bair, 2001). Where scientific studies are at the centre of lawsuits, law and science attempt to merge, often creating conflict. Conflicts arise when scientific methods are portrayed to legal experts. The credibility, methods, and analysis of experts can be questioned, and scientific terms are used in a legal context (Loth, 1986). Adjudicators and jurors can be swayed by the personalities of the experts more so than by the facts and opinions that the experts present (Bair, 2001). Legal process is primarily geared to conflict resolution and therefore may be less concerned about identifying an underlying or global truth, as it is framed in the scientific process (Hughes, 1999). By taking this approach, there is the real danger of silencing scientific truth amongst the mire of legal process. 


\subsubsection{Independent Adjudicator and Fishery Client}

The sole responding FC displayed mixed views towards the IA's role in the Objection Process. They were generally "satisfied" with the IA's role, primarily because their objection was successful.

Dissatisfaction stemmed from the role of the IA prior to the adjudication phase. In line with previous comments by $\mathrm{CBs}$, the FC expressed distaste for the scope the IA is permitted leading up to adjudication and the ability of an IA to make a decision prior to this phase.

(The Objections Procedure) "leaves too limited scope for the IA to move and make decisions prior to the expensive oral hearing"

As discussed previously, the OB has the potential to determine whether an objection should proceed to adjudication. This is something that requires attention as it may empower OBs to impose the financial burdens of an Objection onto smaller, less resourced fisheries, potentially requiring them to withdraw from certification.

\subsection{Objections Costs and Barriers to Participation}

One area of great contention and a source of diverse opinion was the issue of who should pay for and objection and whether the costs represent a barrier to participation. 


\subsubsection{Objections Cost and the Objecting Body}

There were three primary themes identified regarding the issues of who should pay for an objection. These were:

1. MSC should pay.

2. Payments should be dependent on merit.

3. The OB should pay.

Those who felt the MSC should pay for the objection approached their conclusion from a legitimacy point of view. Their reasoning was that the OP provided a way in which the MSC assessment could be transparently evaluated, providing an arena for legitimate issues to be resolved, validating the transparent nature of MSC certification.

It was considered that the objections fee provided a "severe impediment to lodging an objection". By presenting a barrier to objection, there is a "direct impact on access and thus legitimacy of the MSC process". Where potential OBs are prevented from objecting due to costs, an assessment is considered to not have been robustly evaluated because all concerns have not been adequately addressed.

From this angle, it can be interpreted that the financial burden of an objection should be MSC's responsibility to pay in order to ensure its credibility as a transparent eco-label.

Whilst there is clearly merit in MSC financing an objection, the application of such a system may prove challenging. MSC is an independent, non-profit organization. Reallocating the financial burden of an objection from OBs to MSC has the likely outcome of MSC having to 
raise the licencing cost of its label. In doing so, the price of MSC certified seafood may increase further, restricting consumers to those who can afford the greater expense and causing all consumers to more carefully weigh the sustainability benefits against the financial costs of MSC products. Because the success of the MSC label is determined by its market share, such an effect could undermine MSC's effectiveness.

The second notion, that payment should be dependent on merit, stems from the fact that a $\mathrm{NoO}$ can only be accepted if the IA determines that the arguments presented are valid and require further investigation. Therefore, should an objection be accepted by the IA, MSC should cover the cost of the objection as it is “in MSC's best interests" to "ensure that its label is being appropriately applied".

Similar to the idea that MSC should pay, MSC would be exempt from paying for unsuccessful objections. This type of structure is logical in theory; however there is scope for illicit use. Because the requirement for MSC to pay for an objection shifts from the occasional fee waiver to paying every accepted objection, the criteria for an objection to be allowed to be accepted could be influenced in a way that favours not allowing objections. MSC could be incentivised to reduce the number of objections allowed in order to contain costs. Such an action would directly threaten the legitimacy of the MSC label.

Thirdly, one Objecting Body agreed with the current system where the OB pays a fee for the right to object. This notion was condoned on the basis that the fee waiver option remains available. According to the MSC Objections Methodology, OBs can apply for a fee waiver under exceptional circumstances (MSC, 2010d: Sec 4.10.5). Considering many ENGO’s are often donation funded, poverty would likely not be an exceptional circumstance. Therefore 
the definition of 'exceptional circumstance' requires clarification by $\mathrm{MSC}$ in order to formally outline what this means for Objectors.

\subsubsection{Objections Cost and the Certification Body}

There were two notable themes to emerge from the views of the CBs regarding the costs of an objection. The first was that the cost responsibility should be outcome dependent, the second that OBs should bear the financial burden.

The idea of outcome dependent payment determination follows the logic that the validated party should not be responsible for the objection costs as they have proved an objection is necessary.

\footnotetext{
"(if) an Objector puts in an objection which ultimately results in little or no changethey should pay and pay costs to the Client. However, if the objection has merit and results in significant change, or a change in outcome, then the Client should cover their own costs and the cost of the Certification Body"
}

It is interesting here that the $\mathrm{CB}$ feels that it would be the responsibility of the FCs to cover the CB's costs in this circumstance. Considering the $\mathrm{CB}$ would have carried out the assessment, and all objections seek to question the assessment itself, one might conclude that any mistake made would likely be the fault of the $\mathrm{CB}$, having little to do with the FC. Additionally, CBs previously argued that the costs of an objection were a disincentive to small scale fisheries to apply for MSC certification. CBs appear here to consider their role purely as an assessment body, acting on behalf of the FC, devoid of consequence when fault is found. 
An outcome-based fee system would provide a different set of considerations for any 'would be' OB. The likelihood of success could become crucial as OBs seek to avoid paying for objection costs. At the current success rate for an $\mathrm{OB}$, this type of change could ultimately discourage objections being filed. However, the current rate of OB success is so low that most OBs are required to seriously count this cost regardless of outcome.

Discouraging objections via a compulsory fee is further pushed by the remaining themes presented by Certifiers. CBs felt that the objection fee kept potential OBs in check, reducing the filed objections to those who were more serious about objecting and had substantial resources.

"By allowing OBs to object without financial risk or penalty, there is no disincentive to object, and objections become more frequent and opportunistic. If an NGO doesn't have to pay to object, and they have a salaried member of staff who can do so, then why not object? Even if they only want a small change”.

The use of a fee for OBs certainly provides a disincentive to object as one must weigh the marginal benefits against the marginal costs of objecting. However, as previously identified by OBs, the fee and its size determines which organizations(s) have the capacity to object, regardless of the merit their case has. Frequently OBs are NGO's and non-profit organizations with a limited ability to allocate funding to an objection, especially at short notice. Eliminating or reducing the objections fee would open the door to smaller organizations that wish to object but are restrained by the actual and opportunity costs of objection. As pointed out, any such action will also provide an opportunity for those who wish to abuse the objections system to do so by presenting frivolous cases. 
CBs also indicated that they felt the OP was open to abuse without an objections fee from OBs seeking publicity.

"An objection is very good publicity for an NGO, almost regardless of the outcome..... In short, it's good publicity for the $O B$ whether they win or lose, so they may as well object - unless there is a financial penalty"

It is common for OBs to release a statement online after filing an objection and to keep its readers up to date with the objection happenings. Occasionally there are articles presented in other fora e.g. newspapers, blogs, magazines. As previously identified, an objection can be a form of protest in that the OBs make their view known publicly challenging the actions and views of another body. There is scope for an $\mathrm{OB}$ to pursue an objection with the goal of reputational gain and positive publicity. An objections fee may in part moderate this type of effect; however it is unlikely to prevent publicity itself being a motivating factor in an objection.

Should an OB be motivated by publicity, only controls on an organization's ability to publicise objection happenings can provide barriers to objections with little merit. Restrictions surrounding press releases and dates in which organizations can make information available are examples of these types of controls. Such controls however would provide barriers to the openness and transparency MSC strives to maintain. The maintenance of transparency standards in eco-labelling is seen as essential in maintaining credibility amongst consumers and reducing trade frictions (Ward, 1997). Limiting the availability of information to the consumer regarding any objection could provide a wall behind which those wishing to keep sensitive information out of the public fora could hide information. Such an occurrence would be in violation of the FAO's Code of Conduct for Responsible Fisheries (FAO, 1995), a Code in which MSC's values are based upon. 


\subsubsection{Objections Cost and the Fishery Client}

The perspective provided by the $\mathrm{FC}$ was not dissimilar to the $\mathrm{CB}$, yet with unique attributes. Two themes emerged from the data: 1 . the FC alludes to the notion that the OB should pay for the objection, 2. the costs to the FC are already high and could require a FC to abandon certification should they be required to pay for an objection.

The FC was quick to identify the costs to itself despite the objection fee being paid by the OB. It was felt that the consequences of having to pay for an objection would have resulted in the FC abandoning certification without challenging the objection.

"the...... fishery would NOT have been able to pay all the costs the objection brought

along. The fishery would have been forced to stop the assessment, giving in to the $O B$ 's requirements, and not have had the chance to win the objection and be certified"

As previously noted the FC is required to cover their own associated costs (e.g. staff, travel, accommodation) when attending adjudication meetings and preparing objection statements. These costs can be great when considering most travel is international and each meeting can take days to conclude. Therefore it is understandable that some FCs would struggle to meet the financial burden of an objection. Should the FC have to pay for the objection, it may indeed cause some to pull out of certification without challenging the Objecting Body.

This problem is the reverse of the OBs' point of view which seeks to put the costs of an objection on the FC and/or CB. Whilst this may enable smaller organizations with legitimate cases to object, FCs unable to bear the cost can be pushed out of certification. This type of arrangement leaves room for OBs to 'bully' smaller fisheries into abandoning certification. This is problematic as small scale fisheries tend to be more sustainable than larger fisheries 
(Jacquet \& Pauly, 2007). Any seafood eco-label seeking to promote sustainability needs to be able to attract small scale as well as large scale participants.

\subsubsection{Barrier to Participation}

When respondents were asked whether they considered the objections fee as a barrier to participation, there were two polar themes identified. The OBs were primarily of the opinion that the objections fee limited the ability of an organization to object, whilst the CBs and FC felt strongly that there was no such effect.

OBs allege that "Stakeholder involvement is stifled by costs of participation". This was said to be further exacerbated by the fact that OBs "rarely win". OBs are required to "weigh their odds of a successful objection (unlikely in the MSC process) against the fee" before pursuing an objection. This is an obvious barrier to participation in that OBs must first gather the finances to cover an objection and consider whether the cost is worth losing an objection for. Despite this, some organizations "still feel obligated to object rather than let certifications proceed unchallenged".

One $\mathrm{OB}$ noted that in addition to the financial cost of the $\mathrm{OP}$, there were also additional costs of "complexity, length and frustration of the (objections) process" which provides further barriers to participation. 
The CBs perceived the ability of stakeholders to object to be well within their capacity, and that the various costs of an objection appeared not to hinder OBs pursuing an objection.

"NGO stakeholders seem very keen to use expensive legal-type processes" and "most objections come in from organisations with plenty of money and salaried individuals able to spend time on it"

This is an insightful perception, and gives evidence for OB's argument that small or poor organizations truly cannot object. Because objections do present a significant cost, participating OBs can be filtered down to those with a large resource base or an ability to raise resources. In doing so, an impression may be given that NGO stakeholders who chose to object are well resourced in most cases. The question in this scenario is how many objections have not occurred due to the financial costs involved? This is needs further study.

CBs also identify a significant issue faced by the FC with regards to an objection and its associated costs. CBs feel that the cost of an objection "ironically limits the certification to big industrial fisheries" by requiring the FC to weigh the costs of certification and potential objection against the benefits of certification. Again, CBs argue that the Objections Procedure itself may be restricting small scale fisheries from applying for MSC certification.

"The current situation means that the cost of an objection could exceed the cost of an assessment - even where the objection does not result in a material change (i.e the CB reached the correct conclusion in the first place). This is clearly crazy and is a further disincentive for small scale fisheries to enter the MSC scheme" 
These comments are further supported by those of the FC. When asked if the costs of an objection limited the OBs participation, they replied:

"NO, this amount is peanuts compared to what costs are involved for the fishery/FC concerned"

Clearly the costs of the Objections Procedure to the FC and CB are considered significant. The FC has the most to lose in that if an objection cannot be challenged, then certification would need to be withdrawn after already paying for the assessment to be completed. The $\mathrm{CB}$ has the reputation of its assessments to defend, something that future FCs will consider when selecting a CB. From this view point, the costs of an objection are initially greater for the $\mathrm{OB}$, yet at its conclusion the $\mathrm{OB}$ can claim accolades regardless of the outcome. The costs applied to the $\mathrm{CB}$ and $\mathrm{FC}$ will almost certainly be a factor in the decision to seek certification.

\subsection{Improvements to the Objections Procedure}

Respondents were forthcoming when asked to comment on potential improvements to the Objections Procedure. A diversity of answers were given, many contrasting with the others and providing a unique insight into the interactions between stakeholders. 


\subsubsection{Objection Fee}

The "elimination" of an objection fee was solely identified by OBs. Two considered such a move would bring improvement to the OP. Interestingly there was an acknowledgement of the costs to the FC also. Not only was there a plug to remove the objections fee, but also "the costs to industry of the MSC certification". This statement may indicate some form of sympathy towards the industry and the cost burden incurred during an objection. Additionally, it also indicates a view that costs should be applied to the CB.

\subsubsection{Independent Adjudicator}

The OBs and FC proposed several changes to the use and role of the IA. Three OBs were of the view that the IA could not be truly independent unless "not selected and employed by the MSC'. Currently the IA's are selected by MSC and changed every three years. During this time they are contracted and paid by MSC. This arrangement has led some OBs to identify potential principal-agent issues, with the IA being incentivised to provide a good record of certification for its MSC employer. As a result, the OBs were of the opinion that the IA should be employed by an independent body.

Furthermore, IA's were seen by one OB to primarily be "legal experts" and not "qualified to adjudicate substantive matters of sustainability”. As mentioned previously, IA's are selected based on three potential areas of expertise: 1. Jurisprudence 2. Fisheries law 3. Dispute resolution and/or mediation preferably related to natural resource management. From these criteria, it is evident that expertise in fisheries science is not a prerequisite in IA selection. 
The selection criteria do indicate a perception by MSC of the OP to be a legal type process requiring legal expertise, rather than an objective forum for scientific debate requiring expertise in fisheries science.

The question in this instance becomes is the OP an application of process or mediation of debate? The former would be suited to individuals who have expert experience in legal matters as they are attuned to applying rules. Should the latter be the case, expertise in rule application and process is required; however a good understanding of the science would also be necessary to make any informed rulings and to communicate clearly with stakeholders. One $\mathrm{CB}$ suggests the Objections Procedure is currently treated as a quasi-legal process stating:

Any method which avoids a legal-type approach would be an improvement in my opinion: "......"the current approach will never be efficient (and alarmingly has required personal attendance of people at hearings in some cases)".

Instead of an OP, it is suggested that a "more in-depth peer review process would be a better approach (e.g. a panel of 3 independent assessors with relevant technical knowledge)". This is similar to the "Appeals Panel" approach used by the Forest Stewardship Council which is "comprised of (sic) one to three persons that are impartial and free of any conflict of interest in relation to the appellant and to the appeal" (FSC, 2009. Sec. 4.2) and is consensus based in its ruling. The advantage in this is that panel members can apply a more diverse background in experience when assessing an appeals' merit and to allow for debate amongst members. However the difficulty in finding individuals qualified to conduct such reviews consistently and independently is challenging (Deep Sea News, 2008) and likely to be incur greater costs. 
The FC was supportive of the IA being empowered to decide an objections direction and outcome earlier on in an objection. The FC believes that the IA should have the authority, and be motivated to "drop or sustain points in the objection at that moment (moment of objection)".

Additionally, it is felt that the decision to proceed to an oral hearing "should be up to the FC/fishery to decide" and the "initiative should NOT be left to the OB".

Their reasoning follows the logic that if "the IA has all the elements to base her decision upon, why should there be an oral hearing on request of the OB?". This idea is further supported by one CB who felt that "most issues can (be) dismissed out-of-hand, but take time and resources to deal with".

As previously mentioned, should the $\mathrm{OB}$ conclude that their concerns have not been adequately addressed and recommend proceeding to formal adjudication, then the IA has little power to deny this request. From this perspective, the OP is very process driven. Should the IA already know their position regarding issues raised, then there is logical reason to contend that the IA should have the power to determine a ruling prior to adjudication provided the IA felt that all information and opinions had been expressed. This type of change may reduce the number and scopes of objections filed and reduce overall costs as formal adjudication would be necessary less frequently. 


\subsubsection{Methodology and Reporting}

Respondents suggested improving the Objections Procedure methodologies and the way in which data and actions are reported. One $\mathrm{CB}$ was concerned with the complexity of the Objections Procedure despite the methodology being simplified in 2010. The changes made are acknowledged to make it "much easier and transparent to explain a certification", however there is an expressed concern that complexity is returning, although what is considered complex is not defined.

The primary issue is that "complexity results in errors", and consequentially an "increasing likelihood that fisheries will fail or objections will be upheld due to technical mistakes in the methodology, rather than because the fishery does not meet the MSC principles fisheries".

OBs are indeed able to object on grounds that the $\mathrm{CB}$ made one or more mistakes in their application of MSC assessment methodology. Because of the process-based nature of MSC certification, one significant mistake can block certification if objected to and if the objection is upheld as a significant error. Determining which methodological mistakes are significant and which are trivial becomes the issue. The answer to this question is then part of the decision making by the IA.

In addition, it was indicated by one CB that the way in which MSC reports its objections proceedings and assessment process requires further attention. The summary report released by MSC contains much of the assessment documentation including stakeholder submissions and the final report. The size of the MSC summary reports are said to make "it almost impossible for anyone without enormous amounts of free time to follow what went on". This type of reporting is thorough yet difficult to synthesise efficiently. Those wishing to look at criteria used by the $\mathrm{CB}$ and the process followed are required to trawl through what can be hundreds of pages of documentation. It is felt by the $\mathrm{CB}$ that many "issues can be dealt with by improving clarity in reporting, well defined forms of evidence and improved scoping (what falls within MSC 
requirements)". By having a more succinct form of reporting, issues with assessment methodology and application may become less frequent as the outline of what has occurred becomes more accessible. 


\subsection{Summary \& Conclusions}

The results of this study have illuminated many of the inner workings of an MSC objection and revealed major areas of contention amongst actors. It is clear that the structure of the MSC Objections Procedure has shaped the way in which actors behave during an objection and the course the objection takes. It has been identified that the Objections Procedure is an important component of MSC's assessment process, helping to maintain transparency and to ensure certified fisheries have satisfied all the MSC requirements of a sustainable fishery. However significant issues and areas of concern have been identified that threaten may the credibility of MSC's reputation and endanger the legitimacy of the Objections Procedure.

\subsection{Inter-organizational Dynamics}

The structure of the MSC OP creates incentives and motivations within actors, defining their position.

The $\mathrm{CB}$ is required to approach an objection from a defensive point of view, rather than one that seeks to improve the sustainability of fisheries. In doing so, the MSC Objections Procedure inhibits the willingness of $\mathrm{CBs}$ to reason with the OBs case, regardless of its legitimacy.

The MSC Objections Procedure could be greatly improved by nurturing an Objections environment that motivated its actors to behave in a way that required improved fisheries sustainability remain the primary objective. 


\subsection{Principal Agent-Issues}

The questionnaire data clearly highlights principal-agent issues within the MSC structure that directly affect the OP. MSC ratification of selected CBs that FCs may choose to assess their fishery immediately incentivises $\mathrm{CBs}$ to try and gain favour with MSC which may require $\mathrm{CBs}$ to be generous in their certifications. Because FCs pays the CB to conduct an assessed, and is instructed by MSC to find a CB whom will give value for money, the FC is incentivised to hire a comparatively cheap $\mathrm{CB}$ with a record favourable to the $\mathrm{FC}$. This further incentivises the $\mathrm{CB}$ to remain competitive by assessing favourably unless a fishery is blatantly unworthy of certification.

The clear possibility of principal-agent issues in the MSC's structure directly influences the MSC OP. The current relationship and incentive structure between FC, MSC and CB requires revision in order to maintain transparency and integrity in its label.

\subsection{An Inefficient Process}

The technical prescriptions and explanation of assessment details during and Objection cause it to appear inefficient. Explanations of stock assessment, particularly to individuals and IA's are who are not fisheries experts require large amounts of time and resource invested on the part of the CB. Many of the technical issues of an objection could be clarified in a modified assessment process, requiring assessors to be more thorough in the reporting of their assessment methodology to stakeholders. 


\subsection{Transparency; MSC's Strength or Weakness?}

The MSC OP is a key component in maintaining a transparent eco-labelling system. However this study has found that there is scope for OBs to use the OP as a means of self-promotion. Publicly released criticisms by OBs have the ability to remain in the public psyche long after an objections conclusion, regardless of their vindication. Therefore, regardless of whether an $O B$ is successful in their objection or not, long lasting damage can be inflicted to an opponent's public image. Therefore the $\mathrm{OP}$ is open to abuse by OBs with the resources and motivation to use an objection in order to harm a target organizations reputation.

Aside from the financial burden of an objection, OBs do not experience many further consequences from objecting. Because small changes are frequently made in an objection, OBs are able to claim moral victory regardless of the overall outcome.

Measures to control such effects may include further financial penalties and restrictions on interactions with media and social networking. The legal legitimacy and benefit of such a move requires further research.

\subsection{Determining an Objections Direction?}

If the $O B$ is not satisfied that the $C B$ has addressed the issues raised at the oral hearing stage, they may request adjudication. Because the IA can only prevent adjudication where all issues have been addressed, the IA is almost always obliged to accept the OBs request. Because the Objections Procedure requires significant financial expenditure by the $\mathrm{FC}$, the $\mathrm{OB}$ has the potential to force the 
withdrawal of smaller fisheries from the MSC programme by Objecting. In order to prevent OBs forcing adjudication, the FC suggests that the IA should be empowered to make the decision to proceed if all information has been made available. The position of the FC has merit and should be investigated by MSC.

\subsection{Independent Adjudicator Gives Balance}

This study found the IA to give balance to an Objection, particularly with regards to the position of the OB. The IA gave weight to issues raised by OBs, even when such issues were dismissed by the CB or FC. The IA's role is essential in maintaining a focus on issues raised during an objection and ensuring such issues are addressed adequately in the judgement of the IA.

\subsection{Independent Adjudicator's Purview too limited}

Because the IA cannot rule a fishery unsuitable for certification, the scope in which the IA can act during an objection is very limited. Unless an assessment has made a particularly poor judgment, the IA is permitted by MSC rules to prevent certification. The IA can only remand the assessment back to the $\mathrm{CB}$ to make any recommended revisions. Because the IA cannot rule on an assessments agreement with the MSC Principles and Criteria for Sustainable Fishing, it is easy for CBs to justify their position as they define the scoring criteria for the assessment.

The results of this study suggest it may be beneficial for the IA be given the power to uphold or turn down an assessment earlier on in the objection, particularly where the IA considers the OB to have a legitimate case. 


\subsection{Objection Payment Responsibility}

When discussing who should be responsible for an objection, OBs proposed three positions: 1. MSC should pay for the objection. 2. Payment should depend on whether the IA agrees that the issues raised require by the $\mathrm{OB}$ are worth investigating. 3. One $\mathrm{OB}$ agreed with the current framework where the OB pays.

CBs proposed that the objections payment should either be outcome dependent, where payment is the OB's responsibility if an objection is unsuccessful and the CB's responsibility if an objection is successful. The FC was of the opinion that the OBs should pay for an objection. CBs and FC both felt that the objections fee is a way to mediate the legitimacy of an objection and to limit objections to those who have legitimate motivations.

Each contributors view had merit in some context. However, it was most clear that there are real dangers of creating perverse incentives through the responsibility of an objections payment. A thorough, independent review of the Objections fee system is required in order to help determine a more robust financing system. 


\subsection{Objection Fee: a Barrier to Participation?}

\section{Objectors}

OBs considered the objections fee to stifle the participation by eliminating the potential of those stakeholders with few resources to object. This is said to be exacerbated by the fact the OBs rarely win an objection; causing would be OBs to weigh the financial costs against the benefits of objecting.

The position of OBs has legitimacy and demands further research into how many would be OBs have decided against objecting due to objection costs.

\section{Certification Body's}

CBs felt that the objections costs did not seem to prevent organizations objecting at all and that the publicity gains of an objection were often a motivation for OBs. CBs also point out that the costs of participating in an objection to the $\mathrm{FC}$ have the potential to limit MSC certification to large scale fisheries able to finance such a process.

Further research into the way in which the costs of an objection may prevent small scale fisheries applying for certification is required

\section{Fishery Client}

The FC was of the view that the OB should pay. The FC considered the objections fee to be small in comparison to the costs incurred by the FC's during an objection.

Further research into the costs of an objection applied to a FC and its impact on the FCs motivation to seek certification is required. 


\subsection{Suggested Improvements}

Three OBs were of the opinion that a removal of the objections fee would be an improvement to the Objections Procedure. However, OBs did recognise the significant cost to the FC during certification and an objection, encouraging MSC to address these issues of cost. OBs and the FC indicate that they feel IA should not be employed by MSC as this implies principal agent-issues. They suggest that the IA should be employed through an independent body, removing any employer influence when considering fishery certification.

One CB considered the quasi-legal approach of the OP to be inappropriate for matters of sustainability, leading to inefficient outcomes. It suggested that an in-depth peer-review type process would be a better approach.

A review of the goals of an objection and whether the current process type is appropriate is required. Additionally, consideration of a more in-depth and independent system of objecting is merited.

The FC was supportive of increasing the scope in which the IA could operate, allowing IA's to drop or sustain points in an objection as they see appropriate. Additionally, it was considered that the IA should be able allow or decline certification.

The FC suggests increasing the scope of the IA's purview to include the ability to reject or accept certification at their discretion would improve the OP.

Finally, CBs felt that reporting methods could be improved greatly. Currently reporting of methodology and assessment is presented in large documents which require great amounts of time to 
read. Simplifying reporting could increase the understanding of assessments and reduce the occurrence of objections. However, maintaining transparency and communicating holistic information whilst trying to achieve simplicity in reporting is difficult. An Investigation into to communicating simplified yet transparent methodological reporting requires further research. 


\section{References}

Akerlof G: 1970. The Market for 'Lemons': Qualitative Uncertainty and the Market Mechanism.

Quarterly Journal of Economics. 84. 488-500

ANP: 1996. Unilever, WWF Unite in Bid to Save Fish Stocks. English News Bulletin . Stitching Algemeen Nederlands Persbureau, February 23 1996. Available at: http://web.lexis-nexis.com

Atyi R. E, Simula M: 2002. Forest certification: pending challenges for tropical timber. Yokohama, Japan. International Tropical Timber Organization, Available from http://www.itto.or.jp

Barham E: 2002. Towards a theory of values-based labelling. Agriculture and Human Values. 19. 349360

Batstone C. J., Sharp B. M. H: 2003. Minimum information management systems and ITQ fisheries management. Journal of Environmental Economics and Management. 45 (2). 495504

Baumol W. J, Oates W. E: 1988. The Theory of Environmental Policy. $\left(2^{\text {nd }}\right.$ ed), Cambridge University Press, Cambridge, 1988

Bensch A, et al: 2008. World Review of Bottom Fisheries in the High Seas. United Nations Food and Agriculutre Organisation, Fisheries Technical Paper 522. Rev 1.

Berkes F, Folke C, Eds: 1998. Linking Social and Ecological Systems: Management Practices and Social Mechanisms. Cambridge Univ. Press, Cambridge. 99

Berkes F: 2003. Alternatives to Conventional Management: Lessons from Small-Scale Fisheries. Environments. 31, 1. 5-19

Bostrom M: 2006. Regulatory Credibility and Authority through Inclusiveness: Standardization Organizations in Cases of Eco-Labelling. Organization Articles. 13, 3. 345-367

Caswell J. A, Anders S. M: 2009. The Economics of Market Information Related to Certification and Standards in Fisheries. In Round Table on Eco-Labelling and Certification in the Fisheries Sector, Hotel Steigenberger Kurhaus Gevers Deyneetplein 30 The Hague, Netherlands 22-23 April 2009. Background paper

Christy F.T: 1973. Fisherman Quotas: A Tentative Suggestion for Domestic Management. (Law of the Sea Inst., Univ. Of Rhode Island, Occasional Paper No.19, 1973)

Christensen V. et al: 2002. in Fisheries Impacts on North Atlantic Ecosystems: Models and Analyses (eds Guénette S; Christensen V; \& Pauly, D.) Fisheries Centre Res. Rep. 9(4), 1-25 (also available at http://www.fisheries.ubc.ca) (Fisheries Centre, Univ. British Columbia, Vancouver, 2002)

Commission of the European Communities (CoEC) : 1996. "On Environmental Agreements," Communication from the Commission to the Council and the European Parliament, Brussels 
Costello C., Gaines S. D., Lynham J: 2008. Can Catch Shares Prevent Fisheries Collapse?

Science. 321. 1678-1681

Chu C: 2009. Thirty years later: the global growth of ITQs and their influence on stock status in marine fisheries. FISH and FISHERIES. 10. 217-230

Cloutier T. M: 1996. Conflict of Interest on Regional Fishery Management Councils: Corruption or Cooperative Management? Ocean \& Coastal L.J. 101; National Research Council, Improving the Management of U.S. marine Fisheries 23 (1994)

Colby B. G: 1995. in The Handbook of Environmental Economics, D. Bromley, Ed. Blackwell Publishers, Oxford, 475-502

Constance D. H, Bonnano A: 2000. Regulating the global fisheries: The World Wildlife Fund, Unilever, and the Marine Stewardship Council. Agriculture and Human Values. 17, 125-139

Cummins A: 2004. The Marine Stewardship Council: A Multi-Stakeholder Approach To Sustainable Fishing. Corporate Social Responsibility and Environmental Management. 11. 85-94

Delgado C.L, Wada N, Rosegrant M.W, Meijer S, Ahmed M: Fish to 2020: 2003. supply and demand in a changing world. IFPRI; Washington, DC: 2003

Dietz T et al: 2002. Committee on the Human Dimensions of Global Change, National Research Council, New Tools for Environmental Protection: Education, Information, and Voluntary Measures Eds. (National Academy Press, Washington, DC, 2002)

Dietz T, et al: 2003: The Struggle to Govern the Commons. Science. 302. 1907-1912

Dommen C: 1999. Fish for Thought: Fisheries, International Trade and Sustainable Development. International Centre for Trade and Sustainable Development. IUCN, Natural Resources, International Trade, and Sustainable Development Series No.1

Dubbink W, Vliet M: 1996. Market regulation Versus co-management? Two perspectives on regulating fisheries compared. Marine Policy. 20, 6. 499-516

Eisenhardt K: 1989. Agency theory: A Review. The Academy of Management Review. 14, 1. 57-74

Espach R:2006. When is Sustainable Forestry Sustainable? The Forest Stewardship Council in Argentina and Brazil. Global Environmental Politics. 6, 2. 55-84

FAO: 1999: Use of Property Rights in Fisheries Management. FAO Fisheries Technical Paper 404/1. Proceedings of the FishRights99 Conference Fremantle, Western Australia 11 - 19 November 1999

: 2007. State of World Fisheries and Aquaculture. United Nations Food and Agricultural Organization Technical Paper. http://www.fao.org/docrep/009/A0699e/A0699e00.htm : 2004. Ecolabelling in fisheries management. Available at: www.fao.org/fishery/topic/12283/en 
Fela J: 2010. Smarter economics key to restoring fisheries. Frontiers in Ecology and the Environment. 8, 7. 340-340

FSC: 2010. Forest Stewardship Council Fact Sheet. Available from: www.fsc.org/fileadmin/webdata/public/document_center/publications/Fact_Sheets/Forest-Stewardship-Council-Fact-SheetEN.pdf

Forest \& Bird: 2007. Hoki fishery does not deserve its sustainability tick. http://www.forestandbird.org.nz/what-we-do/publications/media-releases/hoki-fishery-doesntdeserve-its-sustainability-tick

Gilman, et al: 2008. Shark interactions in pelagic longline fisheries. Marine Policy. 32. 1-18

Gordon H. S: 1954 . The economic theory of a common property resource: The fishery. Journal of Political Economy. 62. 124-142

Green Peace: 2009. Hoki Fact Sheet. Written by Barry Weeber. http://www.greenpeace.org/raw/content/new-zealand/press/reports/greenpeace-species-factsheet.pdf

Gulbrandsen LH: 2005. Mark of sustainability? Challenges for fishery and forestry eco-labeling. Environment. 47(5):8-23

Gullastigue I. G: 2002. The Use of Eco-labels: A Review of Literature. European Envrionment. 12. 316 $-331$

Hannesson R: 1993. Bioeconomic Analysisof Fisheries. FAO/Fishing New Books, Oxford, 1993.

Heal G. M: 1998. Valuing the Future: Economic Theory and Sustainability. Colombia Univ. Press, New York, 1998. 100

Highleyman S: 2004. An independent assessment of the MSC. Draft Report, Prepared for the Homeland Foundation, Oak Foundation and Pew Charitable Trusts.

Hochstetler K: 2003. Fading Green? Environmental Politics in the Mercosur Free Trade Agreement. Latin American Politics and Society. 45, 4. 1-32

Homans F. R., Wilen J. E: 2002. A Model of Regulated Open Access Resource Use. Journal of Environmental Economics and Management. 32 (1). 1-21

Jacquet J, Pauly D: 2007. The rise of seafood awareness campaigns in an era of collapsing fisheries. Marine policy. 31, 3. 308-313

Jenkins R: 2000. Eds Industry and the Environment in Latin America. London: Routledge

Jensen F: 2007. Uncertainty and asymmetric information: An overview. Marine Policy. 32. 89-103

Joseph J: 1994. The tuna-dolphin controversy in the Eastern Pacific Ocean: Biological, economic, and political impacts. Ocean Development and International Law. 25, 1. 1-30 
Kirkley J et al: 2003. Excess Capacity and Asymmetric Information in Developing Country Fisheries: The Malaysian Purse Seine Fishery. American journal of Agricultural Economics. 85, 3. 647-662

KRAV: 2011. KRAV Sweden official website information page. Available at: www.krav.se/System/Spraklankar/In-English/About-KRAV/

KRAV: 2010. KRAV Standards. www.krav.se/System/Spraklankar/In-English/KRAV-standards/

KRAV: 2008. Regler fo" r KRAV-certificered production - utgåva January 2008. KRAV ekonomisk fo" rening. Uppsala, Sweden

LEI/DLO Fishery Department: 1991 report. LEI/DLO, Den Haag, 1991

Ludwig D, Hilborn R, Walters C: 1993. Uncertainty, resource exploitation, and conservation:

lessons from history. Science. 260: 17-36

Mason C. F: 2008. On the Economics of Eco-Labelling. EAERE Conference, Southampton

Mora C, et al: 2009. Management Effectiveness of the World's Marine Fisheries. Plos Biology. 7, 6. 111

Moss R, Schneider S. H: 2000. in Guidance Papers on the Cross-Cutting Issues of the Third Assessment Report of the IPCC, Pachauri R., Taniguchi T., Tanaka K., Eds. ( World Meteorological Organization, Geneva, Switzerland, 2000), pp. 33-51

MSC: 1998. Principles and criteria for sustainable fishing: Arlie House meeting report. Marine Stewardship Council (April 1 ). www.msc.org/cgibin/library/articles/cgi/view_article.pl?section=2\&area=1\&id=891616876\&html=te mplate.html> 11/9/98

: 2002. New Zealand Hoki Fishery - Independent Panel Decision. Available at: http://www.msc.org/track-a-fishery/certified/pacific/new-zealand-hoki/assessment-downloads1/NZ_Hoki_Panel_Decision.pdf. Accessed on 27/01/2012

: 2005. Final Decision and Summary of the Report of the Marine Stewardship Council Independent Objections Panel on the Gulf of Alaska Pollock Fishery. Available at: http://www.msc.org/track-a-fishery/certified/pacific/gulf-of-alaska-pollock/assessment-downloads1/2005_GOA_Pollock_Objection_Panel_Report_Remand.pdf. Accessed on 27/01/2012

: 2003. Lessons Learned in Fisheries Certification

: 2008. Objections panel for New Zealand hoki fishery concludes process. Available at: http://www.msc.org/newsroom/news/objections-panel-for-new-zealand-hokifishery?searchterm=msc\&set_language=en

: 2009. MSC Objections Procedure Overview. Available at: http://www.msc.org/getcertified/fisheries/assessment-process/assessment/objections?searchterm=object

: 2010a. MSC Fishery Standard: Principles and Criteria for Sustainable Fishing

Version 1.1 - 1st May 2010. Available at: http://www.msc.org/documents/schemedocuments/msc-standards/MSC_environmental_standard_for_sustainable_fishing.pdf 
_:2010b: Marine Stewardship Council Fisheries Certification Methodology. Version 6.1. Available at: www.msc.org/documents/schemedocuments/methodologies/Fisheries_Certification_Methodology. pdf

: 2010c. Fisheries Certification Methodology, version 6.1. Available at: http://www.msc.org/documents/schemedocuments/methodologies/Fisheries_Certification_Metho dology.pdf

: 2010d. TAB Directive 023: Revised Fisheries Certification Methodology Objections Procedure. Available at: http://www.msc.org/documents/msc-factsheets/TAB\%20D-023\%20 20Revised\%20Fisheries\%20Certification\%20Methodology\%200bjections\%20Procedure.pdf/view

Mullon et al: 2005. The dynamics of collapse in world fisheries. Fish and Fisheries. 6. 111-120

Nash J: 2002. In New Tools for Environmental Protection: Education, Information and Voluntary Measures, T. Dietz, P. C. Stern, Eds. (National Academy Press, Washington, DC, 2002), 235-252

Neher P. A 1990: Natural Resource Economics: Conservation and Exploitation. Cambridge University Press, Cambridge

National Research Council: 1992. 'Dolphins and the Tuna Industry," National Academy Press. 1992

Nelson P: 1970. Information and consumer behavior. Journal of Political Economy. 78. 311-329.

: 1974: Advertising as information. Journal of Political Economy. 81. 729-754

NOOA: 2002. Fisheries of the United States. US Department of National Oceanic and Atmospheric Administration. Available at: http://www.st.nmfs.noaa.gov/st1/fus/fus01/2001-fus.pdf. Accessed on: 09/02/2012

O’Riordan B: 1997. Marine Stewardship Council: who's being seduced? Samudra. 18. 10-1

OECD: 2009. Round Table on Eco-labelling and Certification in the Fisheries Sector. Organization for Economic Co-Operation and Development

Pauly D, et al: 2002. Towards sustainability in world fisheries. Nature. 418. 689-695

Peacey J: 2000. The Marine Stewardship Council Fisheries Certification Program: Progress and Challenges. MSC LTD

Pearse P. H: 1994. Fishing rights and fishing policy: the development of property rights as instruments of fisheries management, in Vogtlandes, ed, The State of the World's Fisheries Resources: Proceedings of the World Fisheries Congress Planning Session. IBH Publishing Company, Oxford, 1994

Pearce D. W, Turner R. K:1990. Economics of Natural Resources and the Environment.. Harvester Wheats heaf, New York 
Ponte S: 2006. Eco-labels and fish trade: MSC certification of the South African Hake fishery. TRALAC Working Paper, No.9 2006

Potts T, M Haward: 2006. International Trade, Eco-labelling, and Sustainable Fisheries - Recent Issues, Concepts and Practices. Environment, Development and Sustainability. 9, 1. 91-106

Reiser A: 1997. Property Rights and Ecosystem Management in U.S. Fisheries: Contracting for the Commons? Ecology Law Quarterly. 24. 813-812

Salz P: 1991. De Europese Atlantische Visserij, Structuur, Economische Situatie en Beleid. LEI-DLO, Den Haag

Sammer K; Wustenhagen R: 2006. The Influence of Eco-Labelling on Consumer Behaviour - Results of a Discrete Choice Analysis for Washing Machines. Business Strategy and the Environment. 15. 185199

Samudra: 1996. The mantle of Agoing green, Report Number 15. August. In Constance \& Bonnano 2000

Schoon, N: (1998). "Environment: UN launches battle to save the oceans," Independent 1-13: 7. In Constance \& Bonnano 2000

Shabecoff P: 1990. Three companies to stop selling tuna caught with dolphins. New York Times, April 13,1990

Smelly : 1997. WWF and Unilever to use market forces in bid to halt fisheries decline. http://dspace.dial.pipex.com/town/parade/ hw22/smelly.html> 07/15/98

Stokstad, E: 2010. Behind the Eco-label, A Debate Over Antarctic Toothfish. Science. 329. 1597-1597

Stone C. D: 1997. Too Many Fishing Boats, Too Few Fish: Can Trade Laws Trim Subsidies and Restore the Balance in Global Fisheries? Ecology Law Quarterly. 24. 505-544

Surronen P, Sarda S: 2007. The role of technical measures in European fisheries management and how to make them work better. ICES Journal of Marine Science. 64. 751-756

Sustainable Seas: 2009. Trouble with MSC and NZ Hoki? http://sustainableseas.blogspot.com/2009/09/trouble-with-msc-and-nz-hoki.html

Symes D, Phillipson J: 1997. Inshore fisheries management in the UK: Sea Fisheries Committees and the challenge of marine environmental management. Marine Policy. 21, 3. 207-224

Taylor P. L: 2005. In the Market But Not of It: Fair Trade Coffee and Forest Stewardship Council Certification as Market-Based Social Change. World Development. 33. 1. 129-147

Terra Nature: 2004. Government response to bottom trawling is not good enough: An immediate moratorium is needed. http://www.terranature.org/deepsea_bottomTrawling.htm

Teisl M. F, et al: 2002. Can Eco-Labels Tune a Market? Evidence from 
Dolphin-Safe Labeling. Journal of Environmental Economics and Management. 43. 339-359

Tietenberg T, Wheeler D: 2001. In Frontiers of Environ-mental Economics, H. Folmer, H. Landis Gabel, S. Gerking,A . Rose, Eds.( Elgar, Cheltenham,U K,2 001), 85-120

Tisdell C: 1993. Environmental Economics. Politics for Environmental Management and Sustainable Development. Edward Elgar, Aldershot, 1993

Thorson J. T et al: 2010. Competing interests, economics, and marine fisheries management: an educational case study. Journal of Natural Resources and Life Sciences Education. 39. 71-78

Thrane M, et al: 2009. Eco-labelling of wild-caught seafood products. Journal of Cleaner Production. 17. $416-423$

Unilever: 1998. Press pack. http://www.unilever.com/public/generic/presspack.doc> 7/20/99

U.S. Dept. of Agriculture: 1991. 'Continuing Survey of Food Intakes by Individuals" 1991

Van Dam C: 2003. La econom'ia de la certificacio'n forestal: "Desarrollo sostenible para quien". Paper presented at the Congreso Iberoamericano de Desarrollo y Medio Ambiente: "Desafios Locales Ante la Globalizacio' n". Quito, Ecuador

Vladimarrson G: 2007. Fish in the global food chain: challenges and opportunities. In: FAO Fisheries and Aquaculture Proceedings; International seafood trade: challenges and opportunities

Ward T, Phillips B: 2008. Seafood Ecolabelling: Principles and Practice. Blackwell Publishing, Oxford, United Kingdom

Wilen J. E: 2006. Why Fisheries Management Fails: Treating Symptoms Rather than Cause. Bulletin of Marine Science. 78, 3. 529-546

Worm B et al: 2006. Impacts of Biodiversity Loss on Ocean Ecosystem Services. Science. 314. 787-790 : 2009. Rebuilding Global Fisheries. Science 325. 578-585

WWF: 1996a. The WWF endangered seas campaign, World Wildlife Fund. Available at: www.wwfuk.org/species/marine/fish6.html> 11/07/97

: 1996b. Worldwide interest in MSC grows rapidly. World Wildlife Fund. Available at: www.panda.org/endangeredseas/msc/vol2news/page2.html> 7/8/98

Youssef A. B, Ayed R. L: 2008. Eco-labelling, Competition and Environment: Endogenization of Labelling Criteria. Environmental Resource Economics. 41. 133-154 


\section{Appendix}

\section{Full list of key findings by Highleyman (2004)}

7. MSC's claim of certifying sustainable fisheries in most cases is not justified under the definition established by its standards, the Principles and Criteria;

8. Principle 2 requires fishing operations to maintain the structure, productivity, function, and diversity of the eco-system on which the fishery depends, but routinely is not met. MSC has a leadership opportunity to drive best practices towards eco-system based management;

9. Principle 3 does not require fisheries management systems to be in compliance with national laws. Fisheries that are not in compliance with the law can be, and have been certified;

10. MSC has narrowly interpreted the meaning of controversial fisheries in ways that reduces its flexibility and ability to guide its own future;

11. Certifiers have too much flexibility determining how principles and criteria are applied, including the thresholds for compliance, allowing for inconsistencies and low thresholds. Recognising this, MSC is taking steps to propose greater interpretation and guidance to certifiers;

12. MSC is not yet considered as a credible consortium organization because key environmental stakeholders do not feel that the MSC mission includes them in a substantive way;

13. MSC has made important decisions in the in the last two years to increase stakeholder representation on the board but must continue this trend to restore the organization's credibility;

14. As one of the few non-governmental, multi-stakeholder organizations in the oceans policy arena, MSC has huge potential to become a convener of diverse interests that craft solutions to difficult issues. However, by not placing enough emphasis on consensus building, MSC had at the time currently missed the opportunity; 
15. Staff leadership must continue to push to convene stakeholders, seeking consensus, and implement solutions as top priorities.

\section{Questionnaire Templates}

\section{A. Certification Body}

1. Please state which MSC objection(s) you have been involved in:

2. Of the MSC objection(s) you have been involved with that have proceeded to full certification, have you been involved in a re-objection during re-certification?

3. Overall, how would you rate your experience with the MSC objection process?

Very Good - I am very pleased with how the MSC objections process proceeded and feel it led to legitimate outcomes

Good - Overall I am pleased with how the objections process proceeded. I only harbour minor issues with the MSC objections process

Neutral - I am neither pleased nor displeased with how the MSC objections procedure operates

Mixed - I am pleased with certain elements of the MSC objections process, and displeased with others

Bad - I am displeased with how the MSC objections process proceeds and feel it requires improvement

Very Bad - I believe the MSC objections process is flawed and leads to illegitimate outcomes

4. Please elaborate on and explain your answer in the previous question

5. During the MSC objection you have been involved with, were you satisfied with the role the Independent Adjudicator played?

Very satisfied $\quad \square$ Satisfied $\square$ Neutral X Not satisfied $\square \quad$ Very un-satisfied

Mixed (various points of view) 
6. Please explain your previous answer

7. When putting forth your arguments and evidence during the objections process, how would you rate the level of consideration given to your arguments and evidence by the Independent Adjudicator?

Very Good - I am of the opinion that complete consideration was given to my arguments and evidence by the Independent Adjudicator within the parameters of the MSC objections procedure

Good - I am of the opinion that consideration was given to the majority of my arguments and evidence by the Independent Adjudicator

Neutral - I am of the opinion that the consideration given to my arguments and evidence by the Independent Adjudicator was neither good nor bad

Mixed - There were incidents where I felt that more consideration could have been given to my evidence and arguments, but not all the time

Bad - I am of the opinion that more consideration should have been given to my arguments and evidence by the Independent Adjudicator

Very Bad - I am of the opinion that a lot more consideration could have been given to my arguments and evidence

8. Are you satisfied with the weighting given to your arguments and evidence by the Independent Adjudicator?

Very satisfied $\square$ Satisfied X Neutral $\square$ Unsatisfied $\square \quad$ Very unsatisfied

Mixed (various points of view)

9. Please explain you previous answer

10. During the objection(s) you were involved in, were you satisfied with the level of consideration the objecting body's case was given by the Independent Adjudicator?

Very satisfied $\square$ Satisfied $\square$ Neutral $\square$ Unsatisfied $\square \quad$ Very unsatisfied Mixed (various points of view)

7. Please explain you previous answer 
12. During the objection(s) you were involved in, were you satisfied with the level of consideration given by the Independent Adjudicator given to information put forth by the fishery in question?

Very satisfied $\square$ Satisfied $\square$ Neutral $\square$ Unsatisfied $\square \quad$ Very unsatisfied Mixed (various points of view)

13. Please explain you previous answer

14. In your opinion, who do you feel should pay for the costs of an MSC objection and why?

15. Do you feel the costs of an objection may hinder the ability of stakeholders to object to a certification? Please explain your answer

16. How, in your opinion could the MSC objections process be improved (if at all)?

17. Do you feel the MSC objections process supports its stated intent of providing "an orderly, structured, transparent and independent process by which objections to the Final Report and Determination of a certification body can be resolved"? Please state and explain your reasons. 
These accusations pose a real threat to the reputation of the MSC. If left un-addressed, MSC's credibility amongst consumers and academics has the potential to be lost. This thesis seeks to investigate the legitimacy and robustness of the MSC OP. There is a focus on the way in which the MSC OP facilitates interactions between objection actors, influences actors, and how each actor is empowered by the MSC OP methodology.

\section{B. Independent Adjudicator}

1. As an Independent adjudicator for the MSC, are you satisfied with the parameters of your role in the MSC objections procedure? Please tick or highlight a box

Very satisfied $\quad \square$ Satisfied $\square$ Neutral $\square$ Not satisfied $\square \quad$ Very un-satisfied

Other

2. Please explain the reasons for your choice in question 1

3. How satisfied are you with the MSC Objections procedure and how it operates?

Very satisfied $\quad \square$ Satisfied $\square$ Neutral $\square$ Not satisfied $\square \quad$ Very un-satisfied

Mixed (various points of view)

4. Please explain your previous answer

5. As an Independent Adjudicator in the MSC objection process, do you feel you are able to weight evidence from all parties in a fair and transparent manner? Please explain you answer

6. Do you feel there are any obstacles in the MSC objections procedure that inhibits your ability to make a fair, structured and independent ruling? Please elaborate on you answer 
7a. What are, in your opinion the strengths and benefits of the MSC objections process?

7b. What are, in your opinion the limitations of the MSC objections process?

8. How, in your opinion do you feel the MSC objections process could be improved (if at all)?

\section{C. Objector}

1. Which MSC objection(s) have you been involved in?

2. Briefly summarise the primary concerns you and/or your associated organization raised during the objection process (if multiple objections have been lodged, please answer this and the following questions for each objection process you have been involved in

3. How satisfied are you that the issues raised by yourself or your organisation were adequately addressed by the Certification Body? (Please tick a box, or replace the box with an $\mathbf{x}$ for electronic copy).
Very satisfied
$\square$ Satisfied
Neutral
Unsatisfied
Very unsatisfied

Mixed (various points of view)

Other

4. Please explain your previous answer

5. If you are dissatisfied with how the Certifying Body addressed your issues during an objection, please state what you feel would need to have had occurred for you to consider the issues raised to have been adequately addressed.

6. During each of the objections processes, how did you feel about the level of input and consideration given to the evidence and the arguments of the Certification Body and the 
Applicant (i.e. the fishery applying for certification) (if relevant) by the Independent Adjudicator? Please select for each party.

Applicant:

Excessive $\square$ Too much $\square$ About right $\square$ Too little $\square$ Much too little $\square \quad$ N/A

Certification Body:

Excessive $\square$ Too much $\square$ About right $\square$ Too little $\square \quad$ Much too little

7. Please explain your ratings for the Applicant in the previous question

8. Please explain your ratings for the Certification Body in the previous question

9. Are you satisfied with the role that the Independent Adjudicator plays in the MSC objections process?

Very satisfied $\quad \square$ Satisfied $\quad \square$ Neutral $\quad \square$ Unsatisfied $\square$ Very unsatisfied Mixed (various points of view) $\square \quad$ Other

10. Please explain your answer

11. Who do you think should pay for the objections processes and why?

12. Do you think the current financial charge to lodge an objection limits the ability of stakeholders to object? Please explain your answer

13. In what ways do you think the MSC objections processes could be improved (if at all) and why? 
14. Do you feel the MSC objections processes support its stated intent of providing "an orderly, structured, transparent and independent process by which objections to the Final Report and Determination of a certification body can be resolved"? Please explain your reasons.

\section{D. Fishery Client}

\section{Interview Questionnaire: Certification Body (Individual)}

1. Please state which MSC objection(s) you have been involved in:

2. Of the MSC objection(s) you have been involved with that have proceeded to full certification, have you been involved in a re-objection during re-certification? /

3. Overall, how would you rate your experience with the MSC objection process?

Very Good - I am very pleased with how the MSC objections process proceeded and feel it led to legitimate outcomes

Good - Overall I am pleased with how the objections process proceeded. I only harbour minor issues with the MSC objections process

Neutral - I am neither pleased nor displeased with how the MSC objections procedure operates

Mixed - I am pleased with certain elements of the MSC objections process, and displeased with others

Bad - I am displeased with how the MSC objections process proceeds and feel it requires improvement 
Very Bad - I believe the MSC objections process is flawed and leads to illegitimate outcomes

4. Please elaborate on and explain your answer in the previous question

5. During the MSC objection you have been involved with, were you satisfied with the role the Independent Adjudicator played?

Very satisfied $\quad \square$ Satisfied $\square$ Neutral $\square$ Not satisfied $\square \quad$ Very un-satisfied Mixed (various points of view)

6. Please explain your previous answer

7. When putting forth your arguments and evidence during the objections process, how would you rate the level of consideration given to your arguments and evidence by the Independent Adjudicator?

Very Good - I am of the opinion that complete consideration was given to my arguments and evidence by the Independent Adjudicator within the parameters of the MSC objections procedure

Good - I am of the opinion that consideration was given to the majority of my arguments and evidence by the Independent Adjudicator

Neutral - I am of the opinion that the consideration given to my arguments and evidence by the Independent Adjudicator was neither good nor bad

Mixed - There were incidents where I felt that more consideration could have been given to my evidence and arguments, but not all the time

Bad - I am of the opinion that more consideration should have been given to my arguments and evidence by the Independent Adjudicator

Very Bad - I am of the opinion that a lot more consideration could have been given to my arguments and evidence 
8. Are you satisfied with the weighting given to your arguments and evidence by the Independent Adjudicator?

Very satisfied $\square$ Satisfied $\square$ Neutral $\square$ Unsatisfied $\square \quad$ Very unsatisfied

Mixed (various points of view)

9. Please explain you previous answer

10. During the objection(s) you were involved in, were you satisfied with the level of consideration the objecting body's case was given by the Independent Adjudicator?

Very satisfied $\square$ Satisfied $\square$ Neutral $\square$ Unsatisfied $\square \quad$ Very unsatisfied

Mixed (various points of view)

11. Please explain you previous answer As explained before: we would have preferred the IA to take a closer look to the objection upon posting and acceptance by the IA.

12. During the objection(s) you were involved in, were you satisfied with the level of consideration given by the Independent Adjudicator given to information put forth by the fishery in question?

Very satisfied $\quad \square$ Satisfied $\square$ Neutral $\square$ Unsatisfied $\square \quad$ Very unsatisfied

Mixed (various points of view)

13. Please explain you previous answer

15. In your opinion, who do you feel should pay for the costs of an MSC objection and why?

15. Do you feel the costs of an objection may hinder the ability of stakeholders to object to a certification? Please explain your answer

16. How, in your opinion could the MSC objections process be improved (if at all)? 
17. Do you feel the MSC objections process supports its stated intent of providing "an orderly, structured, transparent and independent process by which objections to the Final Report and Determination of a certification body can be resolved"? Please state and explain your reasons.

\section{Participant Information Sheet}

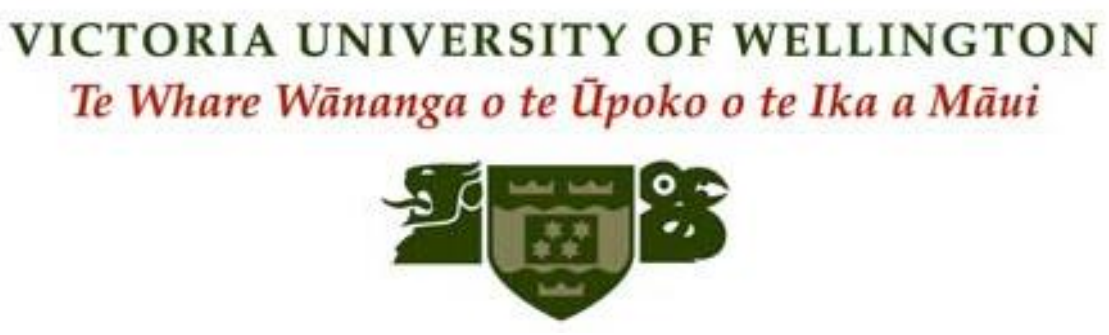

07/06/2011

\section{Participant Information Sheet for a Study of the MSC Objection Procedures}

Researcher: Joseph Edlin: Masters student, School of Geography Environment and Earth Science, Victoria University of Wellington

I am a Masters student in the Environmental Studies programme at Victoria University of Wellington. As part of this degree I am undertaking a research project leading to a thesis. The project I am undertaking is intended to examine the Marine Stewardship Council's objections procedure, and how the MSC objections process facilitates interactions between actors, leading to the final ruling. The University requires that ethics approval be obtained for research involving human participants.

I am inviting people who have been involved in the MSC objections process to participate in this study. Participants will be asked to complete an oral interview, an emailed questionnaire, or an online questionnaire. This relates to your experiences during the objections procedures. The purpose is to gain an idea as to how the MSC objections processes have been perceived to operate by different actors.

Questions are mainly open ended and you may be asked to answer further questions in order to clarify and expand on information gathered. If you can be clear and exact in your responses that 
would help a lot. Should you feel the need to withdraw from the project, you may do so without question, however I would ask that you please do so by September 20, 2011 before the data is analysed.

Responses collected will form the basis of my research project and will be put into a thesis which may also be published in part as academic and professional publications and presentations may be made to the scientific and professional and practice communities. Any information you provide will not be attributed to you or your organisation, but it is acknowledged that those close to MSC and its processes may be able to discern the identity of contributors. All raw data will be kept confidential. All interview transcripts, completed questionnaires and transcripts will be safely secured and no other person besides me and my supervisor, Cath Wallace, will see them and these will be used only for the purposes of this research. At the end of two years after the publication of the research project outputs, all raw data will be destroyed.

The thesis will be submitted for marking to the School of Geography Environment and Earth Sciences at Victoria University of Wellington and deposited in the University Library.

\section{Participant Consent Form}

\section{VICTORIA UNIVERSITY OF WELLINGTON Te Whare Wānanga o te Ūpoko o te Ika a Māui

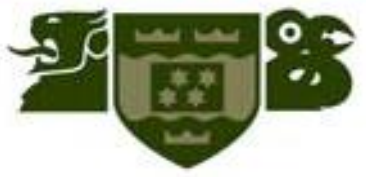

\section{VICTORIA UNIVERSITY OF WELLINGTON CONSENT TO PARTICIPATION IN RESEARCH}

I have been given and have understood an explanation of this research project.

I have had an opportunity to ask questions and have them answered to my satisfaction.

I consent to information or opinions which I have given being used in any reports on this research.

I am aware that all raw data I provide will be kept confidential and will not be attributed to me in any report on this research, though I understand that those familiar with MSC cases may be able to identify the sources of opinions on the MSC processes in any particular case.

I understand that the raw data I provide will not be used for any other purpose than this research and reports on it or released to others except for my supervisor without my written consent. 
I would like to receive a link to the results of this research when it is completed and the thesis has been accepted.

I understand that I may withdraw any information provided by the $20^{\text {th }}$ September 2011 without question or consequence.

I agree to take part in this research.

I certify that I have the authority of my organisation. ...[insert name of organisation] to take part in this research.

Signed:

5. MSC Assessment Methodology (MSC, 2010b: 17-27) 


\section{Tier 2 - Detailed Prescription of the Mandatory Steps to Follow}

\section{Section 1 - Pre-Assessment Evaluation}

1.1 The objective of the Pre-Assessment is to provide a focus for certification body planning the full assessment, should a client move forward, by gaining an understanding of the fishery in the context of the MSC Principles and Criteria for Sustainable Fishing, and to inform the client of the likelihood of achieving certification of their fishery.

1.2 The Pre-Assessment evaluation is conducted after bi-lateral discussions between a certification body and client, and the existence, process and outcomes of the PreAssessment remains confidential to the client and the certification body (unless otherwise directed by the client).

1.3 The client's intention to proceed to certification shall remain confidential until the client confirms their intention to proceed to the full assessment stage and signs (or confirms) an assessment contract.

1.4 The Pre-Assessment shall consist of the following, as a minimum:

1.4.1 A substantive meeting with the client.

1.4.2 Decisions with respect to potential field site visits.

1.4.3 An assessment of the extent to which the fishery is consistent with the MSC Principles and Criteria for Sustainable Fishing.

1.4.4 An evaluation of the fishery's state of preparedness for assessment.

1.4.5 A review of the availability of data in the various categories (Section 1.5).

1.4.6 A determination of the overall scope of the full certification assessment.

1.4.7 A description of potential obstacles or problems that may be a barrier to certification.

1.4.8 A report to the Client covering each of these matters as a minimum.

1.5 The Pre-Assessment evaluation shall be based on, but not restricted to reviewing documentation. The certification body and the client shall determine what documentation and data they review but the following issues shall be addressed, documented and retained by the certification body:

1.5.1 General historical background information on the area of the fishery.

1.5.2 Governance \& political stability issues.

1.5.3 Fishery sector - domestic consumption and export information. 
1.5.4 Overview of the fishery to be certified including management practices and a clear definition of the unit of certification being proposed.

1.5.5 Other fisheries in the vicinity not subject to certification but that may interact with the fishery being assessed.

1.5.6 External factors (such as environmental issues) that may affect the fishery and its management.

1.5.7 A list of key stakeholders in the fishery and their special interests, where relevant.

1.5.8 If relevant, information for any subsequent Chain of Custody certification.

1.5.9 The fishery's management policy objectives and/or relevant regulations.

1.6 The Certification Body shall ensure that the client is fully informed of the requirements and implications of a decision to proceed to a full assessment. These include (but are not limited to) the need to:

1.6.1 Liaise with management agencies, environment groups, post-harvest sectors, relevant commercial and non-commercial fishing groups to ensure their understanding of the MSC process and the implications (including costs and benefits) of certification.

1.6.2 Address issues that may be a barrier to certification.

1.6.3 Identify the type and extent of data and information that should be made available by the client to the certification body's assessment team in the event of a full assessment.

1.6.4 Identify the location, timing and form of any public or limited announcements to be made about the client's intention to proceed to certification. 


\section{Section 2 - Full Assessment, Step 1 - Prior to Assessing the Fishery}

\subsection{Announcement regarding the full certification and public involvement}

2.1.1 After a contract for full assessment has been signed, or the client has formally confirmed its intention to proceed, the certification body shall within 5 days:

2.1.1.1 Inform the MSC in writing about the intent to seek certification, provide the MSC with an indicative timetable for publication on the MSC website and a formal Notification Report (not for publication) containing the following:

- general historical background information on the area of the fishery;

- governance \& political stability issues;

- fishery sector - domestic consumption and export information;

- overview of the fishery to be certified including management practices

- clear description of the unit of certification;

- other fisheries in the vicinity not subject to certification but that may interact with the fishery being assessed;

- external factors (such as environmental issues) that may affect the fishery and its management;

- a list of key stakeholders in the fishery and their special interests, where relevant;

- information for any subsequent Chain of Custody certification including an indication about the point in the chain at which the certification body and its fishery assessment team can ensure chain of custody; and

- the fishery's management policy objectives and regulations.

2.1.1.2 Announce the assessment in at least two media outlets which the Certification Body determines are the best means to inform identified stakeholders and shall justify in its final report. The announcement shall be made at least 30 days prior to consultation closing and shall invite stakeholder participation.

2.1.1.3 Actively invite the stakeholders including those identified in Section 1.5 .7 to participate in the assessment process.

\subsection{Assessment Team Selection}

2.2.1. After the assessment contract is signed (or formally confirmed), the certification body shall assemble an assessment team with expertise in relevant technical disciplines that is of sufficient standing and experience to assess the fishery against the MSC Principles and Criteria.

2.2.2 Each assessment team shall include a Team Leader who shall be responsible, for the certification body, for the carriage of the assessment and satisfactory conduct of the assessment in conformance with the MSC Accreditation Manual and the terms of this Methodology. 
2.2.3 The assessment team shall have appropriate demonstrated technical expertise in each of the following areas, although any one team member may be expert in more than one area:

- Fish stock assessment - must have experience as a leader in the production of peer reviewed stock assessment(s) for relevant fishery(ies), and stock assessment technique(s) being used in the fishery under assessment.

- Fish stock biology/ecology - must have at least five years research expertise in the biology and ecology of the target or similar species.

- Fishing impacts on aquatic ecosystems - at least five years experience in research into, policy analysis for, or management of, fisheries impacts on aquatic ecosystems, and/or marine conservation biology.

- Fishery management and operations - must have at least ten years experience as a practicing fishery/aquatic natural resource manager and/or fishery/aquatic natural resource management policy analyst. Must also have a good understanding of the management system(s) used in the fishery under assessment.

- Current knowledge of the country, language and local fishery context that is sufficient to support meaningful assessment of the fishery.

- Third-party product and management system conformity assessment auditing techniques - must have experience and relevant qualifications as lead auditor. Must have a good understanding of the MSC Principles and Criteria for Sustainable Fishing, MSC Fisheries Certification Methodology and MSC Chain of Custody Standard and Methodology.

2.2.4 The certification body shall ensure that the combined expertise of the team members covers each aspect of the MSC Principles and Criteria and meets the prescribed requirements of this Methodology.

2.2.5 The certification body shall be responsible for ensuring that the team members have a thorough and sufficient understanding of the MSC Principles and Criteria and the MSC Fisheries Certification Methodology.

2.3 Determining Sub-criteria, Performance Indicators and Scoring Guideposts and their weighting prior to the assessment visit

2.3.1 The assessment team shall determine a draft 'assessment tree', including a set of sub-criteria, performance indicators and scoring guideposts specific to the fishery being evaluated. The assessment tree shall be comprised of the following:

- Principles (from Airlie House ${ }^{1}$ ).

- Criteria (from Airlie House). 
- Sub-criteria as necessary (operational interpretations of the criteria developed as sub-set of the level above).

- Performance indicators (the lowest level of the 'tree', where scoring is conducted; developed operationally for each fishery).

- Scoring guideposts (describe the main thresholds in the scoring system), scoring guideposts shall be written for each performance indicator.

2.3.2 The scoring guideposts shall be determined based on:

- 100 - defines the upper boundary of the scoring and represents the level of performance on an individual performance indicator that would be expected in a theoretically 'perfect' fishery.

- 80 - defines the unconditional pass mark for a performance indicator for that type of fishery. Weighted scores for Criteria under each MSC Principle must average to 80 or higher.

- 60 - defines the minimum, conditional pass mark at the Criterion level for that type of fishery. Any score below 60 represents a performance level that is unsatisfactory.

2.3.3 The assessment team shall define, for the fishery being assessed, the scoring guideposts for each performance indicator $(60,80$ and 100 as per 2.3.2).

2.3.4 The draft assessment tree (including Principles, Criteria, any Sub-criteria, Performance Indicators and Scoring Guideposts) shall be publicly available and provided to stakeholders for at least 30 days prior to the on-site assessment visit to enable any stakeholder who wishes to comment a chance to do so.

2.3.5 The draft assessment tree shall also be submitted to the MSC for discussion and comment 30 days prior to the first on-site assessment visit by the assessment team.

2.3.6 Any comments or changes to the assessment tree suggested by the MSC, the client or any stakeholder shall be considered by the assessment team, and if appropriate, a revised assessment tree will be prepared by the assessment team for use in the following stages of the assessment.

2.3.7 The certification body shall document and retain a record of the assessment team's rationale for any decisions about the assessment tree. A summarised rationale for each of the performance indicators and scoring guideposts shall be required in the Preliminary and subsequent Draft Reports (Sections 3.6-3.8).

2.3.8 If the assessment tree is revised, it shall be provided to the MSC, who shall place it on the MSC website for the remainder of the assessment process.

2.3.9 The assessment team shall determine the weighting to be assigned to each performance indicator prior to the assessment visit and scoring session. 


\section{Section 3 - Full Assessment, Step 2 - Assessing the Fishery \& Preparing Reports}

\subsection{Assessment visits and information collection}

3.1.1 The client and stakeholders shall be advised at least 30 days in advance of the first on-site assessment visit. The client shall be provided with a summary list of anticipated objective evidence that may be required by the assessment team.

3.1.2 Stakeholder interviews shall be conducted to ensure that the assessment team is aware of any and all concerns of relevant stakeholders. Where stakeholders do not wish to be interviewed they shall be advised that they may submit written information to the assessment team.

3.1.3 The assessment team shall ensure that all relevant information (including technical, written and anecdotal sources) is analysed prior to scoring the fishery. Where such information is not available or assembled by the client or stakeholders in time for the first assessment visit, the assessment team may require further assessment visits in order to adequately assess and analyse the evidence.

\subsection{Scoring the fishery}

3.2.1 After the evidence is compiled and assessed by the certification body's team, the assessment team shall score the fishery against the Principles and Criteria in the final assessment tree (including Principles, Criteria, any Sub-criteria, Performance Indicators and Scoring Guideposts).

3.2.2 In scoring the fishery's performance, the assessment team shall use the methodology set out in the guidance document entitled "Using the AHP and Expert Choice to Support the MSC Certification Process".

\subsection{Interpreting the scores}

3.3.1 The scoring requirements in 3.3.2 constitute the Marine Stewardship Council's minimum threshold for a sustainable fishery. However, in order to be granted a fishery certificate, the client shall also agree to meet the requirements set out in Section 3.4 .

3.3.2 The certification body shall interpret the scores allocated to the fishery as follows:

- It is required that the fishery obtains a score of 80 or more, based on the weighted average score for all Criteria scored under that Principle, for each of the three Principles in order to be certified. If a fishery achieves a score of less than 80 on any Principle, certification will not be awarded.

- It is required that the fishery obtains a score of 60 or more for each Performance Indicator and Criterion in order to be certified. If a fishery achieves a score of less than 60 on any Performance Indicator or Criterion, certification will not be awarded. 
3.3.3 The assessment team shall document the rationale for the scores for each Performance Indicator for inclusion in the Preliminary and subsequent Draft Reports.

\subsection{Conditions}

3.4.1 Conditions provide for agreed further improvement in the fishery and provide one of the bases for subsequent audit. They are intended to improve performance against the MSC Principles (target species status; maintenance of ecological function; and management system performance), and may include among other things, reducing uncertainty; improving processes; improving implementation; reducing risk; or improving outcomes.

3.4.2 Where the fishery achieves a score of less than 80 , but of at least 60 for any individual Performance Indicator, the certification body shall set one or more conditions for continuing certification. The condition(s) shall improve performance to at least the 80 level within a period set by the certification body but no longer than the term of the certification, subject to Sections 3.4.2.1. and 3.4.2.2.

3.4.2.1 The certification body may recognise that achieving a performance level of 80 may take longer than the period of certification under "exceptional circumstances". "Exceptional circumstances" refers to situations in which even with perfect implementation, achieving the 80 level of performance may take longer than the certification period. For example, in relation to natural ecological functions and response times or time required for relevant research.

3.4.2.2 In such exceptional circumstances, the certification body shall specify conditions in the Draft and Final Reports (see Sections 3.6 to 4.1) that spell out the significant and measurable improvements (in terms of milestones or outcomes) that must be achieved and the score that must be reached during the certification period and at the end of the certification period, as well as what constitutes a successful overall outcome to achieve the 80 performance level over a longer, specified time period.

3.4.3 In the event that the scoring of the fishery determines the need for conditions to be set, the certification body shall advise the client that mandatory action will need to be taken to increase the score and that a condition(s) will be attached to the certificate to ensure that the action(s) is taken within a specified timeframe.

3.4.4 The certification body shall specify conditions that are auditable and verifiable. Where possible, quantitative metrics should be specified.

3.4.5 The certification body shall specify conditions that closely follow the narrative or metric form of the performance indicators and scoring guideposts used in the assessment tree (see Section 2.3), and also specify conditions in terms of measurable outcomes or results expected, the specific timeframe over which the condition must be met, and if interim milestones are specified, the outcome and score that shall be achieved at each milestone. These shall be included in the Draft and Final Reports (Sections 3.6 - 3.8, 4.1).

3.4.6 If the condition is related to reducing uncertainty or improving processes, the certification body shall include in its Draft and Final Reports narrative about the 
ultimate ecological or management outcome the condition is aimed at achieving over the longer term.

3.4.7 The certification body shall seek a detailed agreement from the client as to how the conditions will be addressed, by whom and the specified time period, how the action(s) is expected to improve the performance of the fishery and how the outcome will be assessed in audits by the certification body. Where the client and the certification body are unable to agree on the terms of conditions that will achieve the required increase in the score in question, certification shall not be awarded.

3.4.8 The certification body shall consult with all relevant entities ${ }^{2}$ when setting conditions, if those conditions are likely to require investment of time or money by these entities, or changes to management arrangements or regulations, or re-arrangement of research priorities by these entities, in order to satisfy the certification body that the conditions are both achievable by the certification client and realistic in the time frame specified.

3.4.9 Consultation on setting conditions should be complete prior to the release of the Public Comment Draft Report (see Section 3.8).

3.4.10 The certification body shall not accept a 'detailed agreement' to address conditions from a client if the client is relying upon the involvement, funding and or resources of other entities (see footnote 2) without evidence that funding and/or resources are, or will be, in place. If no such evidence is available, certification shall not be awarded.

\subsection{Determination of the point at which fish and fish products enter further Chains of Custody}

3.5.1 If the certification body is satisfied that the system of tracking and tracing in the fishery is sufficient to ensure all fish and fish products identified as such by the fishery originate from the evaluated fishery, then the certification body shall clearly state within its certification report that fish and fish products from the fishery may enter into further chains of custody, and be eligible to carry the MSC logo. This is the scope of the Fishery Certificate after which Chain of Custody Certificates apply.

3.5.2 If the certification body is dissatisfied that the system of tracking and tracing in the fishery or that there is some other risk element and if the certification body cannot ensure all fish and fish products identified as such by the fishery originate from the evaluated fishery or might claim to be from the evaluated fishery ${ }^{3}$, then the certification body shall clearly state within its certification report that fish and fish products from the fishery may not enter into further chains of custody, and are not eligible to carry the MSC logo. This non-eligibility shall remain in force until the decision is reviewed and revised by a subsequent chain of custody assessment. 


\subsection{Preliminary Draft Report - client review}

3.6.1 The certification body shall issue a draft written report (The Preliminary Draft Report) to the client at the completion of the assessment activity.

3.6.2 The Preliminary Draft Report shall contain all intended conditions as set out in Section 3.4.1.

3.6.3 The Preliminary Draft Report to the client shall contain the scores, weightings and certification outcome.

3.6.4 Where there is concern by the client that insufficient information is available to support the assessment team's decisions, or that a decision has been taken in error, the client shall be provided with an opportunity to question the assessment team and have the issue re-examined. However, the assessment team is not obligated to accept client requests for changes in the report, but must provide justifications for whatever responses are made to client comments.

3.6.5 Any comments made by the client and the assessment team shall be documented and retained by the certification body and shall be available upon request to any party.

3.6.6 In response to the Preliminary Draft Report, the client will provide objective evidence in support of any additional claims or any claimed errors of fact.

3.6.7. A period of up to 30 days shall be made available after receipt of the draft report for the client to consider and fully respond.

\subsection{External peer review and Peer Review Draft Report}

3.7.1 The certification body shall arrange for the Peer Review Draft Report to be reviewed by a group of experts considered to be, at a minimum, the peers of the experts comprising the assessment team. The Peer Review Draft Report shall incorporate client response and conditions (if applicable), scores, weightings and certification outcomes,

3.7.2 There shall be a minimum of two people retained as peer reviewers.

3.7.3 The certification body shall notify the MSC and stakeholders of the proposed peer reviewers and allow 10 days for stakeholders and the MSC to submit written comments and/or objections as to the selection of a proposed member of the peer review panel. The MSC shall publish the names and short CVs of the peer reviewers on the MSC website for 10 days. The certification body's decision on the choice of peer reviewers is final.

3.7.4 As a minimum, the peer reviewers shall satisfy the key requirements of Section 2.2.3, particularly as they relate to the fishery under assessment. 
3.7.5 The certification body shall specify a timeframe for the peer review process and notify the MSC for publication of the timeframe on the MSC website.

3.7.6 Upon receipt of the peer reviewers' written comments the Assessment Team shall explicitly address the issues raised and incorporate any appropriate changes into the Public Comment Draft Report and, if appropriate, into any special conditions contained therein.

\subsection{Public Comment Draft Report - review by stakeholders}

3.8.1 Following review by the client and peer reviewers, the certification body shall make the Public Comment Draft Report available for comment by stakeholders for a period of 30 days. The Draft Report made available to stakeholders shall include the scores and weightings, and will include the recommended Determination and any conditions.

3.8.2 The Public Comment Draft Report shall contain the full comments from the unidentified peer reviewers.

3.8.3 Any comments made by stakeholders shall be documented and forwarded by the certification body to its certification decision-making entity.

3.8.4 In response to the Public Comment Draft Report, stakeholders shall be advised that they are to provide objective evidence in support of any additional claims or any claimed errors of fact.

\section{Section 4 - Full Assessment, Step 3 - Final Report, Determination \& Objections}

\subsection{Final Report}

4.1.1 The assessment team shall review the report taking account of the stakeholder comments and revise the report as appropriate. The Public Comment Draft Report of the certification body's appointed assessment team, all written comments by the unidentified peer reviewers, all written comments by stakeholders and relevant responses to stakeholder comments will be submitted to the certification body's decision-making entity.

4.1.2 The certification body will make a Determination and release a Final Report incorporating the Public Comment Draft Report (including scores, weightings and conditions), written comments by the peer reviewers, all written comments by stakeholders and relevant responses to stakeholder comments and the Determination.

4.1.3 The form and content of the Final Report shall be in accordance with Appendix 1.

4.1.4 The Final Report will be posted on the MSC website and the MSC will actively distribute to the public a statement that explains the meaning of the Determination and the process to follow for raising an objection to a Determination.

4.1.5 The certification body and the MSC will actively notify stakeholders involved in the fishery's certification assessment process of the existence of the Final Report. 


\section{MSC Objections Procedure Flow Diagram (MSC, 2009: C139)}

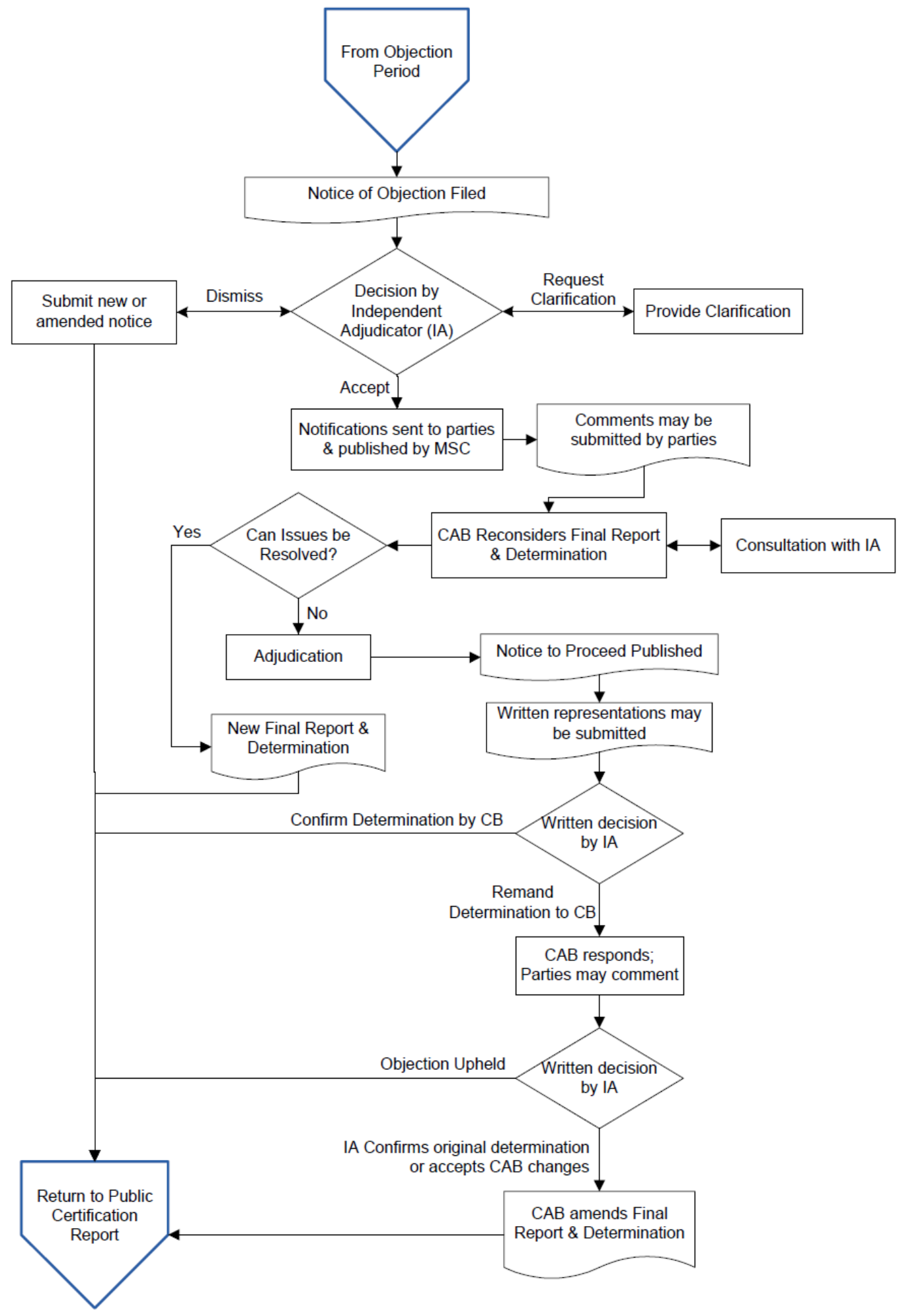




\section{MSC Objections Procedure Methodology (MSC, 2009b: 2-11)}

\section{Objections Procedure}

\subsection{Object and purpose}

4.2.1 The purpose of the Objections Procedure is to provide an orderly, structured, transparent and independent process by which objections to the Final Report and Determination of a certification body can be resolved. It is not the purpose of the Objections Procedure to review the subject fishery against the MSC Principles and Criteria for Sustainable Fisheries, but to determine whether the certification body made an error that materially affected the outcome of its Determination.

4.2.2 Subject to Section 4.4.1(c), the procedure is open only to parties involved in or consulted during the assessment process.

4.2.3 An Independent Adjudicator will examine the claims made by an objector in a notice of objection and will make a written finding as to whether the certification body made an error that materially affected the outcome of its Determination. If any such error is identified, and if there is adjudged to be a real possibility that the certification body may have come to a different conclusion, the Independent Adjudicator will remand the Determination back to the certification body for reconsideration.

4.2.4. In the event that a notice of objection is filed, no formal certificate or logo licensing agreements may be issued or entered into relating to any fishery product until the objections procedure has run its course in accordance with the procedures set out in this Section and the Public Certification Report has been issued in accordance with Section 5.1. 


\subsection{The Independent Adjudicator}

4.3.1. The MSC Board of Trustees shall appoint an Independent Adjudicator to consider all objections to a Final Report or Determination. The Independent Adjudicator shall be appointed for a period of three years and may be reappointed. The decision of the Board in appointing or reappointing the Independent Adjudicator shall be final. The Independent Adjudicator shall perform all the functions allocated to him or her in accordance with the procedures set out in the MSC Fisheries Certification Methodology. An additional Adjudicator may be appointed at any time to act in cases where the Independent Adjudicator is unavailable to act for any reason, including a conflict of interest or unavailability.

4.3.2. The Independent Adjudicator may be removed by the MSC Board of Trustees for good cause, including incompetence, bias or impropriety.

4.3.3. The Independent Adjudicator shall be independent of the MSC Executive, but the MSC Executive may provide him or her with appropriate administrative and logistic support, including sending and receiving notices and correspondence.

\subsection{Notice of objection}

4.4.1 A notice of objection to a Final Report or Determination may be submitted by:

(a) the fishery client(s) ${ }^{1}$;

(b) any party to the assessment process that made written submissions to the certification body during the fishery assessment process or attended stakeholder meetings;

(c) any other party that can establish that the failure of the certification body to follow procedures prevented or substantially impaired the objecting party's participation in the fishery assessment process.

4.4.2 A notice of objection must be submitted no later than 15 days after the date on which the Final Report and Determination is posted on the MSC website.

4.4.3. A notice of objection must be submitted in the format prescribed by the MSC Executive (contact the MSC for details). It shall be addressed to the Independent Adjudicator with a copy to the MSC Chief Executive.

4.4.4. The notice of objection must set out clearly and precisely the basis upon which Section 4.8.2 is said to apply. It must identify the alleged errors in the Final Report and Determination and must explain in sufficient detail why it is claimed that such alleged errors made a material difference to the outcome of the Determination or the fairness of the assessment. If it is asserted that the Determination should be remanded for the reasons set out in Section 4.8 .2 (c), the notice of objection must specify, in sufficient detail, the nature of the additional information that it is asserted should reasonably have been made available to the certification body and the reasons why it is considered that such material, if considered, could have made a material difference to the outcome of the assessment.

4.4.5. Upon receipt of a notice of objection, the Independent Adjudicator shall proceed in the manner set out in Section 4.5. 


\subsection{Procedure on receipt of a notice of objection}

4.5.1. If the Independent Adjudicator, in his or her discretion, determines that the notice of objection is not in the form required by these procedures or has no reasonable prospect of success, the Independent Adjudicator may either:

(a) dismiss the objection, giving written reasons therefore; or

(b) request further clarification from the objector.

For purposes of this Section, an objection has a "reasonable prospect of success" if, in the view of the Independent Adjudicator,

(a) it is not spurious or vexatious; and

(b) some evidence is presented on the basis of which the Independent Adjudicator could reasonably expect to determine that one or more of the conditions set forth in Section 4.8.2 are satisfied.

4.5.2. In the event that the Independent Adjudicator decides to dismiss the objection, the objector may nonetheless submit a new or amended notice of objection within five days of being so notified by the Independent Adjudicator. An objector shall have only one opportunity to submit such a new or amended notice of objection.

4.5.3. In the event that the Independent Adjudicator requests further clarification from the objector, the Independent Adjudicator shall notify the objector in writing of the clarification sought and the time limit for responding (which, in the absence of special circumstances to justify a longer time, should normally be not more than five days). If the objector fails to respond within the time specified, it shall be assumed that the objector does not wish to proceed further and the Independent Adjudicator shall thereupon issue a notice in writing dismissing the objection.

4.5.4. If the Independent Adjudicator, in his or her discretion, determines that the new or amended notice of objection submitted under Section 4.5.2 or 4.5.3 does not disclose any of the grounds set out in Section 4.4.4, is not in the form required by these procedures, has no reasonable prospect of success or is spurious or vexatious, the Independent Adjudicator shall dismiss the objection, giving written reasons therefore.

4.5.5. Where a notice of objection is accepted, the Independent Adjudicator shall promptly notify the certification body, the fishery client(s) and any other objectors, of the objection. The MSC Executive shall also cause a copy of the notice of objection to be posted on the MSC website. The date upon which the notice of objection is posted on the website shall be the "date of publication".

4.5.6. The fishery client(s) or any stakeholder that participated in the fishery assessment process (other than the objector(s)), may, within 15 days of the date of publication, submit written representations on the matters raised in the notice of objection. All such written representations shall be submitted through the Independent Adjudicator and shall be posted on the MSC website.

\subsection{Reconsideration by the Certification Body}

4.6.1. Where a notice of objection has been accepted, the certification body shall be required to reconsider its Final Report and Determination in light of the matters raised in the notice of objection. The certification body shall, within 20 days of the 
date of publication, provide a written response to the notice of objection. The response shall provide appropriate information indicating the extent to which the matters set forth in the notice of objection were considered in the fishery assessment and the impact thereof on the Determination. In formulating its response, the certification body shall also take into account any written representations received in accordance with Section 4.5.6. The certification body shall also indicate and give reasons for any proposed amendments to its Final Report and Determination in the light of the reconsideration.

4.6.2. The response of the certification body shall be made available to all interested parties, including the objector(s), the fishery client(s) and the MSC Executive.

4.6.3. Upon receipt of the response by the certification body, the Independent Adjudicator shall consult with the objector(s), the fishery client(s) and the certification body in order to determine whether the response of the certification body, including any proposed amendments to the Final Report and Determination, adequately addresses the issues raised in the notice of objection. The Independent Adjudicator shall strive to conclude such consultations within a period of 10 days but may if necessary, at his or her discretion after consultation with the parties, extend such period if it appears that there is a real and imminent prospect of reaching a solution that is acceptable to all relevant parties.

4.6.4. In the event that the issues raised in the notice of objection can be resolved through consultations, the certification body, in consultation with the Independent Adjudicator, shall make such amendments and revisions to the Final Report and Determination as may be agreed and shall proceed to prepare a Public Certification Report in accordance with Section 5.1. No further appeal or objection shall be permitted.

4.6.5. In the event that some or all of the issues raised in the notice of objection cannot be resolved through consultations, the Independent Adjudicator shall notify all parties that the adjudication phase will commence immediately in accordance with Section 4.7 .

\subsection{Adjudication}

4.7.1. Subject to Section 4.10 (Costs), the Independent Adjudicator shall, within 30 days of the date upon which the objector(s) have signed a costs agreement with the MSC Executive or obtained a waiver from the Independent Adjudicator pursuant to paragraph 4.10 .4 , convene an oral hearing of the objection, unless the parties to the objection agree otherwise.

4.7.2. The oral hearing is intended to provide an opportunity for the certification body, the objector(s) and the fishery client(s) (if not the objecting party) to present their respective cases in person, including by video or teleconference.

4.7.3. The Independent Adjudicator shall conduct the hearing in accordance with the provisions of this Section but may also promulgate additional rules of procedure, including time limits on oral presentations and rules as to representation. The Independent Adjudicator shall normally aim to complete the hearing during one session, but may, where necessary, adjourn to continue the hearing using electronic communications or other means.

4.7.4. The fishery client(s), the objector(s), and the certification body may submit additional or supplementary written representations on the matters raised in the notice of objection or in the written representations submitted by other parties under 
Section 4.5.6. All such written representations shall be submitted through the Independent Adjudicator and must be received not later than 5 days before the date set for hearing.

4.7.5. The Independent Adjudicator shall evaluate objections solely on the basis of:

(a) the record, which shall include and be limited to:

(i) the Final Report of the certification body and the record on which the Final Report was based, including written submissions and reports provided to the certification body during the assessment process, the written record of oral, written or documentary evidence submitted in the assessment process, as well as any other evidence referenced or cited in the Final Report.;

(ii) the notice of objection;

(iii) any written representations submitted pursuant to Sections 4.5 .6 and 4.7.4;

(iv) any representations made by any party at an oral hearing pursuant to these procedures; and,

(v) other clarifications required by the IA.

(b) any additional information, not forming part of the record, that is relevant to matters accepted in the notice of objection and the circumstances at the date of the scoring of the fishery that:

(i) was known or should reasonably have been known to any party to the assessment process, and

(ii) should reasonably have been made available to the certification body during the assessment process, and

(iii) if considered, could have made a material difference to the outcome of the assessment;

(c) the MSC Principles and Criteria for Sustainable Fishing; and

(d) the Fisheries Certification Methodology and the Fisheries Assessment Methodology current at the time of the assessment in question, together with Directives, Guidance and amendments thereof made by the MSC Technical Advisory Board and the Board of Trustees, any related interpretations to these documents whether or not of mandatory effect with regard to certifying body compliance made by the MSC Executive and the MSC Accreditation Manual.

4.7.6. The Independent Adjudicator may not consider issues not raised in the notice of objection, even if the Adjudicator is of the view that a particular issue should have been raised. In no case shall the Independent Adjudicator substitute his or her own views or findings of fact for those of the certification body; nor may the Independent Adjudicator change the score awarded by the certification body for any particular performance indicator.

4.7.7. The Independent Adjudicator may solicit external advice on technical matters from, and for this purpose may sit with and receive technical advice from qualified experts. Such technical experts shall not take part in decision-making. Any written reports or advice tendered by the technical experts shall be attached to the Independent Adjudicator's written decision. 
4.7.8. The experts selected by the Independent Adjudicator to provide advice in relation to any particular objection shall not be involved in any activity that constitutes a conflict of interest. Such conflicts include, but are not limited to, the following criteria:

(a) Experts shall not be members of the MSC Board, Technical Advisory Board, Stakeholder Council or Executive;

(b) Experts shall not have commercial involvement with the certifier, the subject fishery or the objector(s);

(c) Experts shall not be involved in management, or lobbying for or against the fishery or be involved with an organization that has indicated its opposition to the certification of the fishery under objection;

(d) Experts shall not have been involved in any part of the current assessment process for the fishery under objection.

4.7.9. In order to facilitate the Objections Procedure, the MSC Executive may maintain a public register of suitably-qualified persons willing and available to act as independent experts. Experts may, however, be selected who are not on the register.

4.7.10. In the event that, in relation to any particular objection, there is a conflict of interest involving the Independent Adjudicator, he or she shall excuse him or herself from further participation in that particular objection. The Chair of the MSC Board of Trustees shall appoint another suitably-qualified candidate to act as Independent Adjudicator ad hoc for that particular objection. In the event of any difference of opinion between the Independent Adjudicator and any party to the objection as to whether a conflict of interest exists, the decision of the MSC Board of Trustees on the matter shall be final.

4.7.11. At any stage of the objections process, any party to an objection may, by notification in writing, call the attention of the Independent Adjudicator to an alleged error of fact, procedural error or unfairness on his or her part with respect to the objections process and the Independent Adjudicator shall respond as soon practicable.

\subsection{Powers of the Independent Adjudicator}

4.8.1. The Independent Adjudicator shall issue a decision in writing either:

(a) confirming the Determination by the certification body; or

(b) remanding the Determination to the certification body.

4.8.2. The Independent Adjudicator shall remand the Determination to the certification body if he or she determines that:

(a) there was a serious procedural or other irregularity in the fishery assessment process that made a material difference to the fairness of the assessment; or

(b) the score given by the certification body in relation to one or more performance indicators cannot be justified, and the effect of the score in 
relation to one or more of the particular performance indicators in question was material to the outcome of the Determination, because:

(i) the certification body made a mistake as to a material fact; or

(ii) the certification body failed to consider material information put forward in the assessment process by the fishery or a stakeholder; or

(iii) the scoring decision was arbitrary or unreasonable in the sense that no reasonable certification body could have reached such a decision on the evidence available to it; or

(c) it is necessary to remand the Determination in order to enable to certification body to consider additional information described in Section 4.7.5(b) and described in the notice of objection. In such a case, the remand shall be limited to a request to the certification body to consider the impact of the additional information on its original Determination and to provide a response in accordance with Section 4.9.2.

\subsection{Remand}

4.9.1. In the event that a Determination is remanded, the Independent Adjudicator shall state, in writing, the grounds upon which the objection has been remanded, the specific matters which the certification body must consider in the remand and the relationship of these matters to one or more of the MSC's Principles and Criteria for Sustainable Fishing or procedural rules. Copies of the remand shall be sent to the MSC Chief Executive, the fishery client(s) and the objecting party.

4.9.2 Within 10 days after receipt of the remand instructions, unless the Independent Adjudicator has granted the certification body a specific amount of additional time, the certification body shall respond in writing to the matters specified in the remand, with copies sent to the MSC Chief Executive, the fishery client(s) and the objecting party. The response of the certification body either

(a) shall include a statement of "no change" in relation to the scoring of performance indicators; or

(b) shall indicate any proposed changes to the justification for a score or indicate a change in the score in relation to any of the performance indicators,

(c) and shall give reasons for its decision under either (a) or (b).

4.9.3. Any party to the objection may make written submissions on the matters specified in the remand or on the response thereto by the certification body under Section 4.9.2. Such submissions must be received by the Independent Adjudicator no later than 5 days following the response by the certification body.

4.9.4. The Independent Adjudicator shall, within 10 days of the response by the certification body, either

(a) accept the response as adequate to meet the matters raised in the remand and confirm the original or amended Determination, as the case may be, by the certification body; or 
(b) after reviewing the response of the certification body, determine that the objection shall be upheld on one or more of the grounds specified in Section 4.8.2.

4.9.5 If the certification body does not respond to the remand within the time limits specified in Section 4.9.2 the Independent Adjudicator shall proceed to Section 4.9.4 as if the certification body had made a "no change" response to the remand.

4.9.6. A decision by the Independent Adjudicator under Section 4.9 .4 is final. No additional objections may be lodged under these procedures in respect of such decision. The certification decision of the certification body shall be made with reference to the decision of the Independent Adjudicator.

4.9.7. In the event that the Independent Adjudicator confirms the amended Determination, the certification body shall make such amendments to its Final Report and Determination as may be necessary in the light of the findings of the Independent Adjudicator and shall proceed to issue a Public Certification Report in accordance with Section 5.1.

4.9.8. Nothing in these procedures shall prevent any party to a fishery assessment from submitting a complaint relating to the certification body to the relevant Accreditation Body in accordance with the procedures of the Accreditation Body. No such appeal to the Accreditation Body shall affect the outcome under this Objection Procedure.

\subsection{Costs}

4.10.1. The costs of the adjudication process, up to a maximum level established from time to time by the MSC Board of Trustees, ${ }^{2}$ shall be borne by the objector or, if there is more than one objector, the objectors in equal shares.

4.10.2. In exceptional circumstances, the Independent Adjudicator may decide to waive the costs in respect of an objector in whole or in part in accordance with Section 4.10.6.

4.10.3. The MSC Executive shall provide information relating to the costs agreement and waiver application to the objector(s) at the earliest opportunity after the acceptance of the notice of objection and in any case no later than 5 days from when the notice of objection is accepted as per Section 4.5.5.

4.10.4. Notwithstanding the provisions of Section 4.7, an objection shall not proceed to adjudication unless, within 10 days after the date on which the Independent Adjudicator notifies the parties that the adjudication phase will commence, the objector(s) have:

(a) signed a costs agreement with the MSC Executive; or

(b) obtained a waiver from the Independent Adjudicator in accordance with Section 4.10.6.

4.10.5. An application for a waiver shall be made in writing to the Independent Adjudicator by a duly authorized representative of the objector within 15 days from when the notice of objection is accepted per Section 4.5.5. Such an application should provide the justification as to why a waiver is sought and must be 
accompanied by appropriate evidence to demonstrate exceptional circumstances, including, where available, the objector's most recent audited financial report.

4.10.6. The Independent Adjudicator shall decide within five days, to refuse the application or to waive the whole or part of the costs that would otherwise be attributed to the objector. A waiver shall only be granted if the Independent Adjudicator is satisfied that there are exceptional circumstances justifying such a waiver. The onus is on the objector to demonstrate that there are such exceptional circumstances. In determining whether there are exceptional circumstances, the Independent Adjudicator shall take into account:

(a) any evidence relating to the financial ability of the objector to meet the costs of the adjudication process;

(b) the impact on the objector's other activities of paying the costs of the adjudication process; and

(c) the ability of the objector to raise funds from external sources, including support from other participants in the assessment process, for the purposes of meeting the costs of the adjudication process.

4.10.7. Where the application is refused or where a partial waiver is granted, the objector must sign a costs agreement with the MSC Executive in order for the objection to proceed further.

4.10.8. In the event that, 10 days after the date on which the Independent Adjudicator notified the parties that the adjudication phase will commence, any objector has not either signed a costs agreement with the MSC Executive or obtained a waiver from the Independent Adjudicator in accordance with Section 4.10.6, the objection in respect of that objector shall be considered to have been dismissed. If there is more than one objector, the Independent Adjudicator shall nonetheless go on to consider the notice of objection submitted by those objectors that have either signed a costs agreement with the MSC Executive or obtained a waiver from the Independent Adjudicator in accordance with Section 4.10.6. If the Independent Adjudicator fails to decide the waiver issue within the time specified by section 4.10.6, and such failure is attributable solely to the Independent Adjudicator, the time deadline specified in the first sentence of this subsection shall be extended for such limited period as the MSC Executive considers appropriate under the circumstances

4.10.9. Nothing in this section shall prevent reconsideration by the certification body and consultations pursuant to Section 4.6.

\subsection{General provisions relating to the objections process}

4.11.1. Where these procedures require that any notice or document is to be submitted to the Independent Adjudicator or to the MSC Chief Executive within, or before, a specified time limit, the following provisions shall be applied in order to determine whether the notice or document was served in time:

(a) Service shall be effective if made by hand, or by facsimile or by the provision of the information in an electronic document containing a digital signature;

(b) Service by hand shall be effective when made. Delivery by facsimile shall be effective when the "transmit confirmation report" confirming the 
transmission to the recipient's published facsimile number is received by the transmitter. An electronic document is presumed to be received by the addressee when it enters an information system designated or used by the addressee for the purpose of receiving documents of the type sent and it is capable of being retrieved and processed by the addressee;

(c) Any references to time shall, unless it is otherwise specifically stated, be held to be Greenwich Mean Time;

(d) "Days" means "working days";

(e) A document served after 5 p.m. or at any time on a Saturday, Sunday or a UK Bank Holiday, will be treated as being served on the next working day;

(f) Where the time limits prescribed in these procedures do not account for statutory holidays in countries where involved stakeholders reside, the Independent Adjudicator will have the discretion to allow an extension of time limits so as to give effect to the intent of these procedures; that all parties have the nominated number of days within which to respond.

4.11.2. For the avoidance of any doubt, every notice or document issued, or posted on the MSC website, by the Independent Adjudicator or the MSC Executive, shall bear the date upon which it was so issued or posted and shall also specify the date upon which any subsequent notice, response, submission or document is required to be submitted in accordance with these procedures. Notwithstanding any other provision of these procedures, and regardless of whether a particular document is posted on the MSC website or not, any documentation submitted by any party to an objection, except for documentation relating to costs under Section 4.10 , shall be available to any other party. 